\title{
An Investigation of the Deposition of Alveolar Bone in the Orthodontic Tipping of Teeth in Monkeys
}

James V. Martuccio

Loyola University Chicago

Follow this and additional works at: https://ecommons.luc.edu/luc_theses

Part of the Medicine and Health Sciences Commons

\section{Recommended Citation}

Martuccio, James V., "An Investigation of the Deposition of Alveolar Bone in the Orthodontic Tipping of Teeth in Monkeys" (1967). Master's Theses. 2095.

https://ecommons.luc.edu/luc_theses/2095

This Thesis is brought to you for free and open access by the Theses and Dissertations at Loyola eCommons. It has been accepted for inclusion in Master's Theses by an authorized administrator of Loyola eCommons. For more information, please contact ecommons@luc.edu. (c) (i) $(9)$

This work is licensed under a Creative Commons Attribution-Noncommercial-No Derivative Works 3.0 License. Copyright $\odot 1967$ James V. Martuccio 


\section{AN INVESTIGATION OF THE DEPOSITION OF ALVEOLAR BONE IN THE ORTHODONTIC TIPPING OF TEETH IN MONKEYS}

\section{BY}

JAMES V. MARTUCCIO

A Thesis Submitted to the Faculty of the Graduate School of Loyola University in Partial Fulfillment of the Requirements for the Degree of Master of Science

JUNE 1967 


\section{AUTOBIOGRAPHY}

James V. Martuccio was born in Farrell, Pennsylvania on July $9,1938$.

He was graduated from Girard High School, Girard, Ohio in June, 1956. Pre-dental studies were begun at Kent State University, Kent, Ohio in September, 1956.

In September, 1959 he entered Western Reserve University, School of Dentistry, Cleveland, Ohio. He received the degree of Bachelor of Science in June, 1961 and the degree of Doctor of Dental Surgery in June, 1963.

He was commissioned in the United States Air Force and served two years at Amarillo Air Force Base, Texas. In June, 1965 he began graduate studies in the Department of Oral Biology at Loyola University, Chicago, Illinois. 


\section{ACKNOWLEDGEMENTS}

I wish to express my sincere appreciation to all those who have aided in making this investigation possible, particularly to the following:

To Joseph R. Jarabak, D.D.S., Ph. D., Professor of Orthodontics, Loyola University, my teacher and thesis advisor, my admiration always for his devotion to the orthodontic profession and my sincere thanks for having given me the opportunity to study orthodontics.

To Joseph E. Gowgiel, D. D.S., Ph. D., Assistant Professor of Anatomy, my thesis director, for his guidance and supervision in preparing this thesis.

To Vincent A. Sawinski, M. A., Ph. D., Assistant Professor of Biochemistry, my thesis advisor, for his technical advice and assistance in statistical discipline and proper thesis organization.

To Patrick D. Toto, D. D.S., M.S., Professor of Oral Pathology, for his help in the preparation of the histologic sections.

To Nicholas C. Choukas, D.D.S., M.S., Associate Professor of Oral Surgery, for making available the facilities of the Animal Research Center at Franklin Boulevard Cómmunity Hospital.

To Jan Ødegaard, B. D. S. and John S. Theodorou, D. D.S. my 
classmates and thesis partners without whose assistance this investigation would have been immeasurably more difficult.

To Thaddeus I. Kanabrocki, Senior Dental Research Tehnician, Hines Veterans Administration Hospital for his technical advice and aid in the decalcification procedure.

To my wife, children, and parents for their moral support, complete understanding and encouragement through all the years of my professional education. 


\section{TABLE OF CONTENTS}

CHAPTER

PAGE

I. INTRODUCTION AND STATEMENT OF THE PROBLEM:

1. Introductory Remarks . . . . . . . . . . . 1

2. Statement of the Problem. . . . . . . . . . . 2

II. REVIEW OF THE LITERATURE . . . . . . . . . 3

III. MATERIALS AND METHODS:

1. Animal Selection . . . . . . . . . . . . 17

2. Animal Housing and Care. . . . . . . . . . . 17

3. Animal Handling. . . . . . . . . . . . . . . 18

4. General Anesthesia . . . . . . . . . . . . . . 19

5. Selection of the Teeth for Movement . . . . . . . 21

6. Preparation of the Experimental Animal . . . . . . 22

7. Force Magnitude Determination and Force

System Design . . . . . . . . . . . . . 23

8. Analysis of Force System . . . . . . . . . . . . 24

9. Appliance Construction and Testing. . . . . . . . 30

10. Lead Acetate Vital Staining. . . . . . . . . . . . 41

11. Appliance Cementation and Activation. . . . . . . 45

12. Sacrifice and Perfusion . . . . . . . . . . . . 46

13. Decalcification of Specimens and Precipitation of Lead. . . . . . . . . . . . . . . 47

14. Preparation of Sections . . . . . . . . . 48

15. Method of Assessment. . . . . . . . 50

IV. FINDINGS:

1. Changes in Weight of Animals . . . . . . 56

2. Data Reduction . . . . . . . . . . . . 57

3. Variation Between Lead Lines . . . . . . . . 64

4. Correlation Between Force Magnitude and

5. Analysis of Tipping . . . . . . . . . . 65

6. Correlation Between Force Magnitude and $\quad$. . . . . 79 
CHAPTER

7. Correlation Between Force Magnitude and Axis of Tipping. . . . . . . . . . . .

8. General Histologic Examination .......

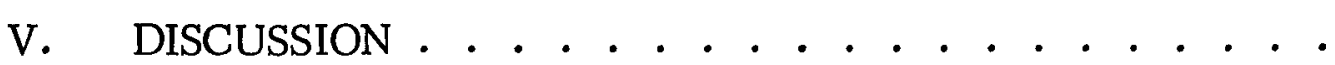

VI. SUMMARY AND CONCLUSIONS:

1. Summary. . . . . . . . . . . . . 121

2. Conclusion . . . . . . . . . . . . 123

VII. BIBLIOGRAPHY. . . . . . . . . . . 125 


\section{LIST OF FIGURES}

FIGURE

PAGE

1. Animal Restraint Cage . . . . . . . . . . . 20

2. Free Body Diagram of Maxillary Central Incisor Tooth . . 26

3. Free Body Diagram of Maxillary Central Incisor Tooth . . 28

4. Diagram of Transverse Helical Loop Design . . . . . . 31

5. Load Deflection Apparatus . . . . . . . . . . 33

6. Load Deflection Characteristics (25 gms.) . . . . . . 35

7. Load Deflection Characteristics (50 gms.) . . . . . . 36

8. Load Deflection Characteristics (75 gms.) . . . . . . 37

9. Load Deflection Characteristics (100 gms.). . . . . . . 38

10. Load Deflection Characteristics (150 gms.). . . . . . 39

11. Load Deflection Characteristics of the Five Springs Tested. 40

12. Helical Loop Appliance and Bite Plane . . . . . . . . 42

13. Decalcification Apparatus . . . . . . . . . . . 49

14. Micrometer Slide Comparator. . . . . . . . . . 51

15. Areas of Measurements. . . . . . . . . . . 54

16. Intercept Line for Animal II. . . . . . . . . . . 70

17. Intercept Line for Animal III . . . . . . . . . . . 71 
18. Intercept Line for Animal I . . . . . . . . . 74

19. Intercept Line for Animal IV. . . . . . . . . 76

20. Intercept Line for Animal V. . . . . . . . 77

21. Labial Alveolar Crest in Animal I . . . . . . . 85

22. Osteophytic Bone on Labial Alveolar Bone Proper. . . . . 86

23. Howship's Lacunae in Lingual Alveolar Bone Proper. . . . 88

24. Howship's Lacunae in Cementum of Root Near Apex . . . 89

25. Osteophytic Bone on Lingual Crest of Alveolar Bone Proper. . . . . . . . . . . . . . 90

26. Lead Lines in Dentin Near Apex . . . . . . . . 91

27. Labial Alveolar Crest in Animal II . . . . . . . . . 93

28. Labial Alveolar Crest in Animal III. . . . . . . . 95

29. Enlarged View of Labial Alveolar Crest in Animal III • . 96

30. Howship's Lacunae in Cementum of Root . . . . . . 97

31. Labial Alveolar Crest in Animal IV . . . . . . . 99

32. Osteophyte Along Labial Surface of Alveolar Bone . . . 100

33. Root Resorption on Lingual Surface of Root Near Apex . . 101

34. Labial Alveolar Crest in Animal V . . . . . . 103

35. Lead Lines in Alveolar Bone . . . . . . . . . . 105 
36. Bone Deposition at Fundus of Alveolar Bone

Proper . . . . . . . . . . . . . 106 


\section{LIST OF TABLES}

TABLE

PAGE

I. Spring Specifications . . . . . . . . . 32

II. Lead Acetate Injections . . . . . . . . . . . 44

III. Location of Areas of Measurement . . . . . . . 55

IV. Sample Data Sheet Animal I . . . . . . . . 59

V. Sample Data Sheet Animal II . . . . . . . . 60

VI. Data Sheet for All Animals. . . . . . . . . 61

VII. Analysis of Variance. . . . . . . . . . . 62

VIII. Correlation Determination Between Force Magnitude X Bone Deposition . . . . . . . . 66

IX. Center and Degree of Tipping . . . . . . . 78

X. Correlation Determination Between Force Magnitude X Degree Tipped . . . . . . . . . . 81

XI. Correlation Determination Between Force Magnitude X Axis of Tipping . . . . . . . . . . . 83 


\section{CHAPTER I}

\section{INTRODUCTI ON AND STATEMENT OF THE PROBLEM}

1. Introductory Remarks:

This is a scientific age. The conveniences of life and often life itself rest upon the development of our science. One of the basic goals of scientific endeavor is to make observations and measurements as accurately as possible. Accurate observation under controlled conditions is the first step in understanding natural phenomenon. Orthodontics, like all biologic sciences, has had a long period of observation but only a limited amount of measurement.

Orthodontics has for its purpose the correction of malocclusions and the placement of teeth in those functional positions condusive to maintaining the correct occlusion. The attainment of this goal depends on the successful movement of teeth. Orthodontic tooth movement is the changing of the biologic environment of a tooth through the medium of forces applied to the crown of the tooth. The orthodontist must understand the manner in which the physical forces initiate the biologic reaction if he is to effect adequate treatment with minimum damage to the tooth and supporting structures. The force systems applied to 
the crown of the tooth must be related with the subsequent qualitative and quantitative changes in the tooth and its supporting structures. As accurate observation of these phenomenon under controlled conditions reduces the many physical and biologic unknowns, orthodontics will truly attain the level of a science.

2. Statement of the Problem:

The purpose of this investigation is to study bone deposition and tooth movement as related to various magnitudes of forces employed in tipping the maxillary left central incisor teeth of five Rhesus Macaque monkeys using lead acetate as a vital stain. 


\section{CHAPTER II}

\section{REVIEW OF THE LITERATURE}

\section{PART I}

Early orthodontists knew when forces are applied to teeth some changes must occur in the supporting structures of the teeth which permit them to move. Their conclusions were based upon clinical observations because there was a lack of adequate instruments and methods to conduct more sophisticated investigations.

One of the early theories concerning the changes occurring in the supporting tissues was that of Schwalbe and Flouren (1847). It stated that there is bone apposition in the area of stress and bone resorption in the area of pressure.

Kingsley (1877) related another theory which was further elaborated upon by Walkoff that the teeth move due to the elasticity, compressibility and extensibility of the bone.

Farrar (1888) theorized that the teeth moved by retrogressive metamorphosis (absorption) and by the flexibility of the alveolar tissues. He found that the most rapid and least painful tooth movement was in the range of $1 / 240$ inch every twelve hours. He asserted that in the 
orthodontic tipping of teeth the root apices remain stationary or possibly move slightly in the opposite direction. The fulcrum of the tooth would then lie a short distance from the root apex.

Sandstedt (1904) reported on the changes occurring in the tissues as a result of orthodontic tooth movement. He examined the teeth and supporting structures in histologic cross sections and found a deposition of alveolar bone on the side of tension. The newly formed bone spicules were found lying in the direction of the strained periodontal ligament. There was resorption of the alveolar bone on the side of pressure. He then described how the teeth move through the alveolar bone and how the bone reacts to excessive pressure. Sandstedt called the latter process undermining resorption. He observed that the crown of the tooth moved in the direction of the force while the apex of the root moved in the opposite direction. This confirmed the histologic findings of both resorption and apposition on each side of the root with a neutral area lying slightly apical to the center of the length of the root.

Oppenheim (1911) explained that his histologic preparations, contrary to Sandstedt's findings, did not show both resorption and 
apposition on each side of the root. There was bone apposition all along the tension side of the root decreasing in intensity from the alveolar crest to the root apex. Similarly there was bone resorption all along the pressure side of the root with a neutral area lying in immediate proximity to the root apex. He concluded, therefore, that the tooth moved like a one-armed lever with the apex of the root serving as the center of rotation. For over two decades Oppenheim's study was considered the only investigation of scientific merit.

Johnson, Appleton and Rittershofer (1926) were the first to record the force magnitude and distance through which the force was active. The incisor teeth of two Rhesus Macaque monkeys were tipped lingually with forces not exceeding two ounces. They observed that there was deformation and resorption of the root at the apex. In addition, the tipping movement demonstrated that the crown moved in an opposite direction to that of the root apex. The tooth moved like a two-armed lever and the fulcrum was approximately in the middle of the root. Schwarz (1932) related the effect of known force magnitudes used to tip premolar teeth of dogs to the response of the tissues. He concluded that forces not greater than the pressure in the blood 
capillaries $\left(20-26 \mathrm{gm} . / \mathrm{cm}^{2}\right)$ produced the most favorable movement with the least damage to the periodontal tissues. He then classified the biologic effect produced by orthodontic forces into four different degrees. These are simply defined as weak, medium and strong. He was, thus, the first to offer a scale for measuring the force that the practitioner must use in orthodontic procedures.

The work of Johnson, Appleton, and Rittershofer (1926) and Schwarz (1932) concurred with the pioneering work of Sandstedt. The problem of tissue changes in consequence of orthodontic measures, considered to be already solved, was again advanced for debate by these papers.

Oppenheim (1933-1934) repeated his earlier experiments with constant and intermittant forces to clarify the conflicting interpretational controversies. He stated that his findings were in accord with the transformation theory of Wolff that bone tissue, both compact and trabecular, reacts upon pressure with the transformation of its whole architecture. This takes place through the simultaneous resorption of the present bone and apposition of new bone to represent the best functional adaptation to these stimuli. As for the neutral axis of tipped teeth, Oppenheim maintained his earlier work that the center of 
rotation lies at the apex if excessive forces are not used.

Orban (1936) found, contrary to Oppenheim's assertions, that root cementum is less sensitive to pressure than is bone and that biologic manifestation of pressure to the teeth are the same for man as they are in the experimental animal. He recommended, as Schwarz did earlier, the use of light continuous forces rather than intermittant forces. Light continuous forces do not reduce the activity of the resorbing connective tissue and, therefore, rest of the tissue is not necessary. Orban also concluded that tooth jiggling does not allow bone deposition on a side of tension and results only in bone resorption. Regarding the axes of tipped teeth, Orban stated that in all his histologic examinations he has never seen the motion center at the apex.

Stuteville (1937) found root resorption when the force was active through a distance greater than the width of the periodontal space and when the tooth was in occlusion. He asserted that the resorbed area of the root will be repaired by secondary cementum and that the necrotic area of the periodontal membrane will heal. Stuteville preferred intermittant forces claiming that undermining resorption would occur if continuous forces are used. He then speculated that if the applied force 
was just above the capillary blood pressure of the periodontal ligament, it would probably be possible to use continuous forces without damage to the roots or supporting structures.

Oppenheim (1942) maintained his earlier stands that cementum is the most vulnerable tissue of the teeth and supporting structures. He cautioned again against using interpretations of animal findings for humans. He concluded by advising the use of light forces with frequent rest periods.

Sicher and Weinmann (1944) found that the constant presence of a superficial layer of uncalcified cementoid tissue renders the tooth relatively immune to resorption. Therefore, the pressure caused by the apposition of bone on one alveolar wall is transmitted by the moving tooth to the opposite alveolar wall where it causes resorption. They concluded that the differential growth of the tooth and the surrounding bone cause the developmental movements of tooth germs and the eruptive and physiologic movements of teeth during their functional period.

Reitan (1947) attempted bodily tooth movement with light continuous forces. He found even tension of the periodontal fibers all along the 
root surface resulting in little or no root damage. The same or even lighter forces when used to tip teeth caused root resorption. He further reported that all teeth moved bodily were displaced more coronally than in the apical portion of the tooth due to the mechanical resistance created by teeth with long roots.

Reitan (1953, 1954) found that a resorption process, once started, may persist up to eight days or more, even if tension has been applied on the surrounding structures. Tension, however, is always followed by formative changes even if resorbed areas persist. Osteoid tissue formed on the pressure side caused a delay in the onset of resorptive changes. Formative changes were initiated earlier in young individuals than in adults.

Storey and Smith (1952) determined the forces which give the optimum rate of tooth movement without causing damage to the tissues. Helical loop springs of heavy and light force magnitudes were used. Comparison of the clinical results of the springs was made weekly by a direct measurement using needle pointed calipers accurate to 0.01 inch. They found that the optimal range to move a canine tooth, yet preventing the teeth in the anchor unit from slipping, was 150 to 200 grams. Forces 
in excess of 400 grams caused the anchor teeth to move mesially while the caine teeth remained stationary due to undermining resorption. Radiographically, they found that the canine tooth tipped approximately about the apical one-third of the root.

Storey (1953) conducted a radiographic study of bone changes associated with tooth movement. Dense lamellated bone was formed in the tension area and the trabeculae were orientated in the direction of the applied forces when forces within the optimum range were used. The cribriform plate was continually reformed ahead of the region of resorption on the pressure side. There occurred, then, four recognizable zones of activity around a tooth being moved with light forces. There was resorption then deposition on the pressure side and there was deposition then reconstructive resorption on the tension side. The apposition of bone was less dense and could be differentiated from the cribriform plate when forces in excess of the optimum range were used. There was no deposition of bone ahead of the area of pressure when excessive forces were used.

Macapanpan, Weinmann and Brodie (1954) found new bone formation on the side of tension after twenty-four to thirty-six hours and resorption 
of bone on the side of pressure after sixty to seventy-two hours of tooth movement.

Reitan (1957, 1961) found that light forces should be applied, especially during the initial stage of tooth movement. Light forces reduce the tendency for the formation of cell-free, hyalinized areas in the periodontal fiber bundles of the' pressure side. The tendency to such formation decreases as soon as the inner alveolar bone plate has been eliminated by resorption. He found also, that forces exerted in a tipping movement caused the formation of more cell-free hyalinized areas than forces applied in translation.

Wentz, Jarabak and Orban (1958) investigated the influence of occlusal trauma imitating cuspal interferences. The orthodontic appliances used were designed to produce buccolingual jiggling trauma. The early tissue changes consisted of pressure and tension areas on both the buccal and lingual surfaces. The three months and six months experiments showed a compensatory increase in width of the periodontal ligament to more than three times their original widths. They concluded that the tissue changes are a functional adaptation due to changes in functional requirements. 
Huettner and Whitman (1958) examined the tissue changes occurring in the Rhesus Macaque monkey during various orthodontic movements. It was found that there was very minute root resorption and that new alveolar bone spicules were laid down in the direction of force during tipping. The tipping movement was conducted for twelve weeks and the force exerted by the appliance was four ounces. To insure tipping, the wire was not seated in the bracket but instead merely ligated to produce a one point contact. They concluded that the tipping axis depends upon the type, amount, and direction of force applied to the tooth and on the physiologic reaction of the supporting tissues. In addition, it was found that the "tip back" movement produced the most severe root resorption and yet, did not prevent the mesial movement of the posterior segments. Early orthodontists realized that excessive forces hindered tooth movement and retarded the reconstruction of bone around the tooth in its new position. Forces within physiologic limits were recommended in almost every article concerning orthodontics; however, few investigators concerned themselves with the actual measurement of forces beyond the sense of touch and clinical symptoms. Jarabak (1960) defined light forces as those in the range of twenty-eight to 110 grams and intermedi- 
ate forces as those in the range of 150 to 180 grams. Values of force beyond this are excessive and result in a slower rate of tooth movement.

In defining the orthodontic tipping of a tooth, Jarabak and Fizzell (1963) assert that "when a tooth is turned about any axis other than its long axis or one parallel to it, that tooth is experiencing tipping or a combination of tipping and translation". The biologic appraisal of the qualities of forces used to move teeth are divided into threshold, optimal, maximal and excessive forces. At the lowest biologic level are the threshold forces which are capable of producing stimuli causing the alveolar bone to remodel. Optimal forces are those that will catalyze cellular activity to resorb bone on the pressure side with a simultaneous apposition of bone on the side of tension. Maximal forces are those approaching the strangulation of the physiologic activity of the supporting structures on the pressure side. Forces crushing the periodontal ligament and temporarily interrupting its physiologic processes are excessive. They are accompanied by hyalinization of the periodontal ligament, hemorrhage and root resorption. To produce rapid tooth movement and avoid injury to the root, forces should not exceed the maximal range. 


\section{PART II}

The discovery of the vital staining quality of madder by Belchier in 1736 was a turning point in the study of the physiology of bones. It was not until almost 200 years later, however, that attention was given to the effect of lead and lead salts on the hard tissues of the living body.

Caffey (1931) roentgenographically showed dark bands of increased density in the growing bones of children with chronic lead poisoning. He was able to reproduce similar findings experimentally by feeding lead acetate to growing dogs. As early as the tenth day, he was able to demonstrate roentgenographically the lead lines in the sub-epiphyseal zones of bones. Due to the constancy of this phenomenon, Park, Jackson, and Kajdi (1931) proposed that the lead lines serve as an aid in diagnosing lead poisoning in children.

Okada and Mimura $(1938,1940,1941,1942)$ devised a method of vital staining hard tissues by lead acetate. They injected a microquantity of lead acetate into an animal and found that lead replaces calcium at the site of calcifying tissues. The lead precipitates as lead phosphate which is even more insoluble than calcium phosphate. The lead is collected in the hard tissues immediately upon absorption and almost no 
transference occurs thereafter. The deposited lead is shown histochemically as a distinct fine line. It then became possible to mark the passage of time in the hard tissues of a living animal with the lead lines and to examine the various responses of hard tissues under experimental conditions.

In 1958 Okada and Asoda attempted to clarify the mechanism of lead deposition in hard tissues and the form of the lead salt in blood. They did this by varying the chemical form and mode of administration of lead salt. They examined the intensity of the black lines since the intensity is in direct proportion to the amount of lead salt injected. They found that lead had the greatest deposition and the other metals tested had less deposition as the solubility product of their phosphate increased. These experiments indicated that with the intravenous injection of lead acetate the form of lead present in the blood is of the labile type which easily dissociates into lead ion. The lead present in the blood after the intraarterial injection is of the stable type like lead phosphate, unless an instillation injection is used. It is believed, then, that the type of lead that undergoes deposition in hard tissues is neither in ionic form nor a sparingly soluble salt form. It must be of the type that combines with 
some substance or receptor which is in competition with calcium. 


\section{CHAPTER III}

\section{MATERIALS AND METHODS}

\section{Animal Selection:}

Six female Rhesus Macaque monkeys between four and six years of age were used in this experiment. The choice of female monkeys was made because the males tend to be more hostile. The animals were procured from the Shamrock Farms of Middletown, New York where they received the necessary immunizations.

Monkeys with a full compliment of permanent teeth, except for the third molars, were required to fulfill the preliminary experimental design. Monkeys at this stage of dental development range in chronologid age from four to six years. The corresponding dental development in man is found in children ranging from twelve to eighteen years of age.

2. Animal Housing and Care:

The animals were housed in individual cages in the monkey colony of the Franklin Boulevard Hospital Animal Research Center, Chicago, Illinois. The animal research facility is maintained by the Department of Stomatology which is associated with Loyola University School of 
Dentistry. The monkeys were identified by Roman numerals assigned randomly from I to VI with monkey VI serving as control. The weight of the animals ranged from 3 kilograms to 4.7 kilograms.

A full-time diener provided routine daily care and conditions in the animal colony were maintained as near optimal as possible. The daily diet consisted of a ration of Rockland Laboratory Primate biscuits, an orange and water. Five cubic centimeters of Vi-Daylin multiple vitamins was injected daily into the orange. Bananas were substituted for the orange and the hard biscuits were softened with water during the active period of experimentation to prevent damage to the orthodontic appliances.

Weekly injections of 300,000 units of penicillin $G$ were administered intramuscularly during the entire course of the experiment as a preventive measure against enteric and pneumonic infections.

\section{Animal Handling:}

A two week colonization period preceeded the experimental procedures to condition and acclimate the animals to their new quarters. Surgical scrub suits, face masks and rubber gloves were worn at all times for the mutual protection of both the animals and the operator 
from potentially communicable infections.

A portable restraint cage or squeeze cage (Figure 1) was used to facilitate handling the animals and to transfer them from their cages to the animal operating room where all experimental procedures were carried out. Heavy leather gloves were worn to protect the handler from bites and scratches until the animal was anesthetized.

4. General Anesthesia:

The experimental procedures were performed with the aid of a general anesthetic. The predetermined weight of the squeeze cage was subtracted from the combined weight of the monkey and the squeeze cage to obtain the weight of the animal and thereby determine the correct dosage. The correct anesthetic dosage was then prepared and recorded. The sliding wall of the squeeze cage was partially raised and the selected leg was isolated for the intravenous injection. The intravenous injection was chosen because it becomes effective immediately and requires less anesthetic agent. The injection site was prepared by scrubbing with soap and water, shaving, and cleansing with alcohol. Twenty-five milligrams of Nembutal Sodium (2\%) per kilogram of body weight was injected into 


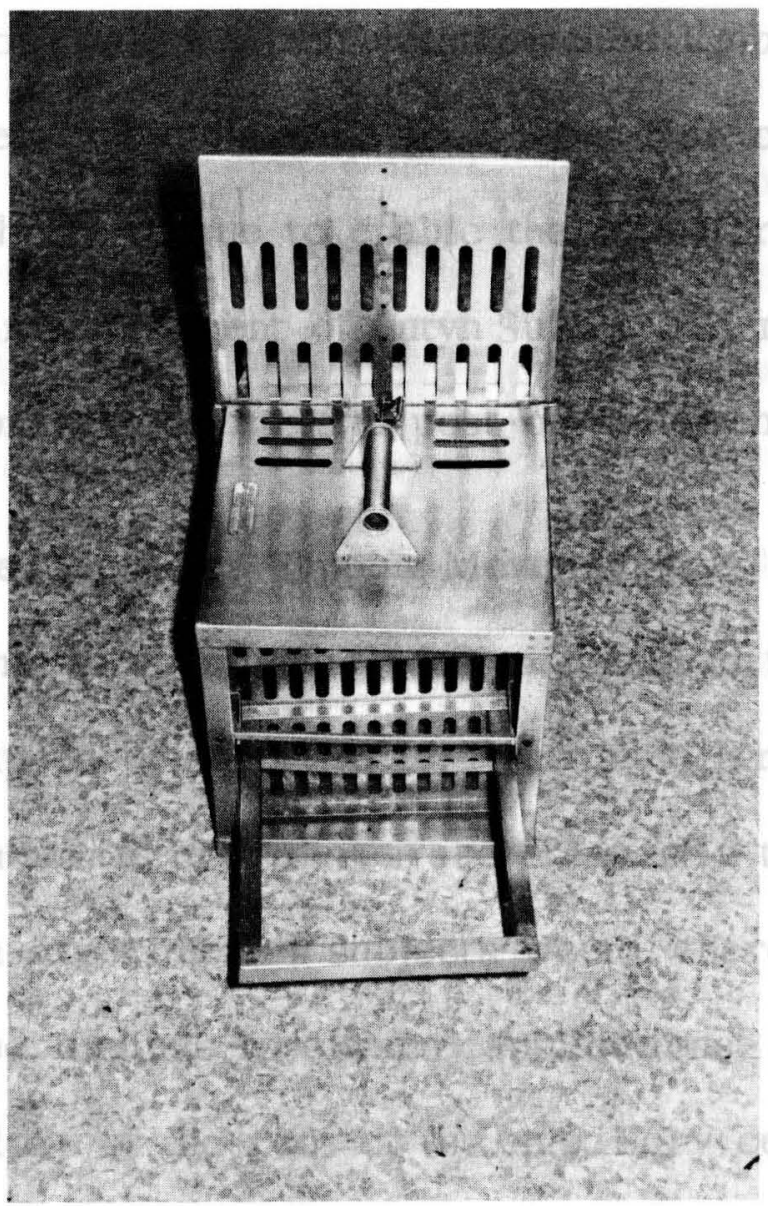

FIGURE 1

ANIMAL RESTRAINT CAGE 
either the saphenous or popliteal vein.

The anesthetized animal was then transferred from the squeeze cage to the operating table. Each outstreteched limb was secured to the corners of the operating table with two inch strips of gauze. A suture was placed through the tongue to enable the operator to maintain a patent airway. An opthalmic ointment of Butyn Sulfate and metaphen was placed into each eye to prevent drying and post-operative infection.

5. Selection of the Teeth for Tipping Movements:

The preliminary experimental design required that the maxillary incisor teeth be tipped orthodontically. The maxillary incisor teeth in many clinical orthodontic procedures are frequently tipped. The tipping of similar teeth in experimental subjects would, therefore, lend ease in correlating these findings to clinical applications.

The morphology of the root of the maxillary central incisors is conical. The recordings of the tipping movements by lead acetate vital staining are more easily interpreted in conical shaped roots than in bifurcated or trifurcated roots. The crowns of the maxillary central incisor teeth are larger and better shaped morphologically for orthodontic band placement than the crowns of the maxillary lateral incisor teeth. 
The maxillary left central incisor tooth was, therefore, selected as the tooth to be tipped in this experiment.

6. Preparation of the Experimental Animal:

Each animal was immobilized in the restraint cage and the general anesthetic agent was administered at the prepared intravenous injection site. The anesthetized animal was secured to the operating table and prepared for a careful examination of the oral cavity. The examination revealed the presence of twenty-eight permanent teeth. The gingival tissues were pink, firm, and stippled and, the mucosa was free of lesions. There were small amounts of calculus and light staining of the anterior teeth. The teeth were scaled and then polished to remove any remaining stains.

Acrylic resin impression trays were then prepared with rubber adhesive and impressions of the dental arches were taken with Coe Heavy Rubber Base impression material. Vel-Mix Class II stone was used to fabricate working models from which the appliances were constructed.

The maxillary right first premolar tooth of each animal was surgically removed to facilitate the experimental procedures of a companion thesis. The monkey was then returned to its cage and 
carefully positioned to maintain a patent airway during recovery.

7. Force Magnitude Determination and Force System Design:

The object of this investigation was to study the effects of various known magnitudes of force employed in tipping the maxillary central incisor teeth of monkeys. It was necessary to use various known magnitudes of force because the optimal force magnitude that will produce tipping is not yet known. Jeffry and Kostiwa (1965), however, found that forty-five to fifty per cent of the force value used for tooth movement in humans may be used favorably for tooth movement in monkeys. The magnitudes of force selected for this experiment were $25,50,75,100$, and 150 gms. These force magnitudes were assigned respectively to monkeys I through $\mathrm{V}$ with the remaining experimental animal serving as control.

An intrinsic horizontal force system was selected to produce the labial tipping movement. The force was derived from a round wire with helical loops designed for activation in the transverse plane. A transverse helical loop devise is one in which the helix is wound buccolingually or in the mediolateral direction. The high elasticity at a low force magnitude, which can be built into a transverse helical loop 
appliance, makes this appliance ideally suited for tipping teeth (Jarabak and Fizzell 1963). The activated wire of the transverse helical loop appliance was sling tied to the bracket of the maxillary central incisor tooth to produce the one point contact necessary for the tipping movement. The maxillary second molars, canines, and remaining incisor teeth served as anchor units. An acrylic resin bite plane was used to eliminate the factors of occlusion in this experiment and the experimental procedures of companion theses.

\section{Analysis of the Force System:}

Tipping is defined as the turning of a tooth about any axis other than its long axis or one parallel to it. A tooth tips when adequate force is applied to it and when the action line of that force does not pass through centroid. The tissue response, however, varies with the magnitude of the force applied. The force system created by forces considered as low magnitude and those considered as high magnitude will be examined separately for purposes of clarity.

The first force system to be considered is that which occurs when low magnitude tipping forces are applied to the tooth. The term low magnitude refers to those forces that do not crush the periodontal 
ligament or endanger its viability. A free body diagram (Figure 2) will be used to analyze the force system. A labially directed force $F_{t}$, such as that derived from a transverse helical loop system, is applied to the bracket of the maxillary central incisor tooth. This force is represented by the vector $F_{t}$. The force $F_{t}$ creates a resisting force system which is distributed throughout the periodontal ligament and alveolar process. The resistance offered by the periodontal ligament occurs mainly as tension along the apical portion of the root on the labial aspect and along the coronal portion of the root on the palatal aspect. The applied force manifests itself as the applied moment $F_{t}$ $\mathrm{X} \mathrm{g}$ where $\mathrm{g}$ is the perpendicular distance from centroid to the action line of the force. The resisting force system in this case must be a force and a couple. The resisting couple is represented by the two vectors labelled $f_{c}$ which are equal and opposite but not collinear to the expected center of tipping labelled E. The resisting force is represented by the vector $F_{r}$. The force system may be expressed by the second law of equilibrium which states: When a body is in equilibrium, the sum of all forces in a horizontal direction is zero.

$$
\mathrm{F}_{\mathrm{h}}=0=\mathrm{F}_{\mathrm{t}}+\mathrm{f}_{\mathrm{c}}-\mathrm{F}_{\mathrm{r}}-\mathrm{f}_{\mathrm{c}}
$$




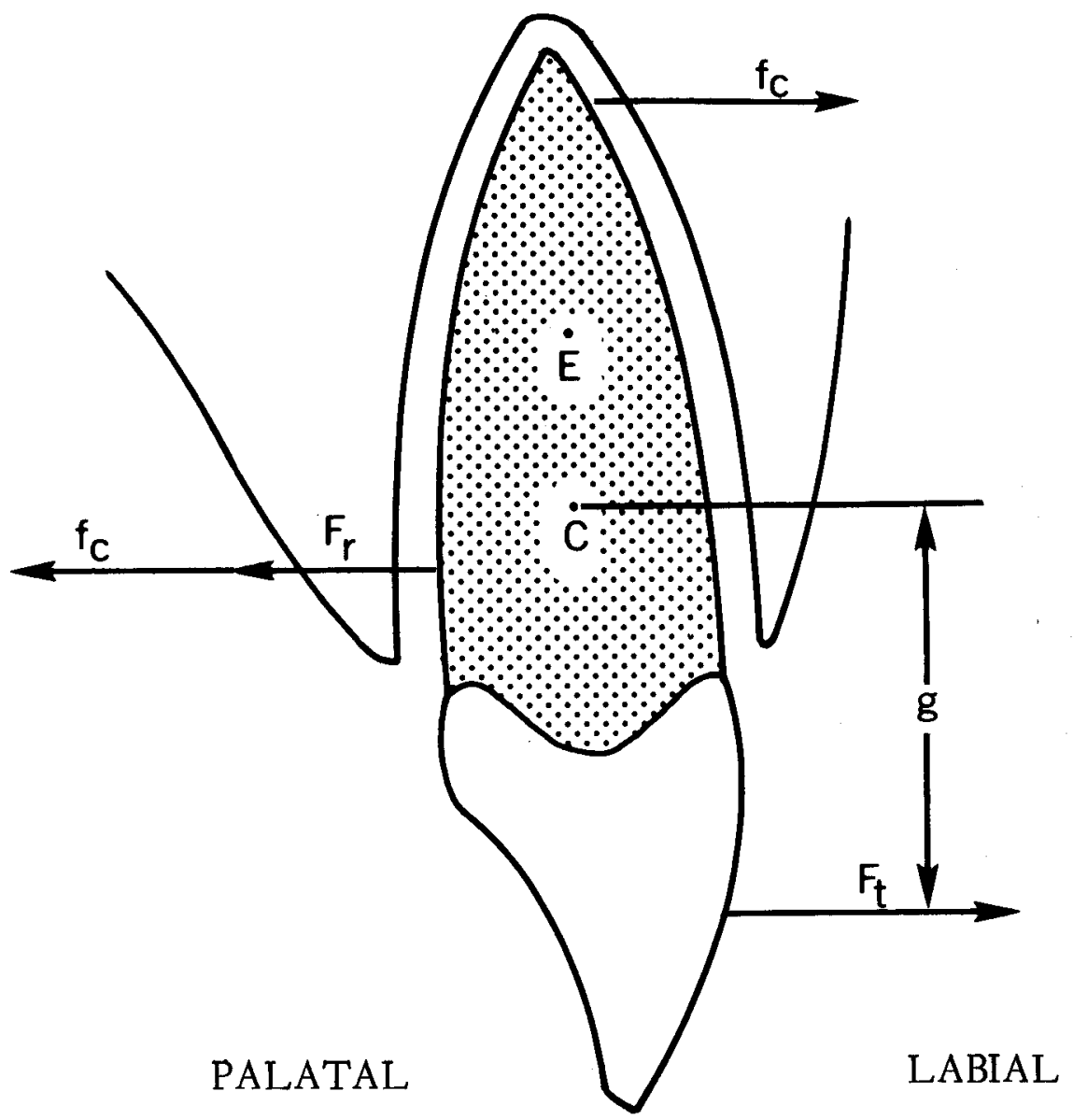

FIGURE 2

FREE BODY DIAGRAM OF

MAXILLARY CENTRAL INCISOR TOOTH 
Solving for $\mathrm{F}_{\mathrm{r}}$, we find that $\mathrm{F}_{\mathrm{r}}=\mathrm{F}_{\mathrm{t}}$ or that the resisting force is equal to the applied force.

The second force system to be analyzed is that which occurs when high magnitude or excessive tipping forces are applied to the crown of the tooth. The term high magnitude refers to those forces which crush the periodontal ligament against the labial alveolar crest and thereby endanger its viability. A free body diagram (Figure 3) will be used to analyze the force system. A labially directed force $F_{t}$ is applied to the bracket of the central incisor tooth. The applied force is represented by the vector $\mathrm{F}_{\mathrm{t}}$ which manifests itself as the applied moment $\mathrm{F}_{\mathrm{t}} \times \mathrm{g}$ where $\mathrm{g}$ is the perpendicular distance from the labial alveolar crest to the action line of the force. The resisting force system in this case must be a force and a counter moment. The resisting force occurs at the labial alveolar crest and is represented by the vector $\mathrm{F}_{\mathrm{r}}$. The counter moment is $f_{a} \times p$ where $p$ is the perpendicular distance from the labial alveolar crest to the action line of the force $f_{a}$. Another resisting force which must be considered is that provided by the periodontal ligament at the lingual alveolar crest. These periodontal ligament fibers are stressed in tension as the tooth advances toward the labial alveolus. This 


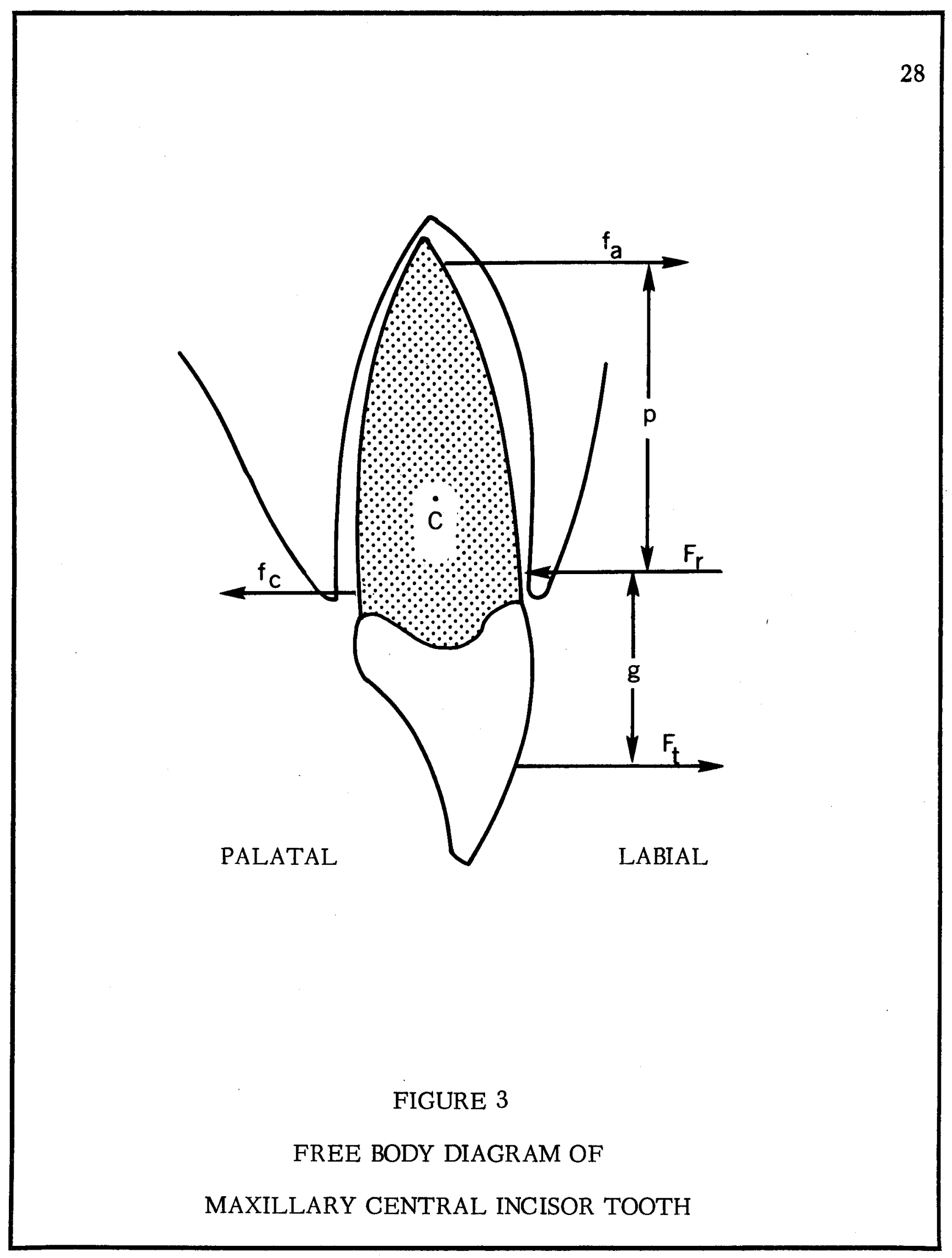


resisting force is represented by the vector $f_{c}$.

The force system may be further expressed by again utilizing the second law of equilibrium.

$$
\sum F_{h}=0=F_{t}+f_{a}-F_{r}-f_{c}
$$

The third law of equilibrium must also be considered. It states: When a body is in equilibrium, the sum of all moments about a point is zero.

$$
\sum M=0=F_{t} X g-f_{a} X p
$$

From this, we can solve for $\mathrm{f}_{\mathrm{a}}$ as follows:

$$
\mathrm{f}_{\mathrm{a}}=\mathrm{F}_{\mathrm{t}} \times \mathrm{g} / \mathrm{p}
$$

Subsituting this value we find that

$$
0=F_{t}(1+g / p)-F_{r}-f_{c}
$$

From this, we can solve for the resisting force $\mathrm{F}_{\mathrm{r}}$ as follows:

$$
F_{r}=F_{t}(1+g / p)-f_{c}
$$

These equations indicate that when excessive tipping forces are utilized, the force exerted on the labial alveolar crest is greater than the applied force itself. The maximum resistance, then, occurs at the labial alveolar crest which then acts as a fulcrum around which further tipping occurs. The remaining resistance is distributed throughout the labial fibers of the periodontal ligament and the lingual wall of the 
alveolus.

9. Appliance Construction and Testing:

The active elements of the appliance consisted of transverse helical loops 'Figure 4). A wide working range is necessary in this appliance to prevent the force magnitude from being expended in the first few increments of tooth movement. The working range may be varied by altering the number of turns in each helix, the leg length, loop diameter, wire diameter, and the wire properties. Wires of several types and diameters were tested for force magnitudes and elasticity by being made up into variations of the basic design. It was concluded that all five transverse helical loop springs would be constructed of Green Elgiloy round wire with $21 / 2$ turn helical loops of $2.5 \mathrm{~mm}$. diameter. The desired force magnitude and working range were obtained by varying the leg length, wire diameter and wire properties. Specifications and dimensions for each of the springs used are given in Table I.

The springs were tested on a load deflection apparatus Figure 5'. The apparatus consisted of two mounted stages, one of which was movable. The movable stage had adjustable pin vices to which the springs to be evaluated could be affixed. Linear displacement was 

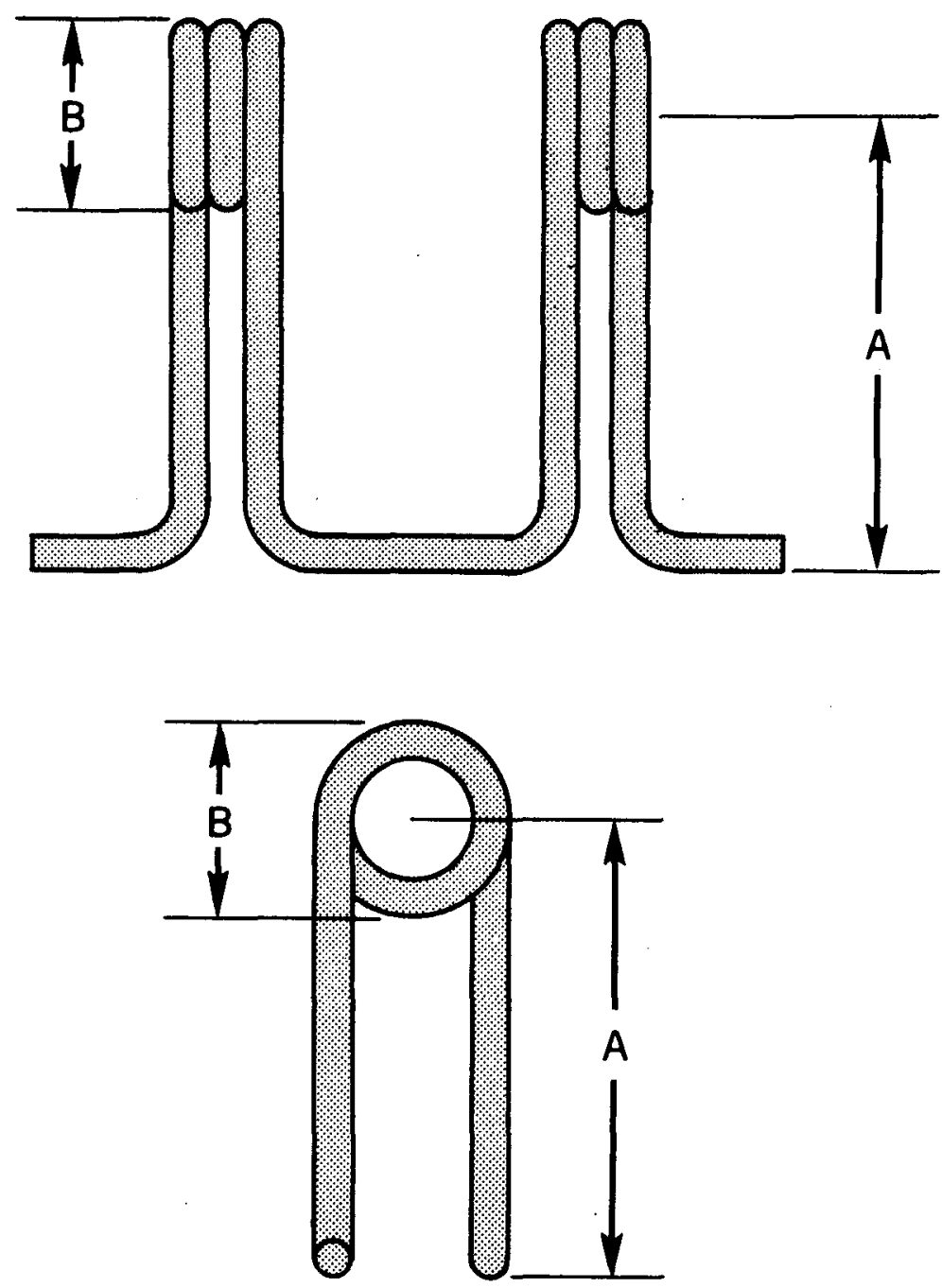

A. LEG LENGTH

B. LOOP DIAMETER

FIGURE 4

DIAGRAM OF TRANSVERSE

HELICAL LOOP DESIGN 


\section{TABLE I}

\section{SPRING SPECIFICATIONS FOR THE}

TWO AND ONE-HALF TURN TRANSVERSE HELICAL LOOP APPLIANCES

Monkey

Force of activation (gm.)

Green Elgiloy wire diam. (in.)

Leg length (mm.)

Loop diameter (mm.)

Spring rate (gm. /mm.)

*heat treated

$\begin{array}{cccccc}\text { I } & \text { II } & \text { III } & \text { IV } & \text { V } & \text { VI } \\ 25 & 50 & 75 & 100 & 150 & 0 \\ .011 & .011^{*} & .014 & .014^{*} & .015^{*} & 0 \\ 5.5 & 6.0 & 6.0 & 6.0 & 6.5 & 0 \\ 2.5 & 2.5 & 2.5 & 2.5 & 2.5 & 0 \\ 13.0 & 14.3 & 30.0 & 34.0 & 34.6 & 0\end{array}$




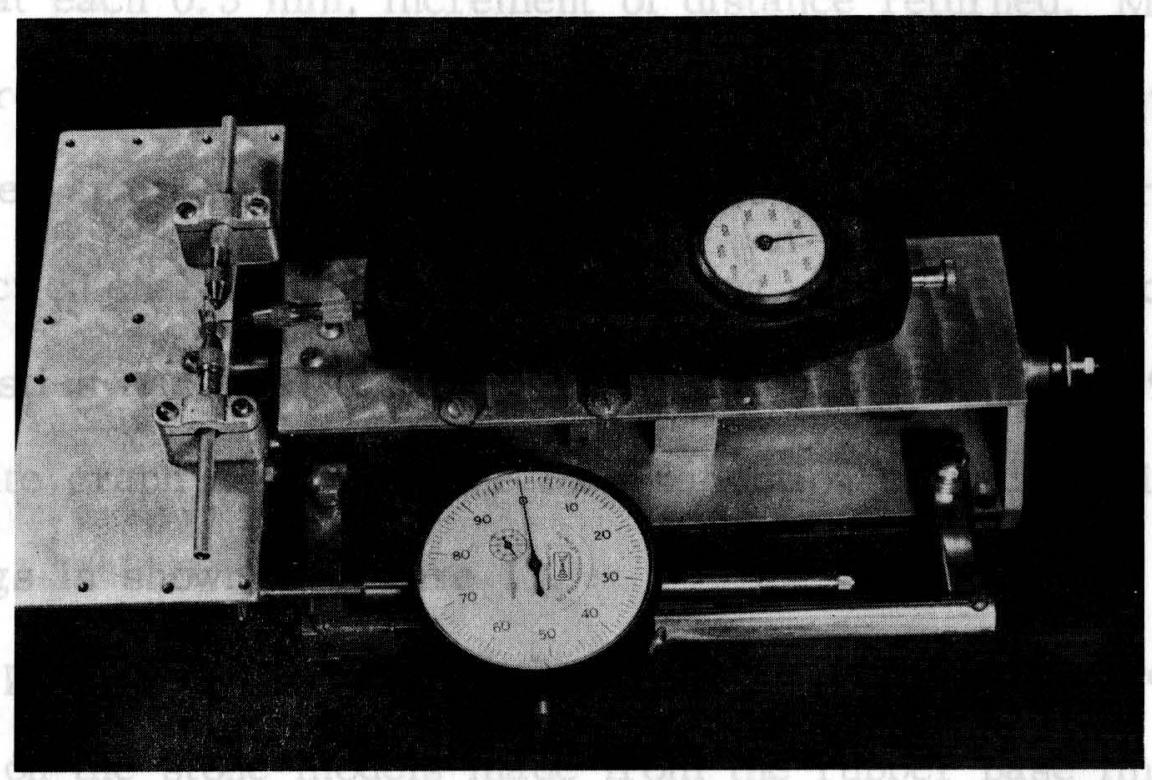

FIGURE 5

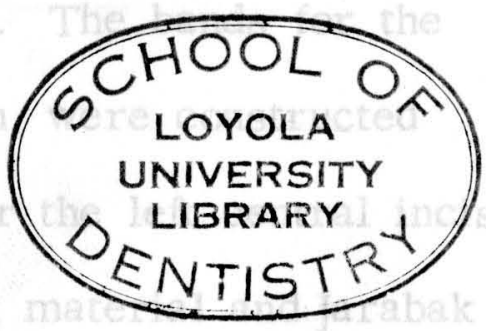

LOAD DEFLECTION APPARATUS 
measured by an attached extensometer calibrated to $0.01 \mathrm{~mm}$. divisions. The magnitude of force was measured on the non-movable stage by a force gauge calibrated in $10 \mathrm{gm}$. divisions.

Each spring was tested three times and the force magnitude was recorded at each $0.5 \mathrm{~mm}$. increment of distance returned. Mean force values were computed from the three tests. The mean force values were plotted against the distance returned to graphically describe the load deflection characteristics of each spring. The load deflection characteristics and trial tests are shown in Figures $6,7,8,9$, and 10 . A composite graph describing the load deflection characteristics of all five springs is shown in Figure 11.

The passive components of the appliance were constructed indirectly on the stone models made from the rubber base impressions. The gingival margins of the second molars, canines, and left central incisor teeth were prepared for band adaptation. The bands for the anchor teeth, the second molar and canine teeth, were constructed from 0.004 inch banding material. The bands for the left central incisor teeth were constructed from 0.003 inch banding material and Jarabak edgewise brackets were attached. A passive palatal arch of 0.036 inch 


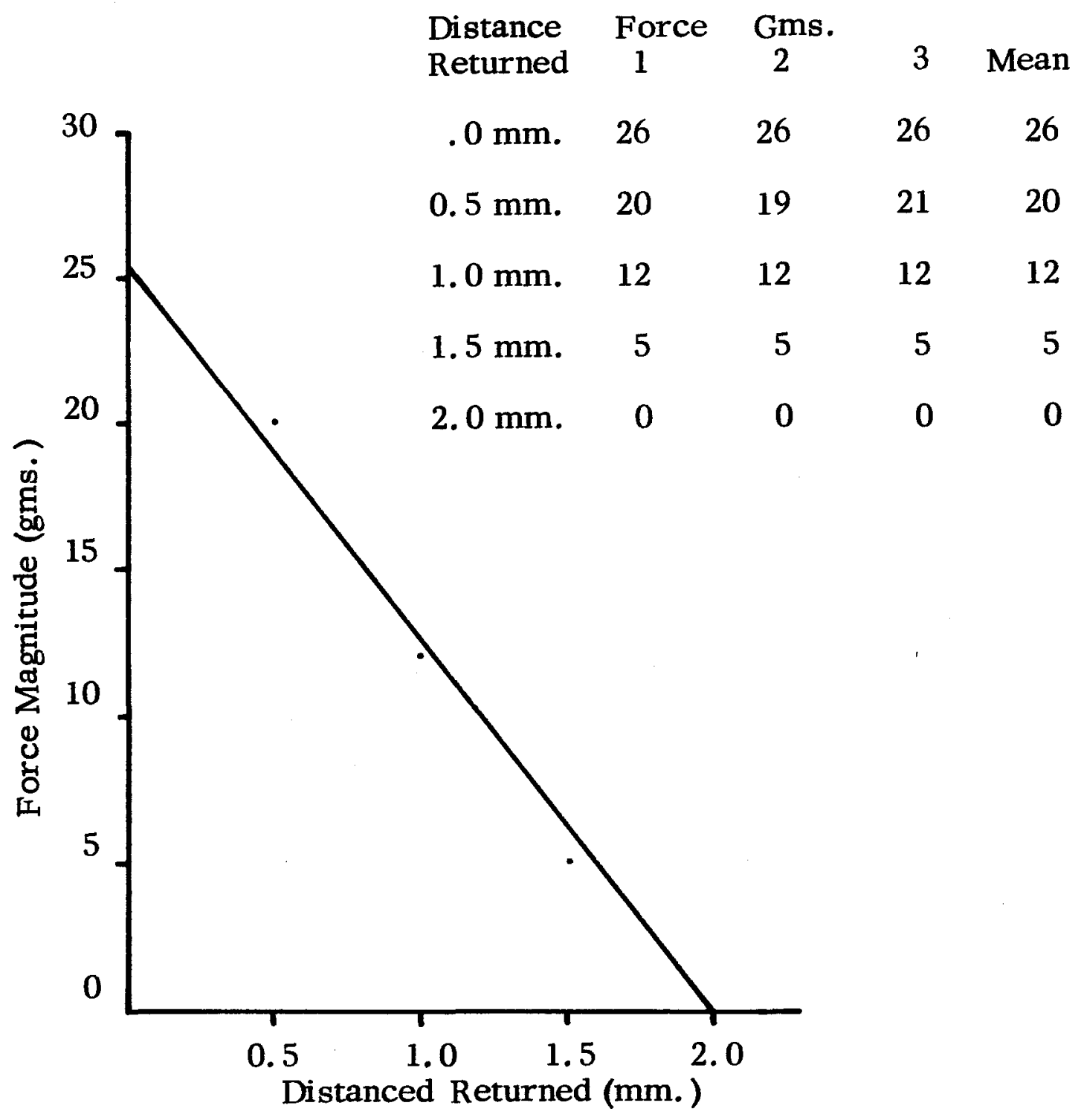

FIGURE 6

LOAD DEFLECTION CHARACTERISTICS (25 GMS.) 


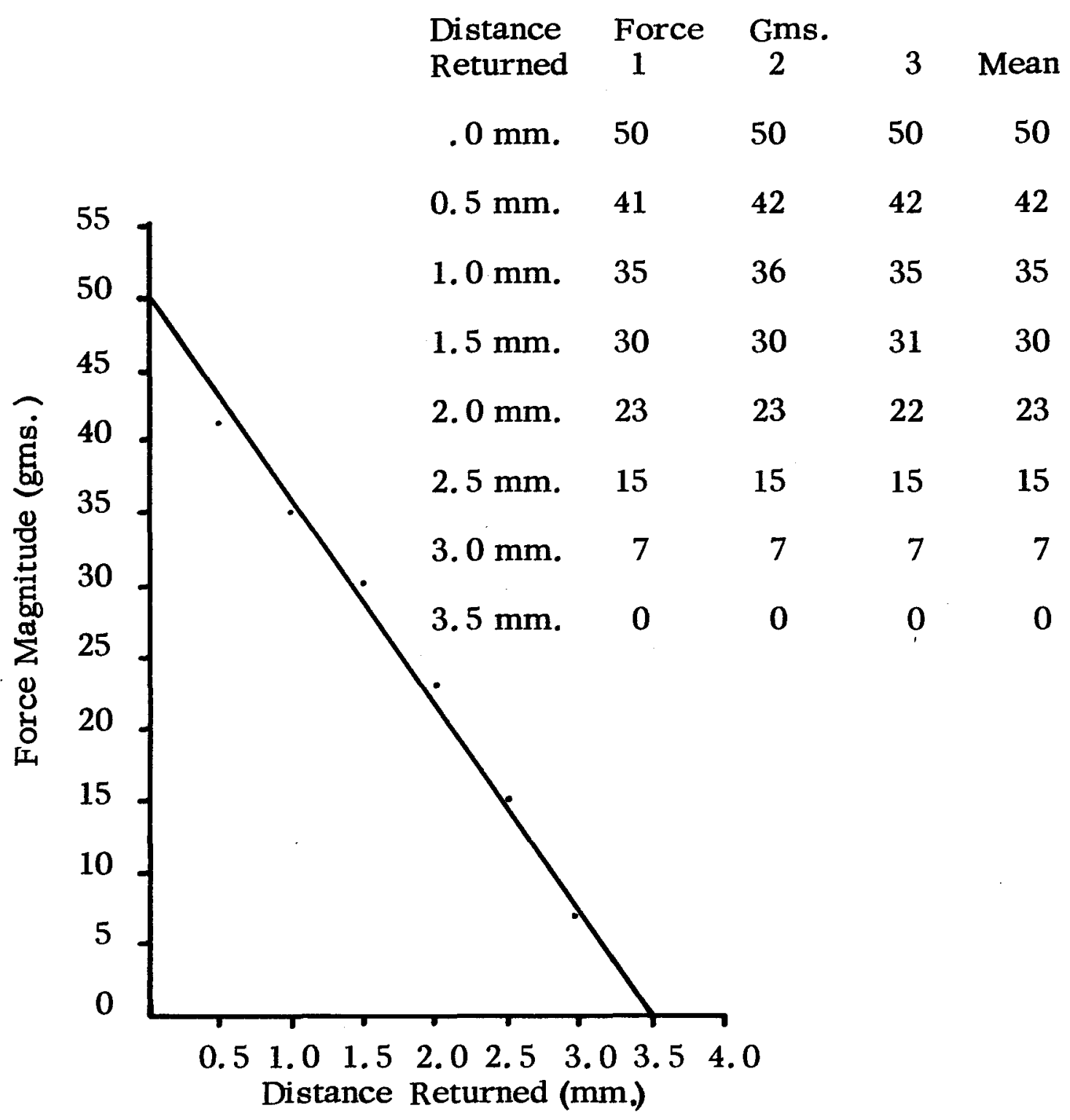

FIGURE 7

LOAD DEFLECTION CHARACTERISTICS (50 GMS.) 


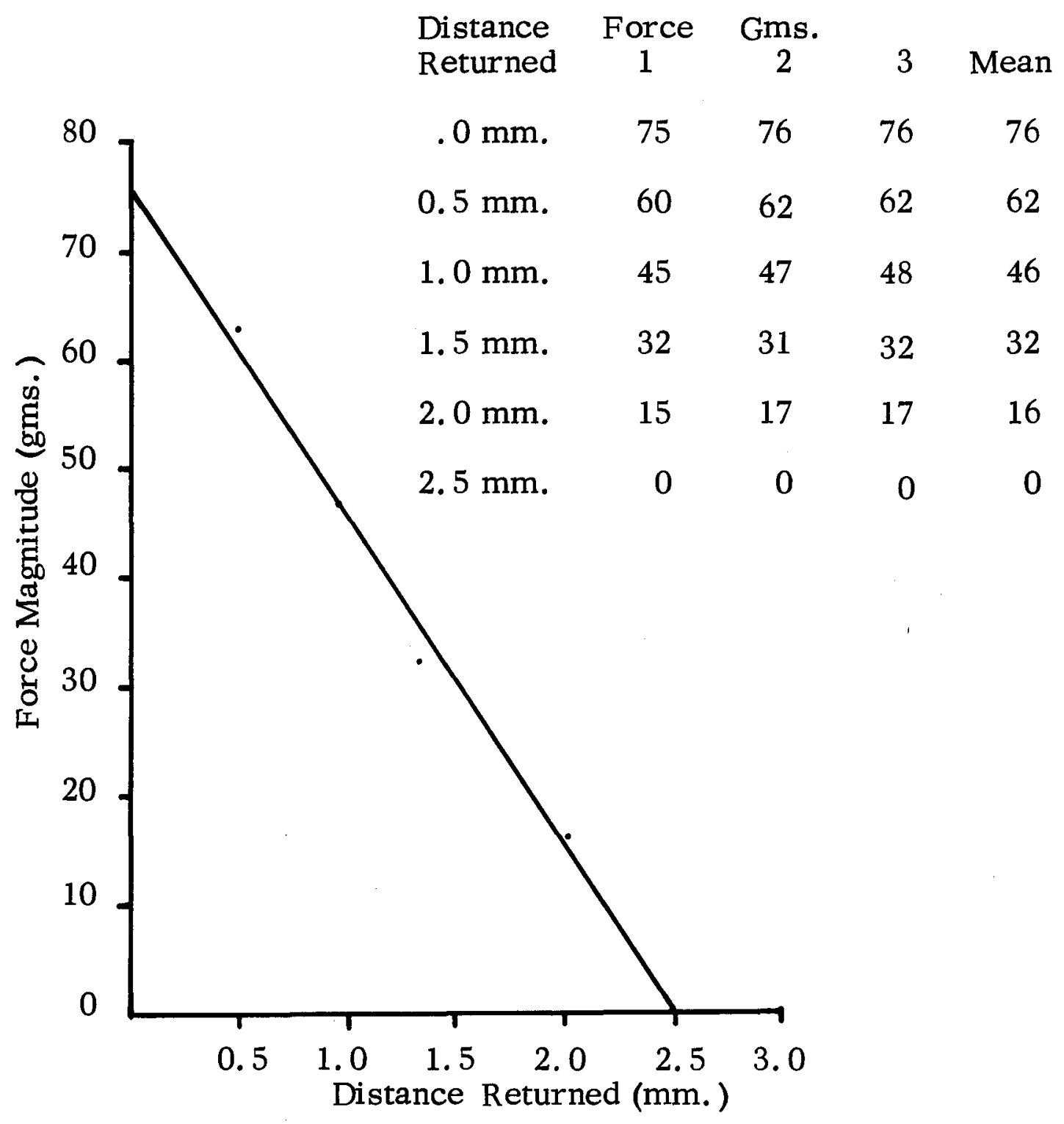

FIGURE 8

LOAD DEFLECTION CHARACTERISTICS (75 GMS.) 


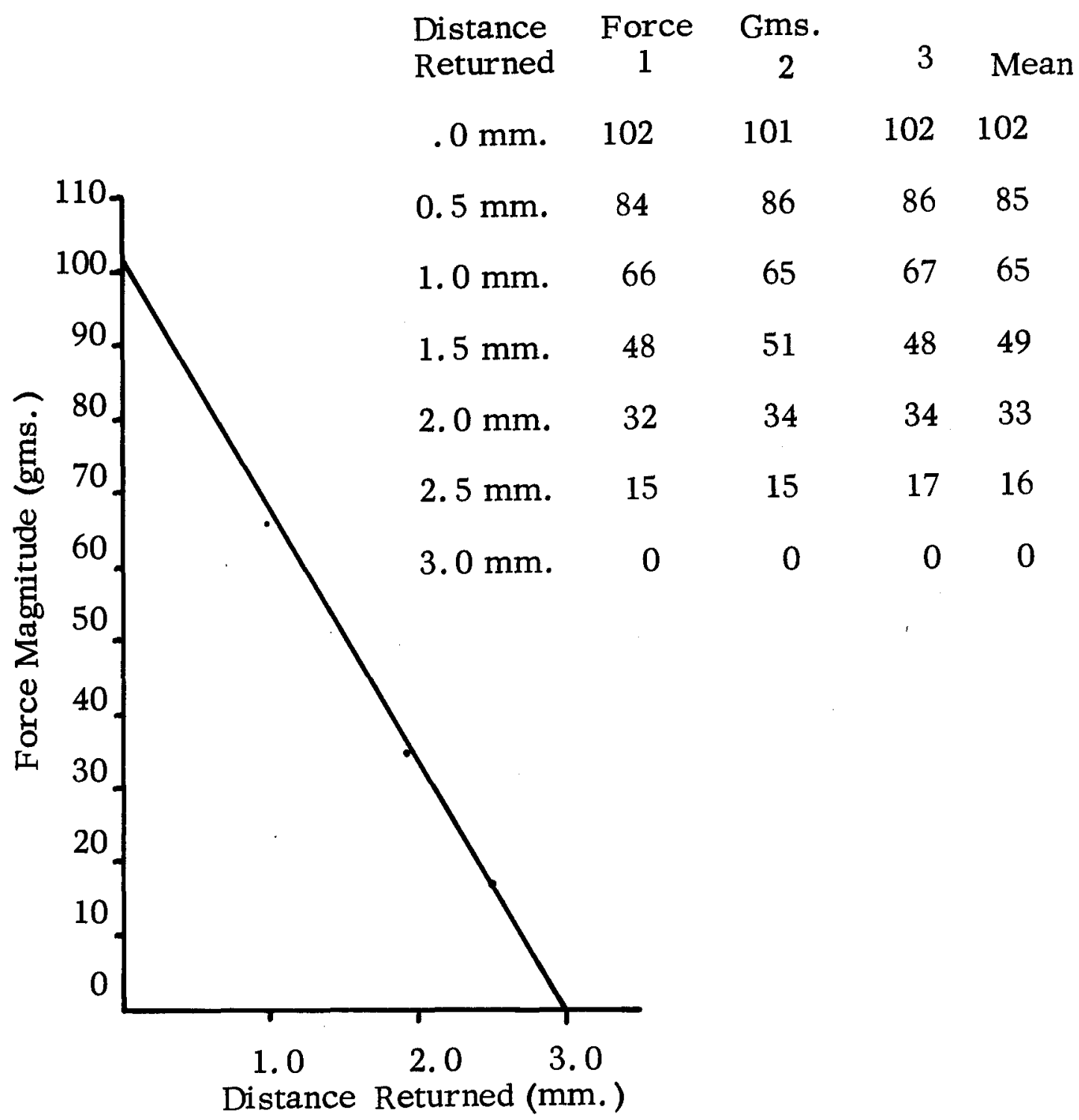

FIGURE 9

LOAD DEFLECTION CHARACTERISTICS (100 GMS.) 


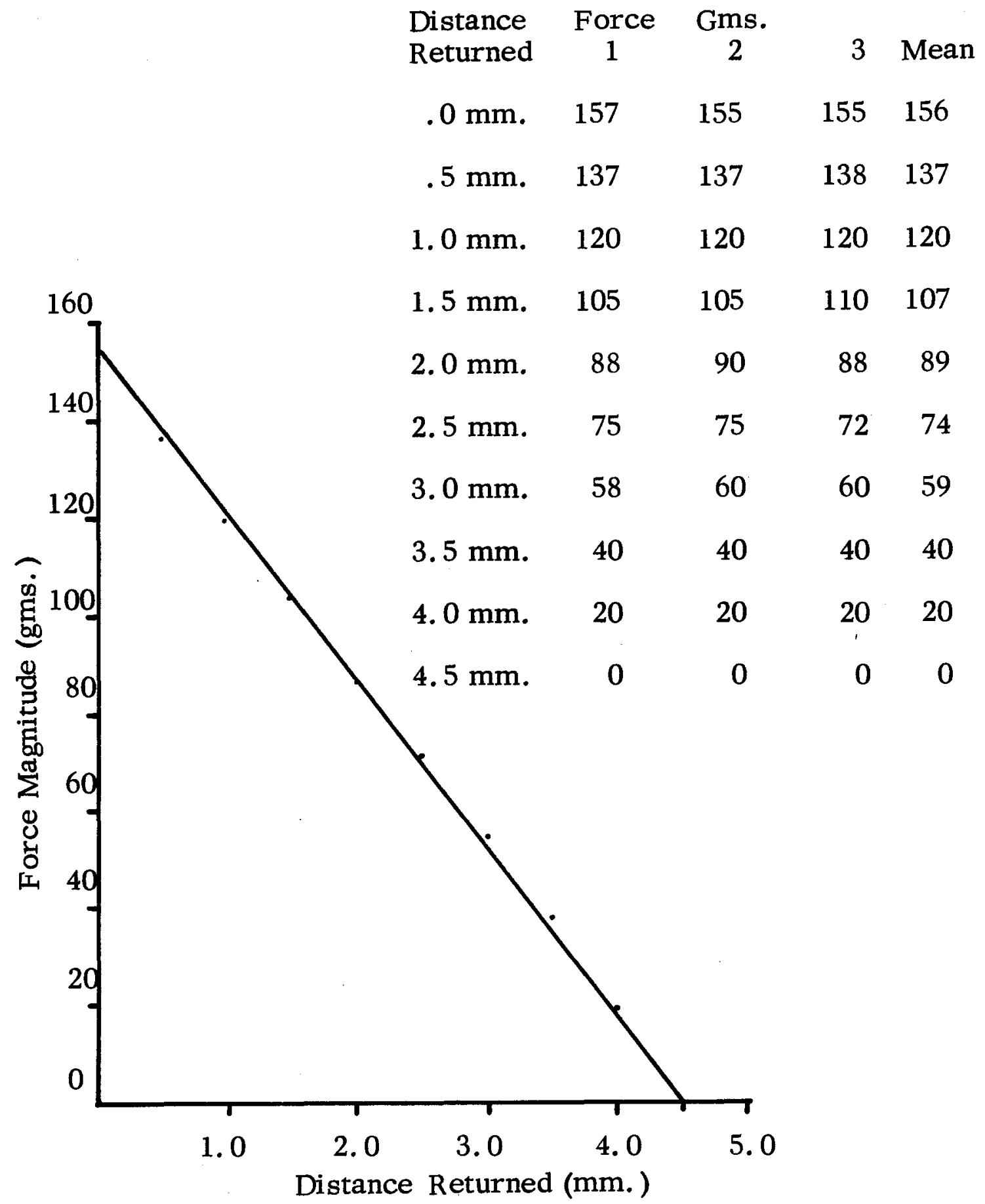

FIGURE 10 


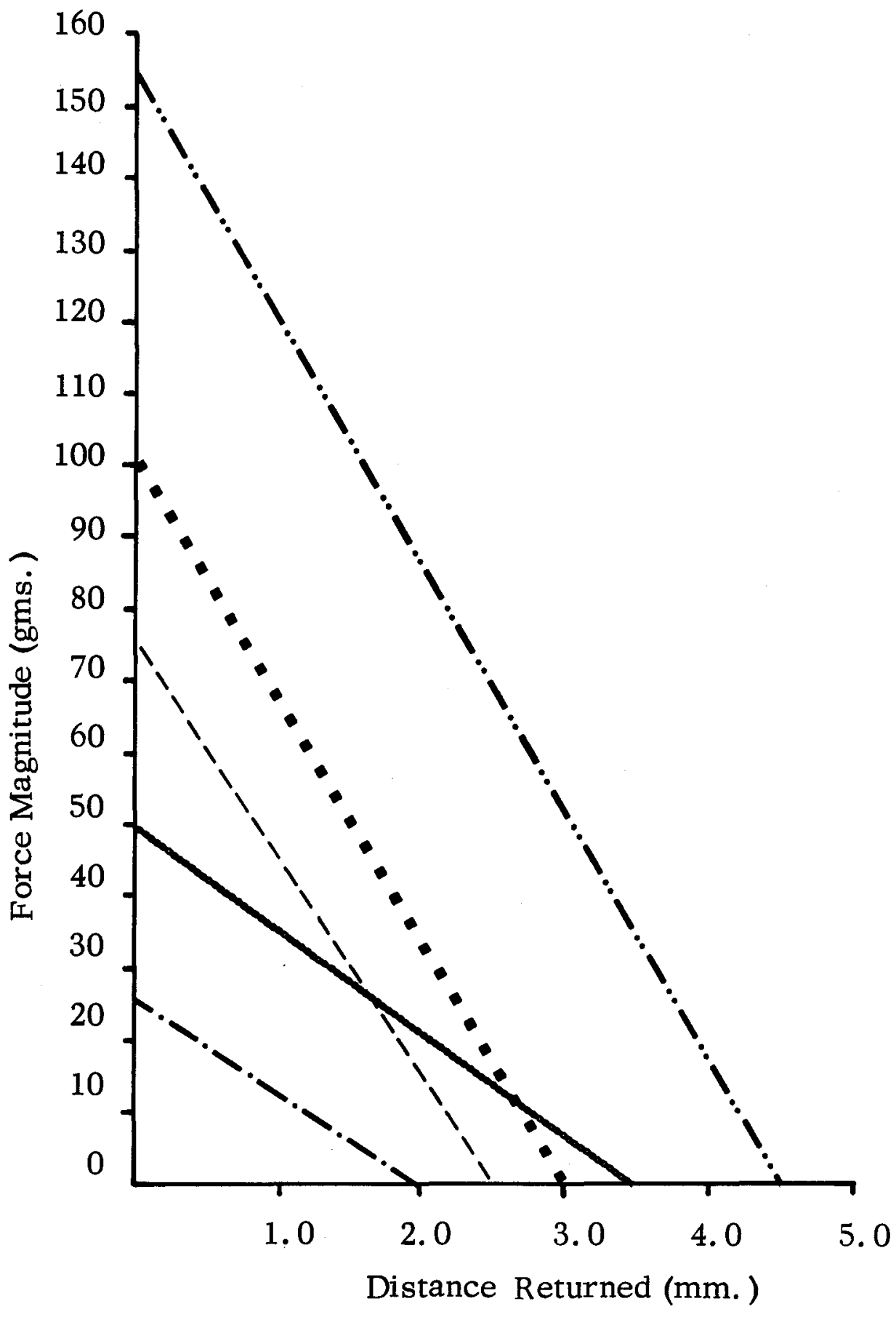

FIGURE 11

LOAD DEFLECTION CHARACTERISTICS OF THE FIVE 
round Tru-chrome wire was adapted to contact the lingual surfaces of the banded anchor teeth. The palatal arch wire was then soldered to each of the bands in the anchor unit. Retention spurswere soldered to the anterior portion of the palatal arch wire and served as attachment for the acrylic resin bite plane.

An acrylic resin bite plane was constructed to cover the anterior teeth and incorporate the anterior portion of the palatal arch wire. The left central incisor tooth remained uncovered to permit the labial tipping movement Figure 12. The acrylic resin was extended into the labial vestibule. The bases of the helical loop springs were incorporated into the labial extensions of the acrylic resin to fix the active components of the appliance to the anchor unit. The labial extension also shielded the helical loop springs but did not interfere with their movement. The acrylic resin bite plane opened the bite approximately $4 \mathrm{~mm}$. in the anterior region.

10. Lead Acetate Vital Staining:

A vital staining technique utilizying lead acetate was used in this experiment. It has been shown that when a microquantity of lead acetate. is injected intravenously into an animal, the lead replaces calcium at the 


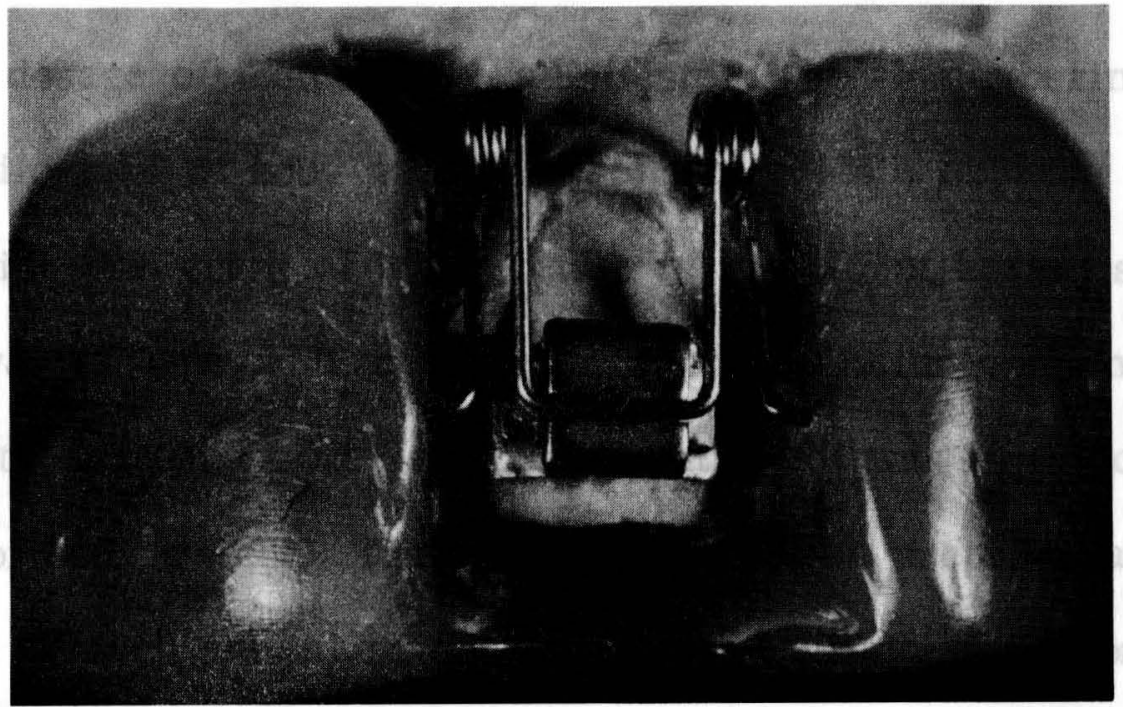

FIGURE 12

HELICAL LOOP APPLIANCE AND BITE PLANE 
site of calcifying tissues. The lead is deposited as lead phosphate almost immediately upon absorption and is shown histochemically as a distinct fine line. This technique makes it possible to mark the passage of time as well as examine the supporting structures of the teeth under experimental conditions.

The dosage of lead acetate administered in this experiment was 4 mg. per kilogram of body weight. The lead acetate solution was prepared by dissolving one gram of lead acetate in $250 \mathrm{cc}$. of heated sterile distilled water. One cubic centimeter of this solution contained $4 \mathrm{mg}$. of lead acetate and, therefore, one cubic centimeter was injected per kilogram of body weight. The correct dosage was prepared according to the weight of each animal prior to each lead acetate injection. Table II lists the body weight of the animals at each injection and the corresponding lead acetate dosage administered. All lead acetate injections were administered intravenously into either the saphenous or popliteal vein at the: rate of $3 \mathrm{cc}$. per minute.

The first lead acetate injection was administered one hour following appliance activation. The remaining four lead acetate injections were administered each week for four weeks. The animals were sacrificed 
LEAD ACETATE INJECTIONS

Monkey I Monkey II Monkey III Monkey IV Monkey V Monkey VI

\begin{tabular}{|c|c|c|c|c|c|c|c|}
\hline $\begin{array}{l}\text { Date } \\
\text { Body Wt. }\end{array}$ & $7-13-66$ & $7-13-66$ & $7-15-66$ & $7-15-66$ & $7-15-66$ & $7-13-66$ & \\
\hline $\begin{array}{l}\mathrm{Kg} . \\
\text { Lead Ace. }\end{array}$ & 4.590 & 3.400 & 3.450 & 3.800 & 4.680 & 3.000 & \\
\hline c. c. & 4.6 & 3.4 & 3.4 & 3.8 & 4.7 & 3 & \\
\hline $\begin{array}{l}\text { Date } \\
\text { Body Wt. }\end{array}$ & $7-20-66$ & $7-20-66$ & $7-22-66$ & $7-22-66$ & $7-22-66$ & $7-20-66$ & \\
\hline $\begin{array}{l}\text { Kg. } \\
\text { Lead Ace. }\end{array}$ & 4.500 & 3.300 & 3.420 & 3.700 & 4.740 & 3.290 & \\
\hline c. c. & 4.5 & 3.3 & 3.4 & 3.7 & 4.7 & 3.3 & \\
\hline $\begin{array}{l}\text { Date } \\
\text { Body Wt. }\end{array}$ & $7-27-66$ & $7-27-66$ & $7-29-66$ & $7-29-66$ & $7-29-66$ & $7-27-66$ & \\
\hline $\begin{array}{l}\text { Kg. } \\
\text { Lead Ace. }\end{array}$ & 4.530 & 3.250 & 3.400 & 3.750 & 4.600 & 3.600 & \\
\hline c. c. & 4.5 & 3.3 & 3.4 & 3.7 & 4.6 & 3.6 & \\
\hline $\begin{array}{l}\text { Date } \\
\text { Body Wt. }\end{array}$ & $8-2-66$ & $8-2-66$ & $8-5-66$ & $8-5-66$ & $8-5-66$ & $8-2-66$ & \\
\hline $\begin{array}{l}\text { Kg. } \\
\text { Lead Ace. }\end{array}$ & 4.540 & 3.200 & 3.530 & 3.820 & 4.400 & 3.630 & \\
\hline c. c. & 4.5 & 3.2 & 3.5 & 3.8 & 4.4 & 3.6 & \\
\hline $\begin{array}{l}\text { Date } \\
\text { Body Wt. }\end{array}$ & $8-10-66$ & $8-10-66$ & $8-12-66$ & $8-12-66$ & $8-12-66$ & $8-10-66$ & \\
\hline $\begin{array}{l}\text { Kg. } \\
\text { Lead Ace. }\end{array}$ & 4.300 & 3.300 & 3.550 & 3.870 & 4. 100 & 3.610 & 禹 \\
\hline c. c. & 4.3 & 3.3 & 3.6 & 3.9 & 4. 1 & 3.6 & \\
\hline
\end{tabular}


one day following the final injection.

\section{Appliance Cementation and Activation:}

The animal was prepared in the same manner as previously described. The contact points of the teeth adjacent to those receiving bands were relieved with a diamond disk. The band of the left central incisor tooth was cemented in place with Black's cooper cement. The remaining appliance with the attached acrylic resin bite plane was cemented to the anchor teeth. The excess cement was removed after setting was completed. The helical loop appliance was tested with feeler gauges prior to ligation to confirm the proper force magnitude. The helical loop spring element was ligated to the bracket with 0.010 inch ligature wire in a sling-tie fashion to insure a one point contact necessary for tipping. The cusps of the canine teeth were reduced to remove the occlusal interferences. The acrylic resin bite plane was adjusted so the mandibular anterior teeth would strike it evenly.

Plaster casts were placed on the forelimbs of the monkeys to prevent them from damaging the appliances. The limbs were bent at almost right angles at the elbows. A knit sleeve was placed over the limb from the hand to the shoulder. The knit sleeve was covered with 
a layer of cotton. Plaster impregnated strips of gauze were soaked in water and applied over the cotton. The plaster casts had to be covered with a layer of adhesive tape during the course of the experiment to prevent the animals from chewing through the plaster.

The first dosage of lead acetate was injected one hour following appliance activation. The animal was returned to its cage and carefully positioned to maintain a patent airway.

\section{Sacrifice and Perfusion:}

The animals were sacrificed one day following the final injection. The animals were anesthetized and prepared in the manner previously described. An incision was made from the left clavicle to the last rib and the skin was reflected. The sternum was removed along with a portion of the right and left ribs. The arch of the aorta was identified by blunt dissection. The superior vena cava and the descending aorta were freed. The descending aorta was clamped and an incision was made into the wall of the left ventricle. A perfusion canula was placed into the left ventricle and advanced into the aortic arch. The canula was tied in place to prevent the escape of the fluids. The superior vena cava was cut. A solution of ten per cent sodium citrate was introduced 
into the circulatory system by a gravity feed system. This was continued until a clear solution of sodium citrate returned through the superior vena cava. The sodium citrate perfusion was then discontinued and a ten per cent formalin solution was introduced into the circulatory system. The tissues of the head and neck became very rigid. The formalin perfusion was continued for approximately ten minutes after it was detected returning through the superior vena cava. The animal was decapitated and the skin was dissected from the head. The mandible, skull cap, and brain were removed. The specimens were then labelled and placed into a solution of ten per cent formalin for one week for fixation.

13. Decalcification of Specimens and Precipitation of Lead:

Block sections of the right and left central incisor and left lateral incisor teeth along with their supporting structures were removed from the jaws following fixation. The specimens were decalcified in $0.1 \mathrm{~N}$ hydrochloric acid. Eighteen liters of the decalcifying solution was used to insure little change in $\mathrm{pH}$ throughout the procedure. The lead phosphate, deposited in bone, was precipitated as lead sulphide which is black in color. This was accomplished by continuously bubbling hydrogen sulphide 
gas through the hydrochloric acid throughout the procedure. The acid solution was presaturated with hydrogen sulphide gas for twenty-four hours before the specimens were placed into the solution. The excess hydrogen sulphide gas was passed through a solution of sodium hydroxide and potassium permanganate to render the gas less noxious. The entire apparatus used for this procedure is diagrammed and labelled in Figure 13. The decalcification process was examined roentgenographicall and considered complete when no evidence of calcified tissues appeared in the roentgenogram. The procedure was completed in two weeks.

\section{Preparation of the Sections:}

The decalcification of the specimens was followed by infiltration of the specimens with gelatin. The specimens were removed from the acid solution and washed with distilled water. They were placed in solutions of 10,20 , and 30 per cent gelatin with $2.5 \mathrm{~mm}$. of concentrated lusol solution. The specimens remained in each of the gelatin solutions for forty-eight hours and maintained at $37^{\circ}$ to $40^{\circ} \mathrm{C}$. in an incubator. The specimens were then imbedded in 30 per cent gelatin and hardened by chilling in a refrigerator. The gelatin blocks were further hardened and stored by placing them in ten per cent formalin and chilling. 


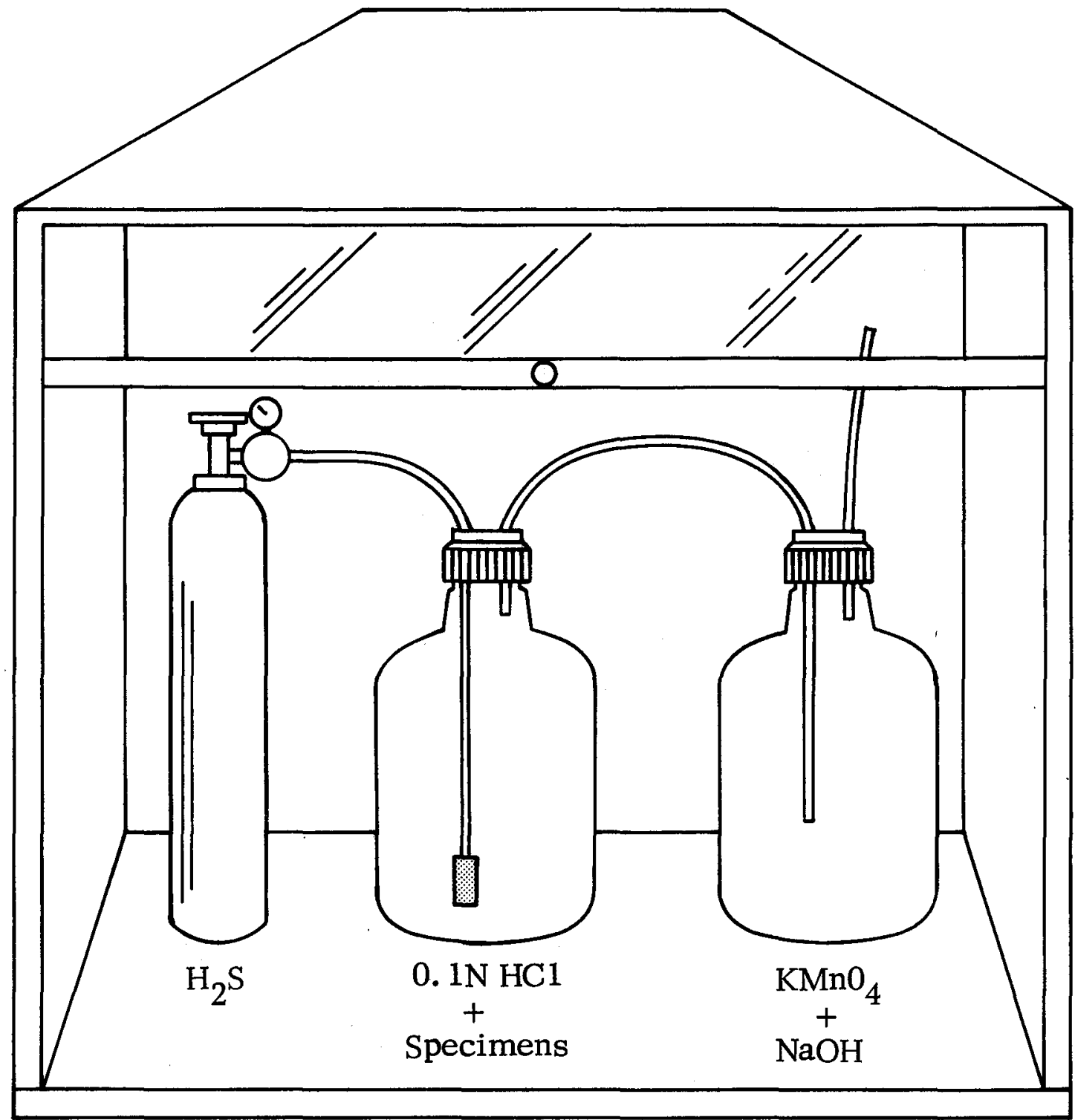

FIGURE 13

DECALCIFICATION APPARATUS 
A cryostat was used at $-20^{\circ} \mathrm{C}$. to section the blocks serially at a thickness of twenty-four microns. The sections were cut labiolingually in the direction of the forces. The sections were floated in a stender dish filled with distilled water and positioned onto a slide coated with egg albumin. The sections were then mounted with glycerine jelly.

\section{Method of Assessment:}

(A) Testing the Measuring Instrument:

A micrometer slide comparator (Figure 14) was used to measure the width of the vitally stained bone and the width of the periodontal ligament. The microscope was mounted on a micrometer slide which was guided by a precision micrometer screw. The micrometer slide is calibrated to $1 / 100 \mathrm{~mm}$. units, but can be interpolated to one micron. The microscope is provided with cross hairs which lie in the center of the field.

The accuracy of the micrometer slide was tested by measuring the distance between two points to the nearest micron. Ten measurements were taken by each of three operators. One operator advanced the instrument, positioning the cross hairs from point to point, and another operator recorded the readings. This procedure was followed for each 


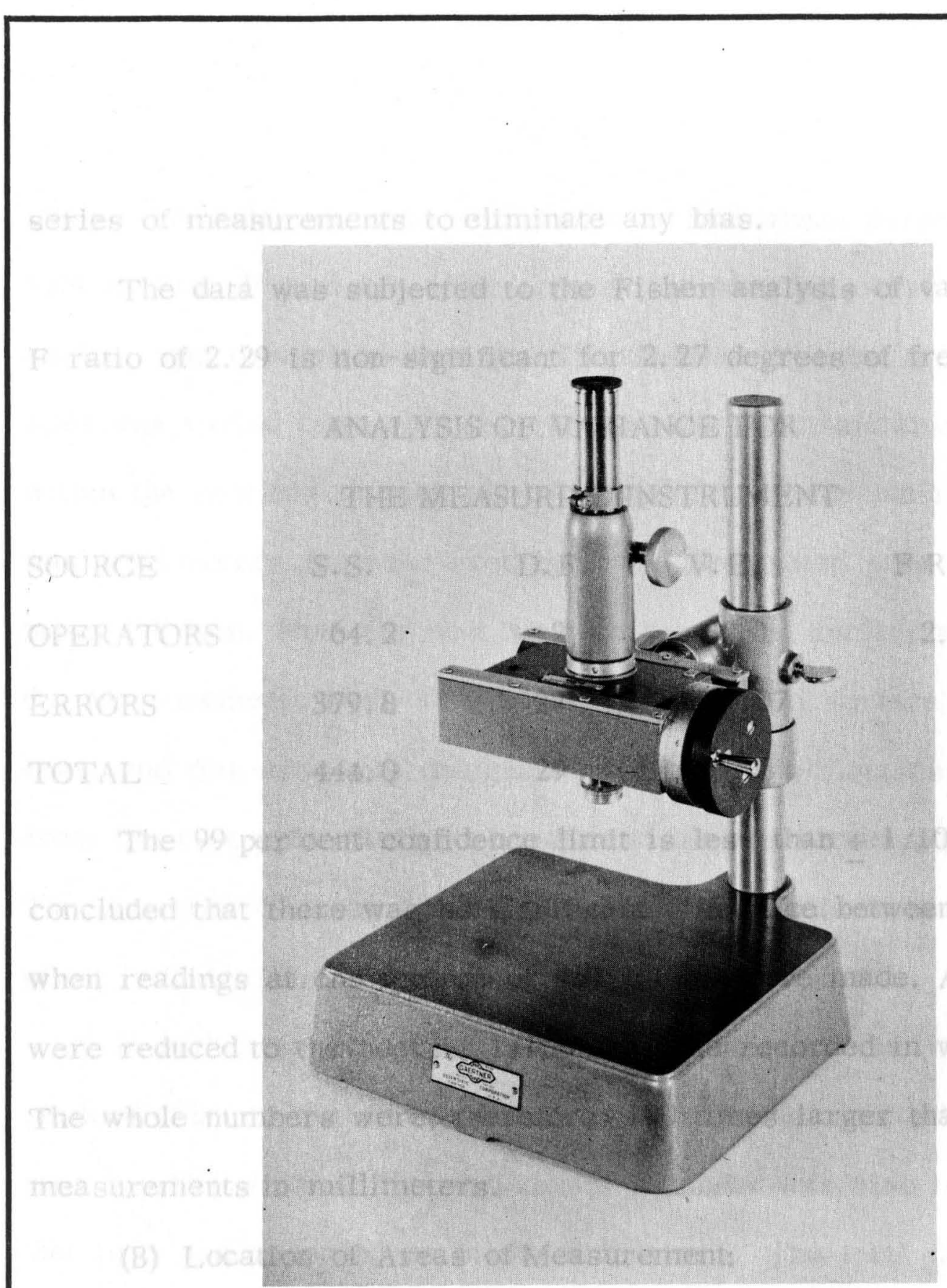

FIGURE 14

MICROMETER SLIDE COMPARATOR 
series of measurements to eliminate any bias.

The data was subjected to the Fisher analysis of variance. The F ratio of 2.29 is non-significant for 2.27 degrees of freedom.

\section{ANALYSIS OF VARIANCE FOR}

THE MEASURING INSTRUMENT

SOURCE

S.S.

D. F.

V.E.

F RATIO

SIGNIF.

OPERATORS

64.2

2

32.1

2. 29

N.S.

ERRORS

379.8

27

14.07

TOTAL

444.0

29

The 99 per cent confidence limit is less than $\pm 1 / 100 \mathrm{~mm}$. It was concluded that there was no significant difference between operators when readings at one micron or $1 / 100 \mathrm{~mm}$. were made. All measurements were reduced to the nearest $1 / 100 \mathrm{~mm}$. and recorded in whole numbers. The whole numbers were, therefore, 100 times larger than the actual measurements in millimeters.

(B) Location of Areas of Measurement:

The slides were placed on a transilluminated field and the micrometer slide comparator was positioned directly over the sections. Movements in the labiolingual plane of space were considered in this 
study. The measurements were taken at four areas perpendicular to the root surface Figure 15. The area at the alveolar crest on the labial surface was designated area A. The distance of area A from the root apex was varied from animal to animal, but was maintained constant within the sections of each animal. The area on the labial surface four millimeters from the root apex was designated area B. Measurements taken $1.5 \mathrm{~mm}$. from the root apex on the labial surface were designated C. Measurements were also taken on the palatal surface at the alveolar crest and this area was designated area $\mathrm{D}$. The distance of area $\mathrm{D}$ from the root apex was held constant within the sections of each animal. The distances of these areas from the root apex in each animal are given in Table III.

In each area, the width of the vitally stained bone was measured perpendicular to the surface of the root and was recorded as measurement one.The width of the periodontal ligament was also measured at that time and recorded as measurement two. The total of the two widths was recorded as measurement three. A diagram of the measurements is shown in the cutaway view in Figure 15. 


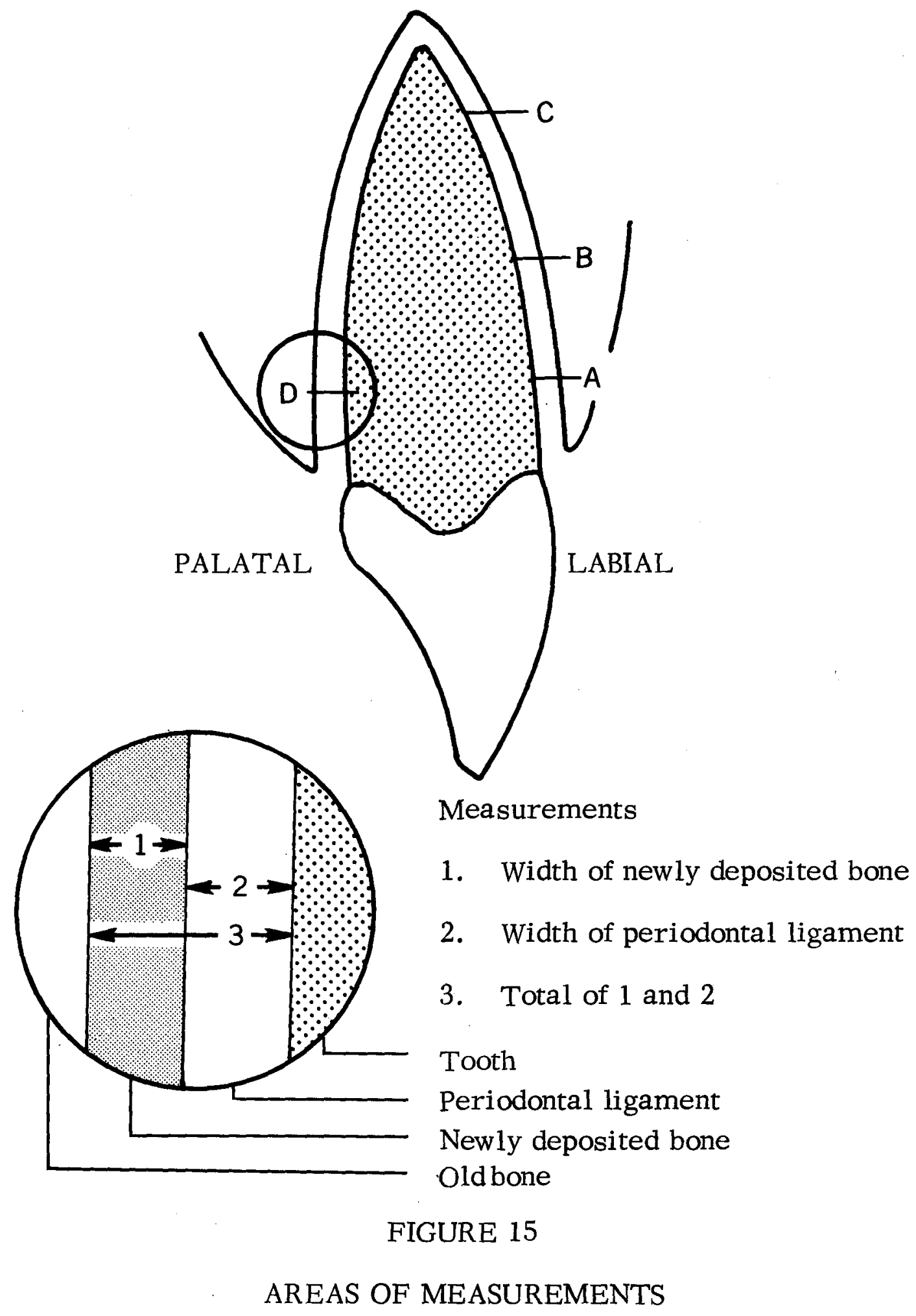


TABLE III

LOCATION OF THE AREAS OF MEASUREMENT

ANIMAL

DISTANCE OF AREAS FROM ROOT APEX IN MM.

A

B

C

D

I

6.3

4.0

1.5

5.5

II

7.5

4.0

1.5

7.5

III

8.0

4. 0

1.5

7.0

IV

7.3

4.0

1.5

6.7

V

8.3

4. 0

1.5

7.5

VI

8. 0

4.0

1.5

7.5 


\section{CHAPTER IV}

\section{FINDINGS}

1. Changes in Weight of Animals:

Weight loss in this experiment was noted from the record sheet following the sacrifice of the animals. The basis of this information was utilized to determine if this was a significant factor by subjecting the acquired data to statistical analysis. The data from Table II was analyzed by Fisher's analysis of variance. The sources of variation in the data were the weight changes in the six animals and the four weeks.

\section{ANIMAL WEIGHT}

SOURCES
D.F.

S.S.

V.E.

F RATIO

SIGNIF.

ANIMALS

5

$154.5 \quad 30.9$

2.55

N.S.

WEEKS

3

19.4

6.5

0.53

N.S.

ERRORS

15

$181.4 \quad 12.1$

The weight changes from week to week were divided by the original weight and multipled by 100 to produce the per centage weight changes. No significant difference was found between animals or between the weeks. The sum of squares for the weeks was, therefore, 
added to the sum of squares for the errors to produce a more accurate estimate of the population. .

SOURCES D.F. S.S. V.E. F. RATIO SIGNIF.

$\begin{array}{llllll}\text { ANIMALS } & 5 & 154.5 & .30 .9 & 2.77 & 5 \%\end{array}$

$\begin{array}{llll}\text { ERRORS } & 18 & 200.8 & 11.1\end{array}$

A significant difference between the animals was found at the $5 \%$ confidence limits. The data was then subjected to the Studentized range test.

$$
\mathrm{K}=\mathrm{k}^{*} \sqrt{\frac{\mathrm{Ve}}{\mathrm{N}_{\mathrm{m}}}}=4.49 \times 1.67=7.5
$$

It was found that a difference of 7.5 or above was significant.

The mean weight changes were then arranged in order of value.

$\begin{array}{cccccr}\text { V } & \text { I } & \text { II } & \text { IV } & \text { III } & \text { VI } \\ -3.1 & -1.68 & -0.75 & 0.48 & 0.75 & 5.0\end{array}$

It was found that there was a significant difference in the weight changes between -3.1 and 5.0 at the $5 \%$ level of probability. The difference in behavior of animal V and VI is significant.

2. Data Reduction:

The measurements were obtained as described in Chapter III, 
Materials and Methods. The measurements were entered on data sheets, samples of which are shown in Tables IV and V. The tables list the ten slides used and the four areas A, B, C and D from which the measurements were taken. The amount of bone deposited, the periodontal width, and the sum these two measurements were recorded for each area. There was no bone deposition in area $\mathrm{A}$ in any of the sections, therefore, only the width of the periodontal space was recorded. The mean, the standard deviation and the standard error were computed for each column of bone deposition, periodontal space, and their total Table VI.

The Fisher Analysis of Variance was used to analyze the data collected for the bone deposition of each animal. The analysis was done to check the validity of the method and the accuracy of the data. Several factors were considered in the design of the analysis. They were as follows: (1) the animals, (2) the areas, (3) the sections, and (4) the interaction between individual main effects.

The results of the analysis are shown in Table VII. The variance ratio or $\mathrm{F}$ value which exists between the animals was significant at the $0.1 \%$ level indicating a very highly significant difference between animals. The $F$ value for the variance between the sections was non- 


\begin{tabular}{|c|c|c|c|c|c|c|c|c|c|c|}
\hline \multirow[b]{2}{*}{ Sections } & \multicolumn{9}{|c|}{$\begin{array}{c}\text { TABLE IV } \\
\text { SAMPLE DATA SHEET } \\
\text { ANIMAL I } \\
\text { AREAS }\end{array}$} & \multirow[b]{2}{*}{3} \\
\hline & $\begin{array}{l}A \\
2\end{array}$ & 1 & $\begin{array}{l}\mathrm{B} \\
2\end{array}$ & 3 & 1 & $\begin{array}{l}\mathrm{C} \\
2\end{array}$ & 3 & 1 & $\begin{array}{l}\mathrm{D} \\
2\end{array}$ & \\
\hline 1 & 25 & 47 & 22 & 69 & 93 & 33 & 126 & 67 & 38 & 105 \\
\hline 2 & 24 & 45 & 21 & 66 & 89 & 40 & 129 & 70 & 39 & 109 \\
\hline 3 & 25 & 44 & 23 & 67 & 91 & 37 & 128 & 68 & 40 & 108 \\
\hline 4 & 25 & 44 & 22 & 66 & 90 & 39 & 129 & 64 & 43 & 107 \\
\hline 5 & 26 & 42 & 22 & 64 & 85 & 43 & 128 & 65 & 42 & 107 \\
\hline 6 & 25 & 46 & 23 & 69 & 89 & 39 & 128 & 65 & 40 & 105 \\
\hline 7 & 27 & 43 & 25 & 68 & 92 & 37 & 129 & 65 & 39 & 104 \\
\hline 8 & 25 & 40 & 24 & 64 & 91 & 41 & 132 & 66 & 40 & 106 \\
\hline 9 & 27 & 41 & 22 & 63 & 88 & 39 & 127 & 66 & 40 & 106 \\
\hline 10 & 27 & 43 & 24 & 67 & 88 & 40 & 122 & 65 & 43 & 108 \\
\hline $\bar{X}$ & 25.6 & 43.5 & 22.8 & 66.3 & 89.6 & 38.8 & 128.4 & 66.1 & 40.4 & 106.5 \\
\hline S.D. & 1.32 & 2.17 & 1.23 & 2.11 & 2.32 & 1.27 & 1.58 & 1.79 & 1.71 & 1.58 \\
\hline S.E. & $0.417^{\circ}$ & 0.686 & 0.388 & 0.667 & 0.734 & 0.277 & 0.496 & 0.566 & 0.124 & 0.50 \\
\hline
\end{tabular}




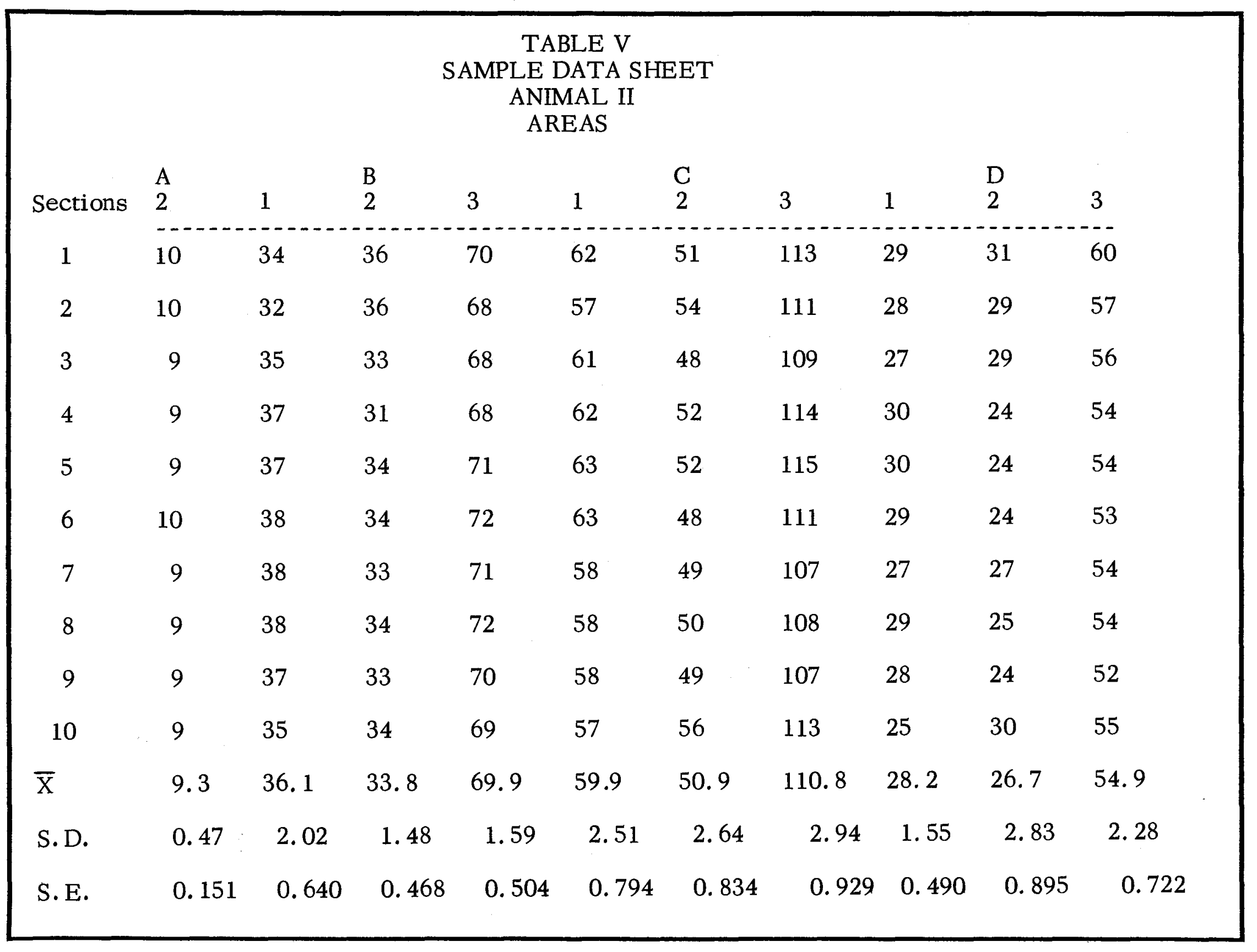


TABLE VI

DATA SHEET FOR ALL ANIMALS

\begin{tabular}{|c|c|c|c|c|c|c|c|c|c|c|}
\hline Areas & $\begin{array}{l}\mathrm{A} \\
2\end{array}$ & 1 & $\begin{array}{l}\text { B } \\
2\end{array}$ & 3 & 1 & $\begin{array}{l}\mathrm{C} \\
2\end{array}$ & 3 & 1 & $\begin{array}{l}\mathrm{D} \\
2\end{array}$ & 3 \\
\hline & & & & & & & & & & \\
\hline $\begin{array}{l}\bar{X} \\
\text { S.D. } \\
\text { S.E. }\end{array}$ & $\begin{array}{c}25.6 \\
1.32 \\
.417\end{array}$ & $\begin{array}{c}43.5 \\
2.17 \\
.686\end{array}$ & $\begin{array}{c}22.8 \\
1.23 \\
.388\end{array}$ & $\begin{array}{c}66.3 \\
2.11 \\
.667\end{array}$ & $\begin{array}{c}89.6 \\
2.32 \\
.734\end{array}$ & $\begin{array}{c}38.8 \\
1.27 \\
.277\end{array}$ & $\begin{array}{c}128.4 \\
1.58 \\
.496\end{array}$ & $\begin{array}{c}66.1 \\
1.79 \\
.566\end{array}$ & $\begin{array}{c}40.4 \\
1.71 \\
.124\end{array}$ & $\begin{array}{c}106.5 \\
1.58 \\
500\end{array}$ \\
\hline
\end{tabular}

Animal II

$\begin{array}{llccccccccc}\overline{\mathrm{X}} & 9.3 & 36.1 & 33.8 & 69.9 & 59.9 & 50.9 & 110.8 & 28.2 & 26.7 & 54.9 \\ \text { S.D. } & 0.48 & 2.02 & 1.48 & 1.59 & 2.51 & 2.64 & 2.93 & 1.55 & 2.83 & 2.28 \\ \text { S.E. } & .151 & .640 & .468 & .504 & .794 & .834 & .929 & .490 & .895 & .722\end{array}$

Animal III

$\begin{array}{lcccccccccc}\overline{\mathrm{X}} & 6.5 & 25.5 & 42.1 & 67.6 & 44.3 & 57.4 & 101.7 & 28.0 & 38.6 & 66.6 \\ \text { S.D. } & .527 & 1.71 & 2.64 & 2.88 & 2.45 & 3.29 & 1.49 & 1.41 & 2.98 & 2.17 \\ \text { S.E. } & .166 & .541 & .834 & .909 & .775 & 1.040 & .472 & .447 & .942 & .686\end{array}$

Animal IV

$\begin{array}{lllllllllll}\overline{\mathrm{X}} & 42.9 & 34.7 & 50.7 & 85.4 & 111.1 & 50.8 & 161.9 & 72.3 & 24.7 & 97.0\end{array}$
S.D.
2.77
$2.06 \quad 2.78$
2.37
2. 85
2.97
$1.73 \quad 1.89$
2.31
2. 0

S.E.

.875

$.650 \quad .879$

.748

$.900 \quad .939$

$.547 \quad .598$

.730

.632

Animal V
$\overline{\mathrm{X}}$
$11.2 \quad 28.7$
32.6
61.3
51.4
32.8
$84.2 \quad 37.3$
24.2
$1.69 \quad 1.06$
0.92
61.5
S. E.
.389
.496
$.202 \quad .472$
$.635 \quad .385$
$.533 \quad .334$
.290
1.35

Animal VI
$\overline{\mathrm{X}}$
25.6
0
$19.4 \quad 19.4 \quad 0$
23.7
$23.7 \quad 24.4$
1.16
$1.16 \quad 1.43$
15.3
39.7
$S . F$ 221 0 371 371

0 366 451 300 
TABLE VII

ANALYSIS OF VARIANCE

\section{SOURCE}

BETWEEN ANIMALS

BETWEEN SECTIONS

BETWEEN AREAS

ANIMALS X SECTIONS

AREAS X SECTIONS

AREAS x ANIMALS

RESIDUAL ERROR

TOTAL
S.S,

$83,102.16$

37.49

$29,432.04$

155. 12

68.67

$24,508.89$

302.62

$137,606.99$
D.F. 5

9

2

45

18

10

90

179
V.E.

F VALUE $1,662,043.20$

$494,655.71$

4. 165

1. 24

$14,716.02$

3.447

$4,379.77$

03

1. 13

729.43

$2,450.89$

3.36
$0.1 \%$

$0.1 \%$

\section{SIGNIFICANCE}

N.S.

N.S.

N.S.

$0.1 \%$ 
significant indicating no significant difference between sections. There .. was a very highly significant difference between the areas B, C, and D. The next considerations lie in the variation of the interaction between the individual main effects. The interaction animals $\mathrm{x}$ sections shows that there was no significant effect of either sections on animals or animals on sections. This was also true of the interaction between areas and sections wherein the $\mathrm{F}$ value was also non-significant. The interaction areas $\mathrm{x}$ animals, however, was very highly significant, therefore, the animals do have an effect on the area $99.9 \%$ of the time.

Since the animals represent various force magnitudes, it can be concluded that the forces had a significant effect on the amount of bone deposited.

The estimate of the experimental error or the residual error was 3.36 and the standard error of measurement was 1.83. The measurements were taken in $1 / 100 \mathrm{~mm}$., therefore the $99 \%$ confidence limits of the distribution of experimental errors was $\pm 0.047 \mathrm{~mm}$. The smallest readable increment on the scale of the measuring instrument was $1 / 100$ $\mathrm{mm}$. The standard error of measurement at the $99 \%$ confidence level of distribution was between four to five times the least count of the 
measuring instrument. This amount of experimental error was accepted as being reasonable for these conditions of measurements.

3. Variation Between Lead Lines:

The histologic examination of the sections revealed that the pattern of bone deposition was very irregular. It was difficult to find uniformity between the lead lines from area to area and section to section. An attempt was made to locate those areas which displayed some regularity and relate the variation of the lead lines to time.

An analysis of variance was used to compare the distance between the lead lines of the sections to the weeks the lead acetate injections were administered.

$\begin{array}{lccccc}\text { SOURCES } & \text { D.F. } & \text { S.S. } & \text { V.E. } & \text { F. RATIO } & \text { SIGNIF. } \\ \text { WEEKS } & 3 & 5.1 & 1.7 & 2.15 & \text { N.S. } \\ \text { SECTIONS } & 9 & 14.9 & 1.65 & 2.09 & \text { N.S. } \\ \text { ERROR } & 27 & 21.4 & 0.79 & & \\ \text { TOTAL } & 39 & 41.4 & & & \end{array}$

No significant difference was found between the weeks or between the sections at the $95 \%$ confidence limits. 
4. Correlation Between Force Magnitude and Bone Deposition:

The correlation coefficient was determined for the force magnitudes applied and the amount of bone deposited in each animal Table VII. The bone deposited in areas $\mathrm{B}$ and $\mathrm{C}$ were totaled for each animal. The bone deposition at areas $\mathrm{B}$ and $\mathrm{C}$ was used because the measurements in these areas were made at the same distance from the root apex in each animal. The bone deposition at area $\mathrm{D}$ was not used because the measurement was made at different distances from the root apex in each animal.

The values of $\mathrm{X}$ were composed of the force magnitudes of each animal. The amount of bone deposited at areas $\mathrm{B}$ and $\mathrm{C}$ for each animal constituted the values of $Y$. The correlation coefficient, $r$, was found to be -0.318 which is non-significant at the $95 \%$ confidence limits.

5. Analysis of the Tipping:

The determinations of the center of rotation and the degree of tipping were found by estimating a regression line from the data. A regression of $\mathrm{Y}$ on $\mathrm{X}$ was determined where $\mathrm{X}$ is the vertical distance of the measurements from the apex of the root and $\mathrm{Y}$ is the estimated tooth movement. The data from animal II will be used to describe the procedure used for animals II and III. 
TABLE VII I

CORRELATION DETERMI NATI ON

FORCE MAGNI TUDE X BONE DEPOSITION

\begin{tabular}{|c|c|c|c|c|c|}
\hline & $X$ & $\mathrm{Y}$ & $x^{2}$ & $\mathrm{Y}^{2}$ & $X Y$ \\
\hline 1 & 25 & 133.1 & 625 & $17,715.61$ & 3327.5 \\
\hline 2 & 50 & 96. & 2500 & $9,216.00$ & 4800.0 \\
\hline 3 & 75 & 69.8 & 5625 & $4,872.04$ & 5235.0 \\
\hline 4 & 100 & 145.8 & 10000 & $21,257.64$ & 14580.0 \\
\hline 5 & 150 & 80.1 & 22500 & $6,416.01$ & 12015.0 \\
\hline $\mathrm{X}$ & 400 & 524.8 & 41250 & $59,477.30$ & 39957.5 \\
\hline $\bar{X}$ & 80 & 104.96 & & & \\
\hline
\end{tabular}


The mean values of the total distances from the first lead lines to the tooth in each of three areas, $\mathrm{A}, \mathrm{B}$, and $\mathrm{C}$, were taken from the data sheet in Table V. The corresponding mean values of the widths of the periodontal ligament in the control animal were subtracted from the total distances to give the estimated tooth movement. These figures were plotted on the $\mathrm{Y}$ axis and are given in $1 / 100 \mathrm{~mm}$.

TOTAL DISTANCE

CONTROL PERIODONTAL WIDTH

LET $\mathrm{Y}=$

$$
\frac{\text { Area A }}{9.3} \quad \frac{\text { Area B }}{69.9} \quad \frac{\text { Area C }}{110.8}
$$

$\frac{-25.6}{-16.3} \quad \frac{-19.4}{50.5} \quad \frac{-23.7}{87.1}$

The vertical distances of each of the three measurements from the root apex are given in millimeters Table III. These values were transposed to let the measurement at the crest, A, equal zero and the subsequent values equal the distance from point $A$. The transposed measurements were plotted on the $\mathrm{X}$ axis.

DISTANCE FROM APEX

$$
\frac{\text { Area A }}{7.5} \quad \frac{\text { Area B }}{4.0} \quad \frac{\text { Area C }}{1.5}
$$

LET $X=$

$\begin{array}{lll}0 & 3.5 & 6.0\end{array}$

This data was then used to determine the slope of the regression line. The slope, or $b$, was found to equal 17.35. The values for the 
regression line may now be computed utilizing the regression equation, $Y-\bar{Y}=b(X-\bar{X})$. The regression line for the data was then found to be:

$$
Y=17.35 X-14.40
$$

The center of rotation is given by the intercept on the $\mathrm{X}$ axis.

$$
\begin{aligned}
& Y=0=17.35 X-14.40 \\
& X=0.83 \mathrm{~mm} .
\end{aligned}
$$

The center of rotation was $0.83 \mathrm{~mm}$. apically from the point on the labial alveolar crest where measurement A wastaken. The measurement of the labial alveolar crest in this case was taken $7.50 \mathrm{~mm}$. from the root apex. This means that the tooth tipped about an axis located within the root, $6.67 \mathrm{~mm}$. from the root apex.

The degree of tipping was found from the arc tangent of the slope divided by 100 .

$$
\begin{gathered}
\text { b } 17.35 \\
\text { arc } \tan =100=100 \\
\text { arc tan }=0.1735=9050^{\prime}
\end{gathered}
$$

The tooth tipped $9^{\circ} 50^{\prime}$ about an axis located $6.67 \mathrm{~mm}$. from the root apex.

The regression line was then calculated by substituting the values of $\mathrm{X}$ into the equation. 


$$
\begin{aligned}
& \text { When } X=0, Y=17.35(0)-14.40=-14.40 \\
& \text { When } X=3.5, Y=17.35(3.5)-14.40=46.33 \\
& \text { When } X=6.0, Y=17.35(6.0)-14.40=89.7
\end{aligned}
$$

These predicated values were then plotted on a graph, (Figure 16). The distance from measurement $A$, or point $A$, given in millimeters was plotted on the $\mathrm{X}$ axis. The bone deposition given in hundredths of a millimeter was plotted on the $\mathrm{Y}$ axis. The point on the graph where the regression line crosses the $X$ axis is the intercept or axis of rotation.

The regression line was then estimated for animal III which received a force magnitude of $75 \mathrm{gms}$. The slope of the regression line was found to be 14.77 and the axis of tipping was located within the root $6.92 \mathrm{~mm}$. from the root apex. The tooth was tipped $8^{\circ} 24^{\prime}$. The computed regression line is shown in Figure 17.

The determination of the center of rotation and degree of tipping for animals I, IV, and V were found by using two points of reference. The bone deposition at areas $\mathrm{B}$ and $\mathrm{C}$ were used. Area A was not considered in the computations because there was bone resorption in this area making estimations of the distances moved questionable. Area 


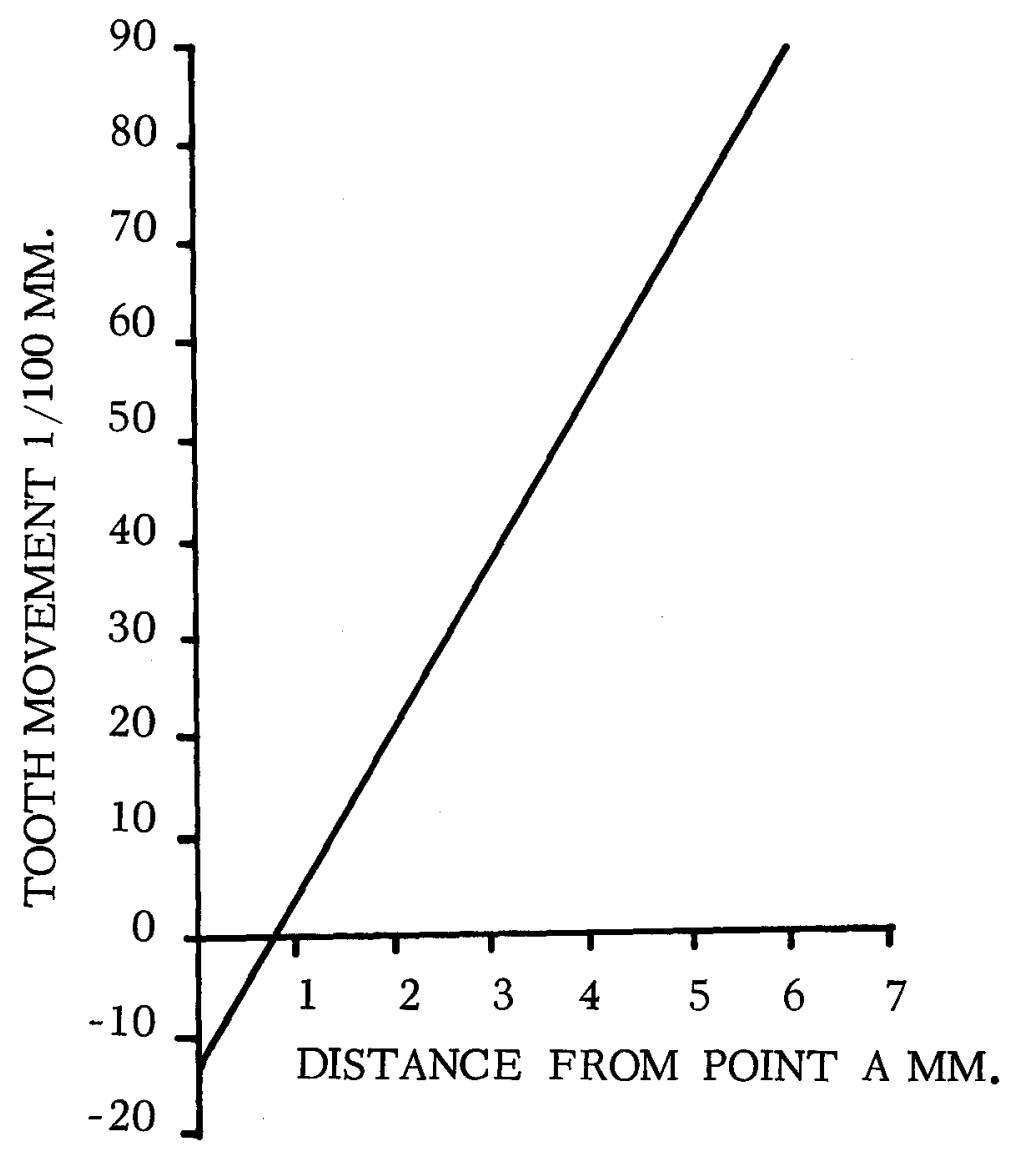

FIGURE 16

INTERCEPT LINE FOR ANIMAL II 


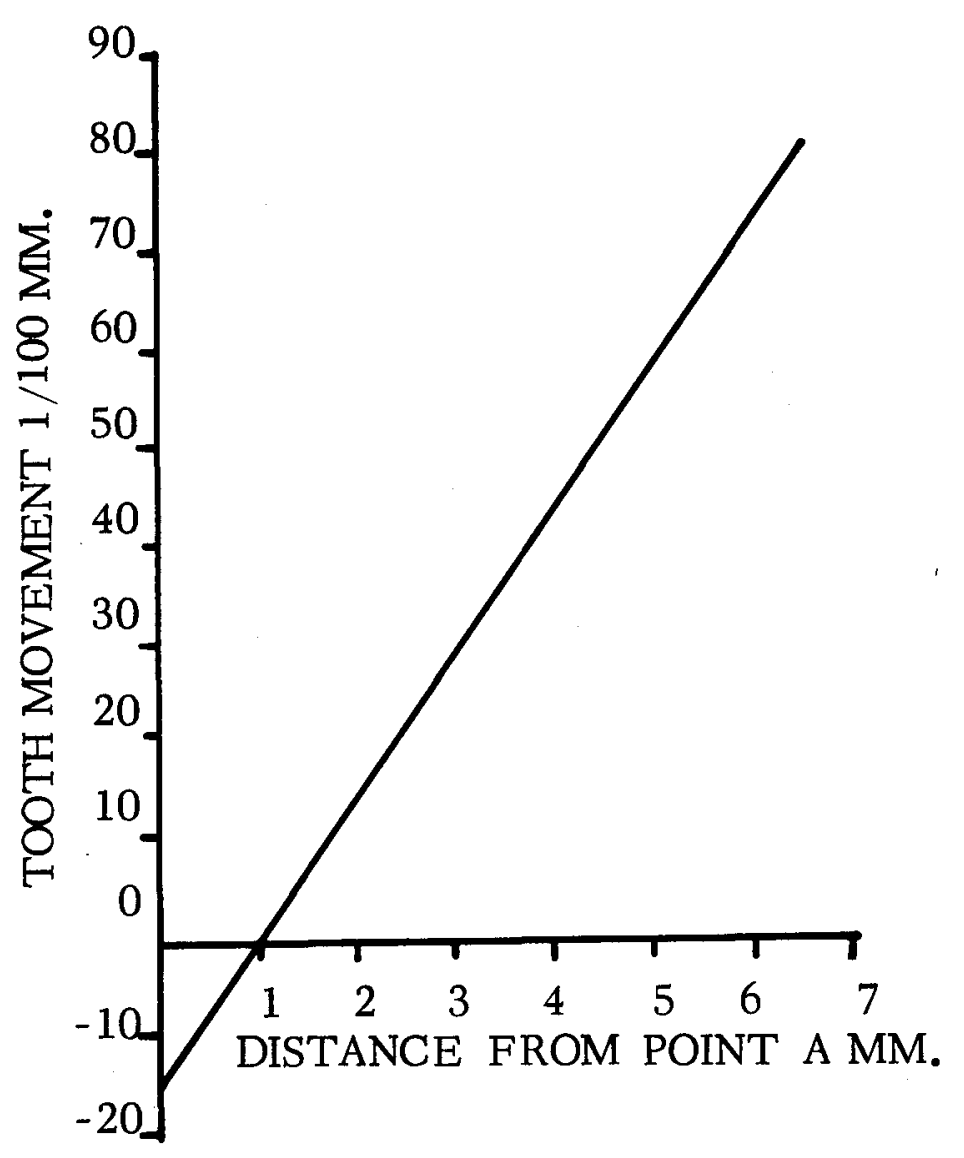

FIGURE 17

INTERCEPT LINE FOR ANIMAL III 
$\mathrm{D}$ also was not used because of the possibility of extrusion and tipping influencing the bone deposition there.

The mean values of the total distances from the first lead lines to the tooth in each of the two areas $B$ and $C$ were taken from the data sheet for animal I in Table IV. The mean values of the periodontal width of the control animal VI were then subtracted from the total distances to give the estimated amount of tooth movement. These figures were plotted on the $\mathrm{Y}$ axis and are given in $1 / 100 \mathrm{~mm}$.

\section{ANIMAL I}

TOTAL DISTANCE

CONTROL PERIODONTAL WIDTH

$\mathrm{Y}=$

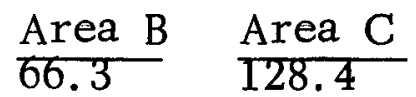

$\underline{-19.4} \underline{-23.7}$

46.9

104.7

The distance of measurements $\mathrm{B}$ and $\mathrm{C}$ from area $\mathrm{A}$ were used in these cases Table III . This was done for uniformity in plotting the graphs. These values were transposed to let the distance of area A from the apex equal zero and the subsequent values equal the distance from point $A$. The transposed measurements were plotted on the $\mathrm{X}$ axis.

DISTANCE FROM APEX

$$
\frac{\text { Area A }}{6.3}
$$

$\frac{\text { Area B }}{4.0}$

$\frac{\text { Area } \mathrm{C}}{1.5}$

LET $X=$

0

2.3

4.8 
This data was then used to determine the slope of the line.

$$
b=\frac{104.7-46.9}{4.8-2.3}=23.12
$$

The values for the line may now be computed utilizing the equation:

$$
\begin{aligned}
& Y-\bar{Y}=b(X-\bar{X}) \\
& Y=23.12 X-6.276
\end{aligned}
$$

The center of rotation is given by the intercept on the $\mathrm{X}$ axis.

$$
\begin{aligned}
& \mathrm{Y}=0=23.12 \mathrm{X}-6.276 \\
& \mathrm{X}=0.27145 \mathrm{~mm} .
\end{aligned}
$$

The center of rotation was $0.27 \mathrm{~mm}$. from area A for animal I. The distance of area A from the root apex in this case was $6.30 \mathrm{~mm}$. The tooth then tipped about an axis located within the root, $6.03 \mathrm{~mm}$. from the root apex.

The degree of tipping was found from the arc tangent of the slope divided by 100 .

$$
\begin{aligned}
& \arctan =\frac{\mathrm{b}}{100}=\frac{23.12}{100} \\
& \text { arc } \tan =0.2312=13^{\circ} 22^{\prime}
\end{aligned}
$$

The values derived from the calculations were plotted on a graph Figure 18. The bone deposition at areas $\mathrm{B}$ and $\mathrm{C}$ was plotted on the $\mathrm{Y}$ 


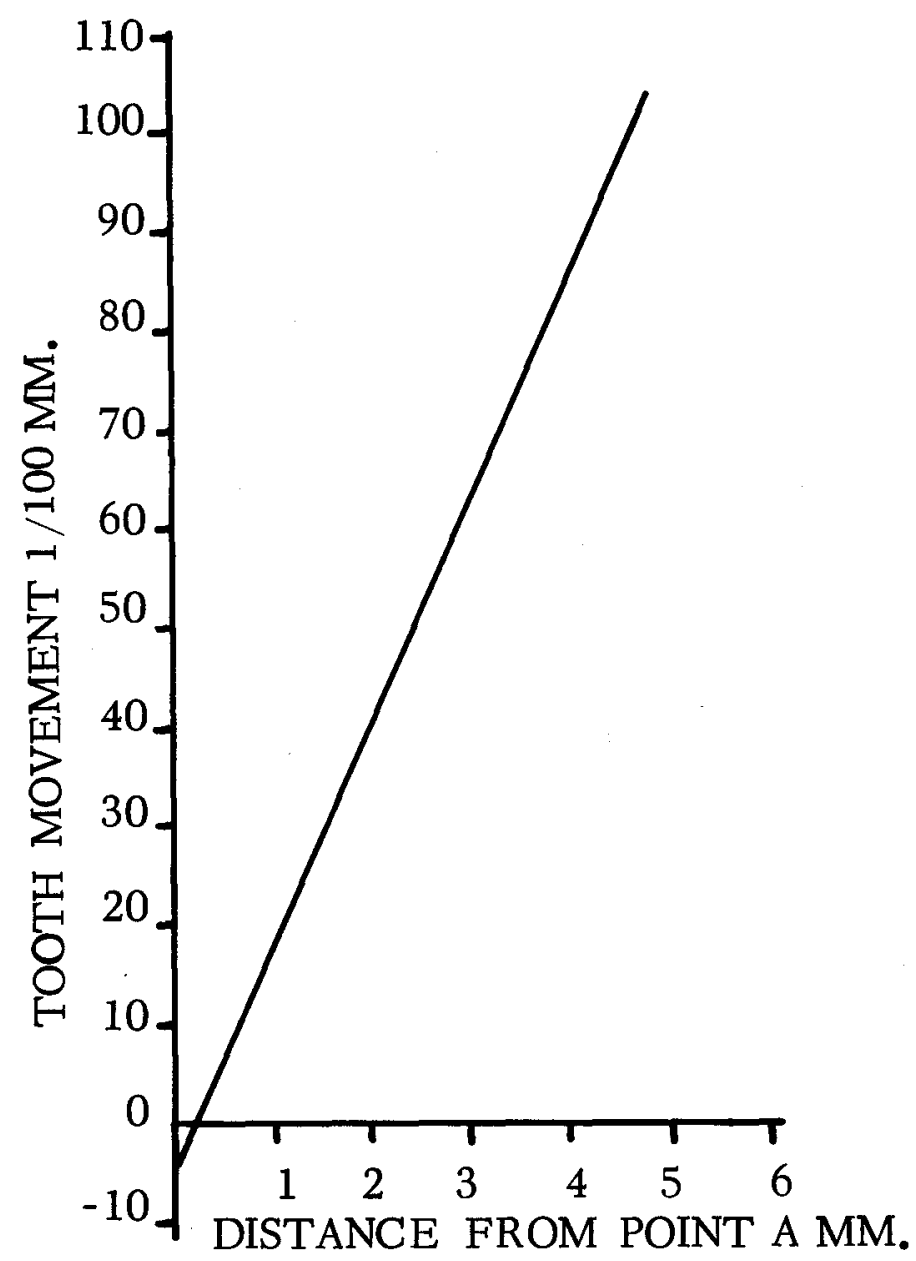

FIGURE 18

INTERCEPT LINE FOR ANIMAL I 
axis. The $X$ axis was used to plot the distance of the measurements $B$ and $\mathrm{C}$ from area $\mathrm{A}$ which was $6.3 \mathrm{~mm}$. from the root apex. The intercept of the line on the $\mathrm{X}$ axis represents the center of rotation of the tooth.

The foregoing procedure was also used for animal IV. The force magnitude used on this animal was 100 gms. The slope of the line was 28. 88. The center of rotation is given by the intercept on the $X$ axis.

$$
\begin{aligned}
& Y=0=28.88 X-29.30 \\
& X=1.01
\end{aligned}
$$

The center of rotation was $1.01 \mathrm{~mm}$. from area A or $6.29 \mathrm{~mm}$. from the root apex. The tooth tipped $16^{\circ} 7^{\prime}$. The line is shown in Figure 19 . The line was then computed for animal $\mathrm{V}$ which received the greatest force magnitude, $150 \mathrm{gms}$. The slope of the line was found to be 7.44. The center of rotation was found to be $6.97 \mathrm{~mm}$. from the root apex. The tooth tipped $4^{\circ} 15^{\prime}$. The line is shown in Figure 20. The results of the five regression lines are tabulated in Table IX. The degrees of tipping, the center of rotation and the regression equation are recorded for each animal except the control animal. A regression line was not computed for the control animal because the tooth did not 


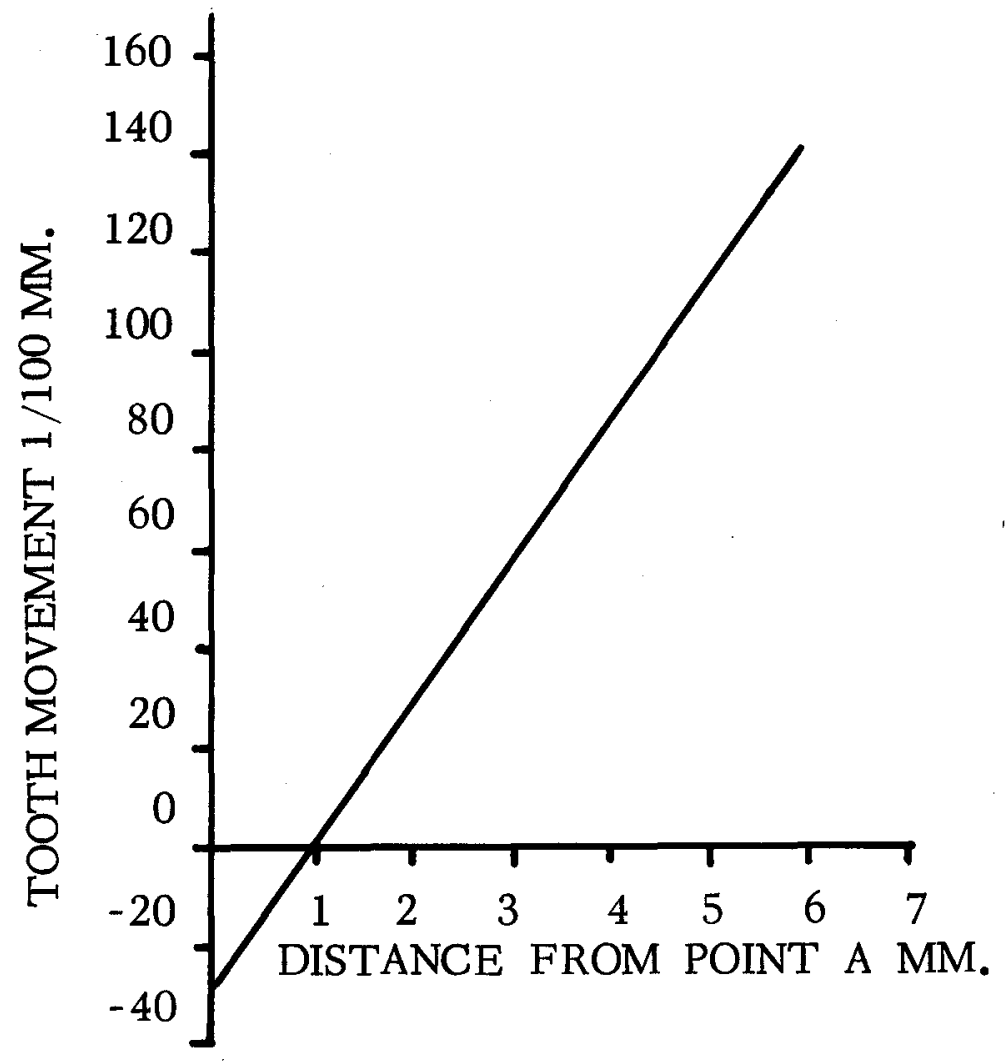

FIGURE 19

INTERCEPT LINE FOR ANIMAL IV 


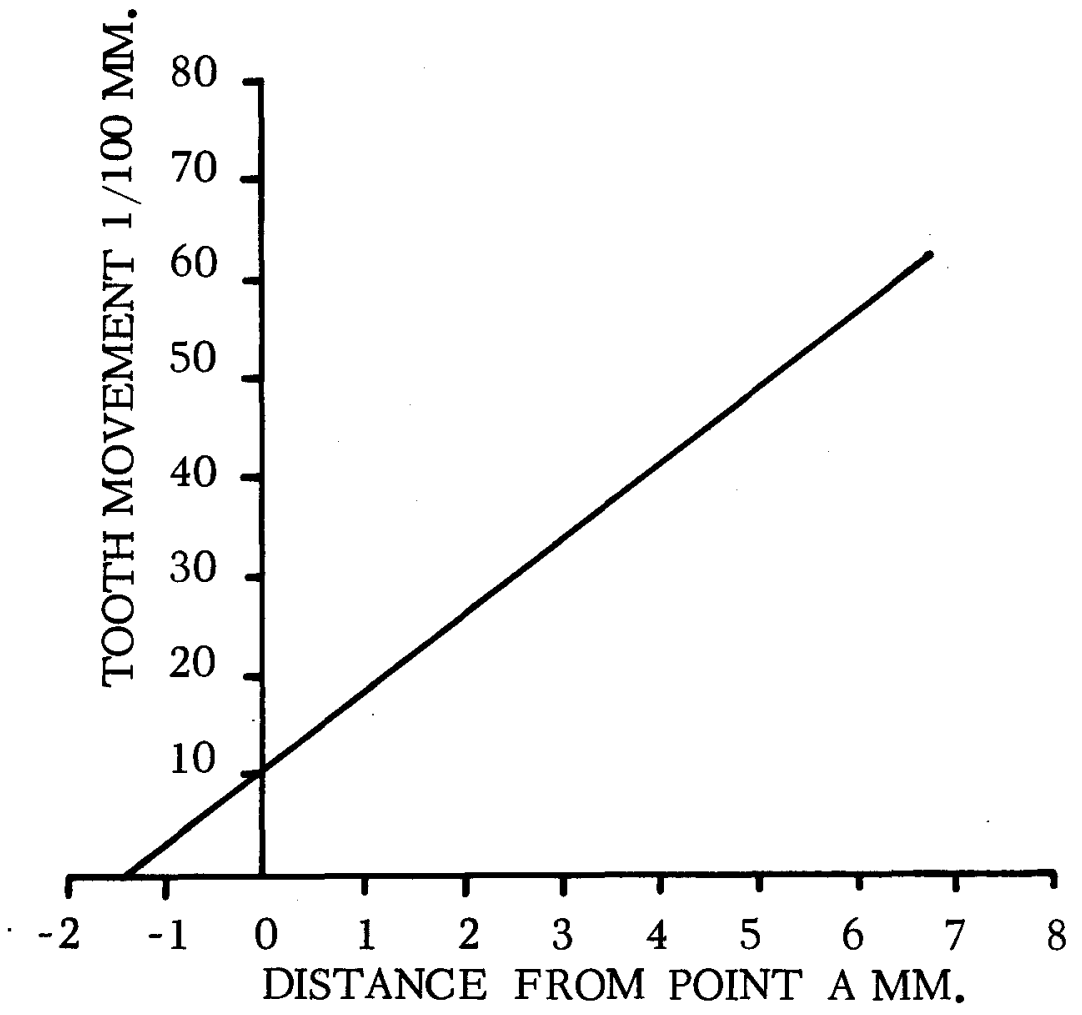

FIGURE 20

INTERCEPT LINE FOR ANIMAL V 
TABLE IX

CENTER AND DEGREE OF TIPPING

\begin{tabular}{lllll} 
Animal & $\begin{array}{l}\text { Force } \\
\text { Gms. }\end{array}$ & $\begin{array}{l}\text { Degree of } \\
\text { Tipping }\end{array}$ & $\begin{array}{l}\text { Center of Rotation } \\
\text { From Root Apex }\end{array}$ & $\begin{array}{l}\text { Regression } \\
\text { Equation }\end{array}$ \\
\hdashline I & 25 & $13^{\circ} 22^{\prime}$ & $6.03 \mathrm{~mm}$. & $\mathrm{Y}=23.12 \mathrm{X}-6.276$ \\
II & 50 & $9^{\circ} 50^{\prime}$ & $6.67 \mathrm{~mm}$. & $\mathrm{Y}=17.35 \mathrm{X}-14.40$ \\
III & 75 & $8^{\circ} 24^{\prime}$ & $6.92 \mathrm{~mm}$. & $\mathrm{Y}=14.77 \mathrm{X}-16.0$ \\
IV & 100 & $16^{\circ} 7^{\prime}$ & $6.29 \mathrm{~mm}$. & $\mathrm{Y}=28.88 \mathrm{X}-29.304$ \\
V & 150 & $4^{\circ} 15^{\prime}$ & $9.63 \mathrm{~mm}$. & $\mathrm{Y}=7.44 \mathrm{X}+9.908$
\end{tabular}


tip and consequently, there was no bone deposition along the labial surface of the toot.

6. Correlation of Force Mangitude and Degrees Tipped:

An attempt was made to find a negative correlation between the force magnitudes and the corresponding degrees of tipping. The correlation coefficient was determined from the findings computed for the regression lines of each animal. The force magnitudes constituted the values of $\mathrm{X}$ and the corresponding degrees of tipping constituted the values of $Y$. The degrees and minutes of tipping were converted to minutes to obtain whole number values for $\mathrm{Y}$. The correlation coefficient was found to be -0.08 . The significance of $r$ was then estimated in terms of $t$.

$$
t=\sqrt{\frac{r^{2}-r^{2}}{I-2)}}
$$

The value of $t$ was found to be 0.14 which was not significant. The degree of tipping which occurred in animal IV, however, appeared unusually large. It was noted from the histologic examination that the spicule of bone at the labial alveolar crest, which was present in the other experimental animals, had been removed by undermining resorption. The fulcrum effect of the spicule of bone was then lost 
allowing the tooth to advance labially into the area where the undermining resorption had occurred.

A second correlation coefficient was determined on the basis of the histologic findings. The determination was made in the same manner as described except that the force magntidue and corresponding degree of tipping for animal IV were omitted Table X. The correlation coefficient was found to be -0.974 . The significance of $r$ was then estimated in terms of $t$. The value of $t$ was found to be 6.08 which is significant at the $95 \%$ confidence limits. A negative correlation has thus been established between the force magnitude applied in tipping and the degrees of tipping obtained.

7. Correlation of Force Magnitude with Axis of Tipping:

An attempt was made to find a positive correlation between the force magnitude applied and locations of the corresponding axes of rotation. The correlation coefficient was determined from the findings computed for the regression lines. The values for all experimental animals except animal IV were used. Animal IV was omitted for the same reasons given in the correlation determination of force magnitude and degrees of tipping. 
TABLE X

FORCE MAGNI TUDE X DEGREE TIPPED CORRELATION DETERMINATION

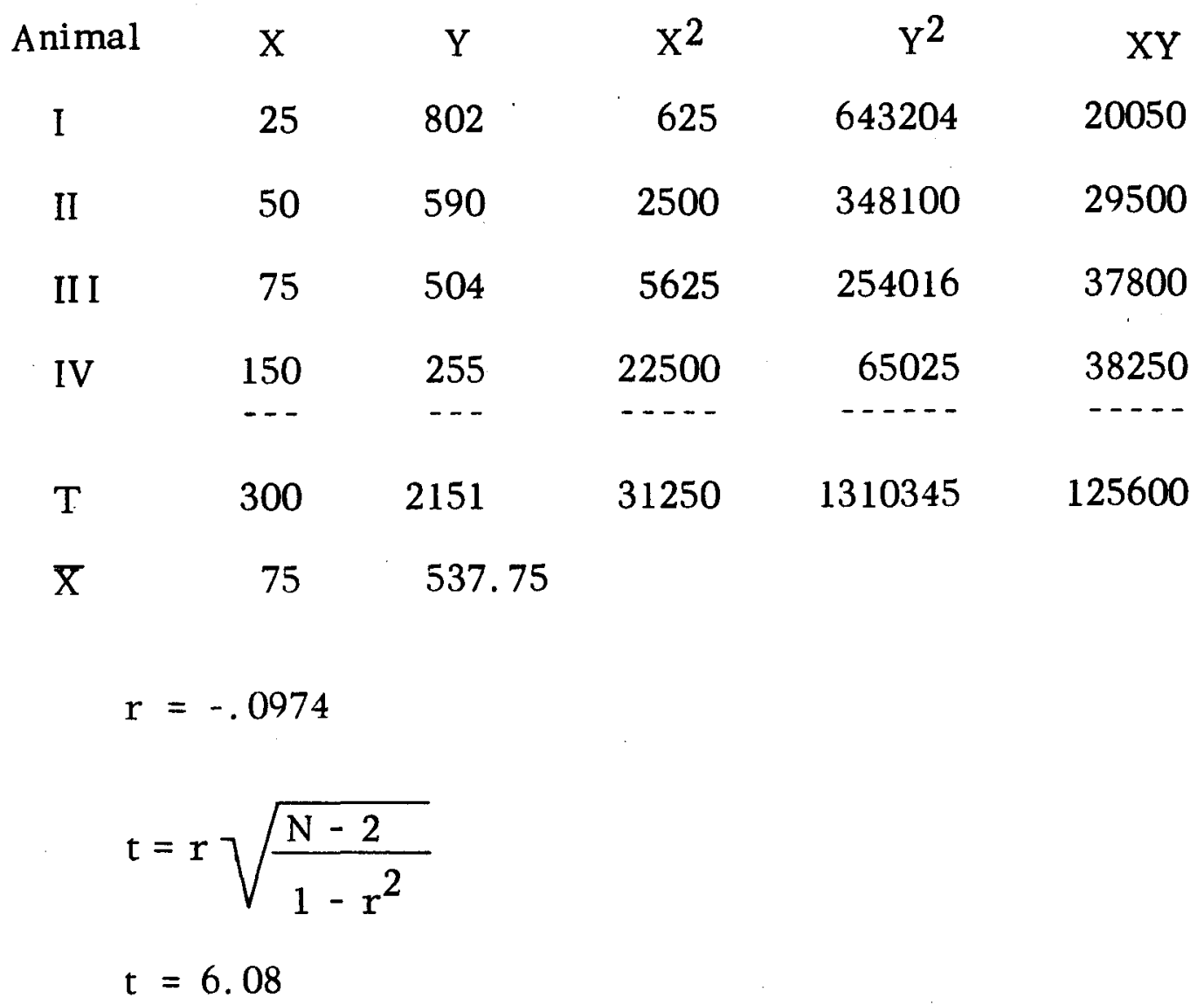

Significant at $95 \%$ confidence limits for two degrees of freedom. 
The force magnitudes constituted the values of $\mathrm{X}$. The corresponding distances of the axes of rotation measured from the root apices of the experimental animals constituted the values of $\mathrm{Y}$ (Table XI). The distances of the axes of rotation were converted to hundredths of a millimeter to obtain whole number values for $\mathrm{Y}$. The correlation coefficient was 0.986 . The significance of $r$ was then estimated in terms of $\mathrm{t}$. The $\mathrm{t}$ value was found to be 8.39 which is significant at the 95 per cent confidence limits for two degrees of freedom.

8. General Histologic Examination:

The histologic examination of the teeth of the five experimental animals showed a generalized pattern of resorption and deposition. There was a resorption and deposition of bone on the alveolar crest at the labial surface. Deposition of bone occurred on the labial aspect of the labial surface of the bone. There was resorption of the alveolar bone proper near the alveolar crest but the remaining alveolar bone generally showed deposition on the labial surface. The lingual surface of the alveolar bone proper toward which the root moved showed resorption. There was bone deposition along the lingual crest of the alveolar bone proper. 
TABLE XI

CORRELATION DETERMINATION

FORCE MAGNITUDE X AXIS OF TIPPING

\begin{tabular}{|c|c|c|c|c|c|}
\hline & $X$ & $\mathrm{Y}$ & $x^{2}$ & $\mathrm{Y}^{2}$ & $X Y$ \\
\hline I & 25 & 603 & 625 & 363609 & 15075 \\
\hline II & 50 & 667 & 2500 & 444889 & 33350 \\
\hline III & 75 & 692 & 5625 & 478864 & 51900 \\
\hline V & 150 & 963 & 22500 & 927369 & 144450 \\
\hline $\mathrm{T}$ & 500 & 2925 & 31250 & 2214731 & 244775 \\
\hline$\overline{\mathrm{X}}$ & 75 & & & & \\
\hline
\end{tabular}

Significant at $95 \%$ confidence limits for two degrees of freedom. 
Animal I

The newly deposited bone at the labial alveolar crest was stained a brown color. The alveolar crest on the labial was totally resorbed and it was replaced by new bone Figure 21. The tendonous portion of the muscle in this area was partially lost. The muscle was undergoing atrophy and was being replaced by fibrous connective tissue. The only remaining muscle attachment was in the old bone below the crest.

Howship's lacunae were present on the labial alveolar bone proper near the cervical portion of the root. The bone there was undergoing direct bone resorption. Bone deposition was seen immediately apical to the area of resorption. The deposition continued to the apical region of the alveolus. The new bone was easily distinguished from the old bone by the lead line and also by the difference in the color between the new bone and the old bone. The bone was deposited in a wedge-shaped manner increasing in thickness as the apex was approached. The bone deposition was very irregular and appeared to be osteophytic. This was noted in the projections of osteophytic bone into the periodontal space Figure 22. The lead lines were faint, irregular, and unevenly spaced. There was bone deposition at the fundus of the alveolar bone 


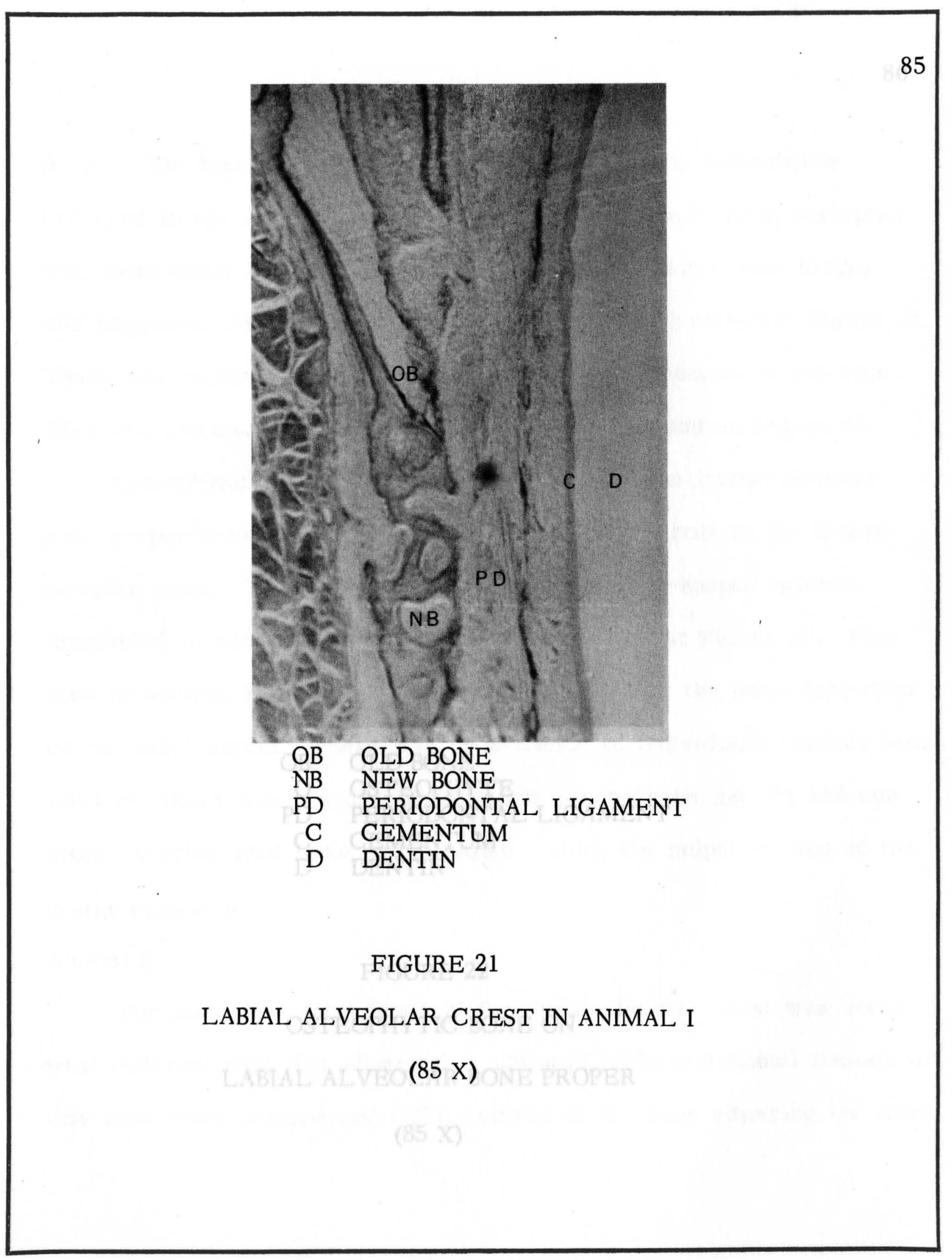




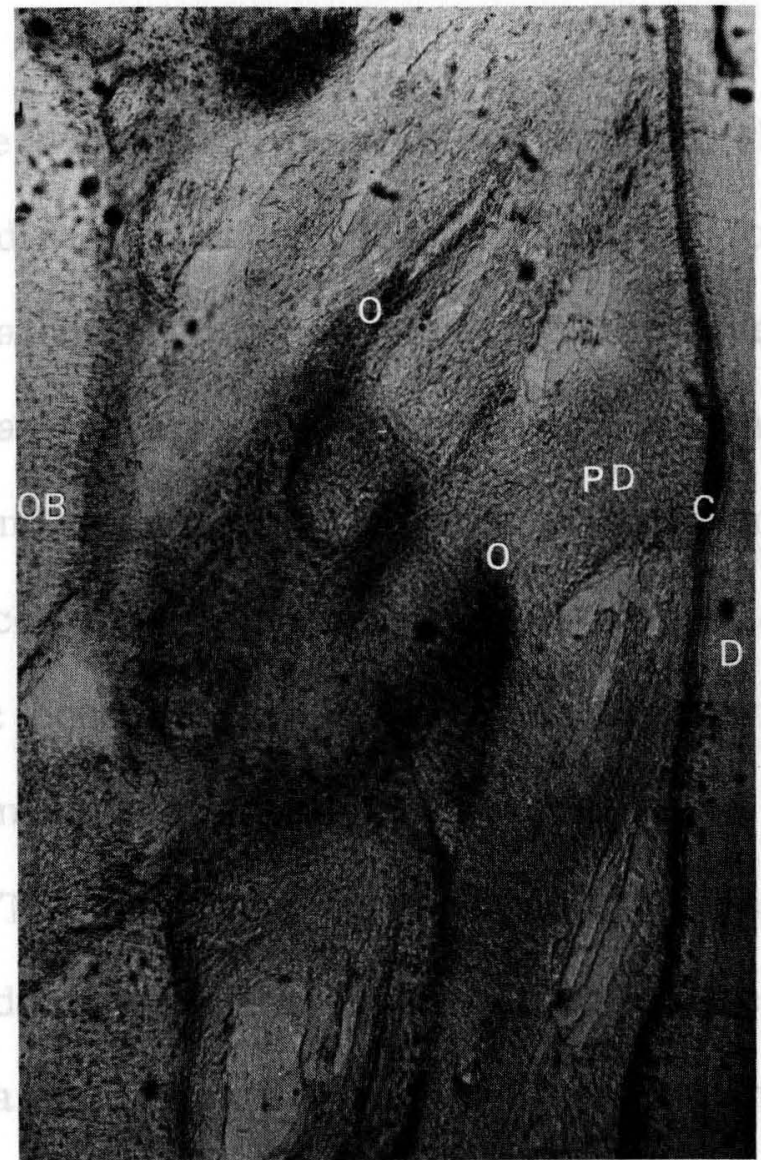

\section{OB OLD BONE \\ O OSTEOPHYTE \\ PD PERIODONTAL LIGAMENT \\ C CEMENTUM \\ D DENTIN}

FIGURE 22

OSTEOPHYTIC BONE ON

LABIAL ALVEOLAR BONE PROPER

(85 X) 
proper. The bone deposition was osteophytic with the osteophytes arranged in the direction of the long axis of the tooth. Bone resorption had taken place along the lingual aspect of the alveolar bone proper and suggested that the apex was moving in a lingual direction Figure 23 . There was evidence of slight resorption of the cementum of the root. This was evidenced by the presence of Howship's lacunae Figure 24 . Osteophytic bone deposition occurred along the lingual alveolar bone proper from approximately the middle of the root to the lingual alveolar crest. The bone was deposited in a wedge-shaped manner, increasing in width toward the lingual alveolar crest Figure 25. This bone deposition appeared more heavily stained than the bone deposition on the labial aspect. There was no evidence of individually distinct lead lines but there was a sharp demarcation line between the old and new bone. Regular lead lines were present along the pulpal surface of the dentin Figure 26.

Animal II

The histologic appearance of the labial alveolar crest was somewhat different than that observed in animal I. The periodontal tissues in this area were compressed. The surface of the bone adjoining the tooth 


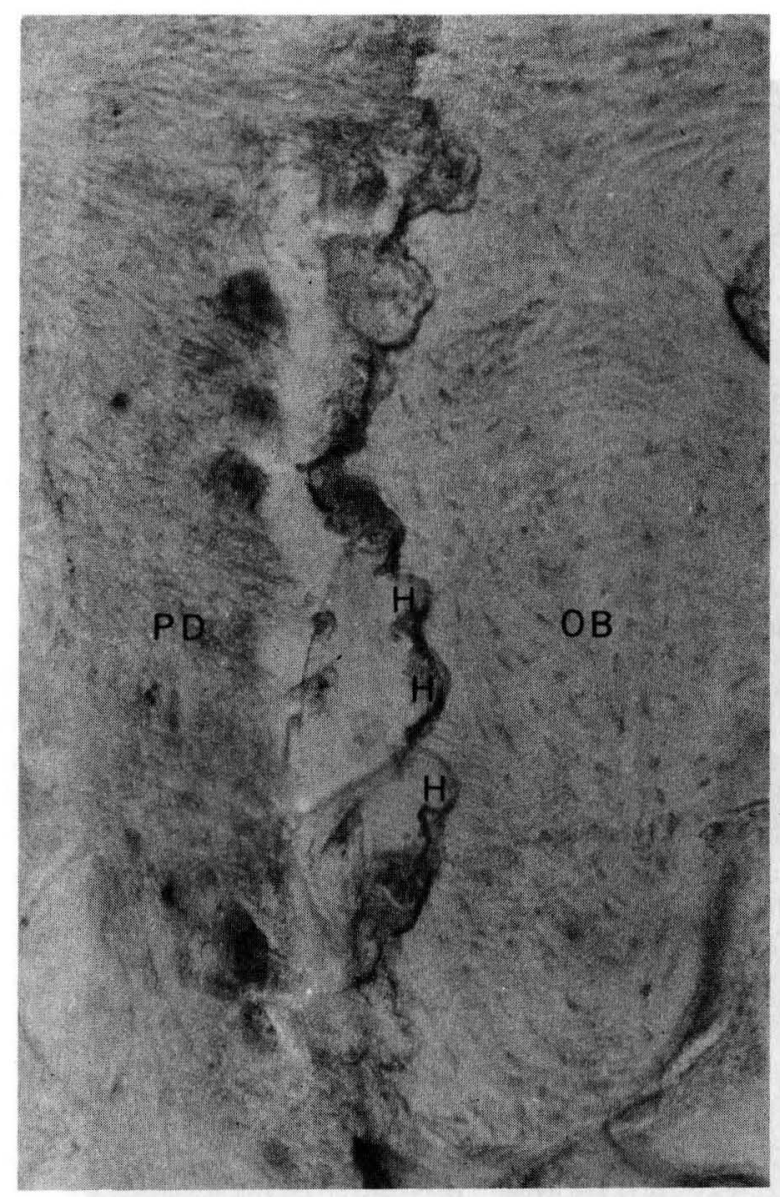

PD PERIODONTAL LIGAMENT

$H$ HOWSHIP'S LACUNAE

OB OLD BONE

FIGURE 23

HOWSHIP'S LACUNAE IN

LINGUAL ALVEOLAR BONE PROPER

(210 X) 


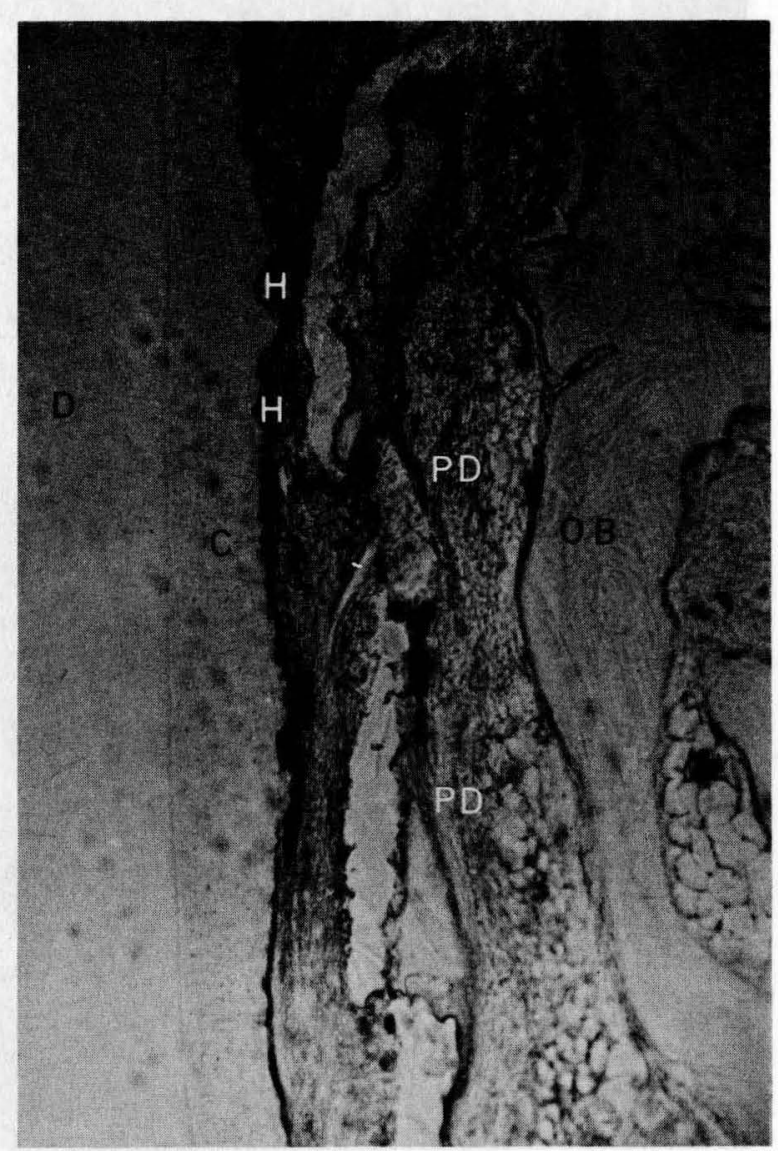

D DENTIN

C CEMENTUM

$\mathrm{H}$ HOWSHIP'S LACUNAE

PD PERIODONTAL LIGAMENT OB OLD BONE

FIGURE 24

HOWSHIP'S LACUNAE IN

CEMENTUM OF ROOT NEAR APEX

(210 X) 


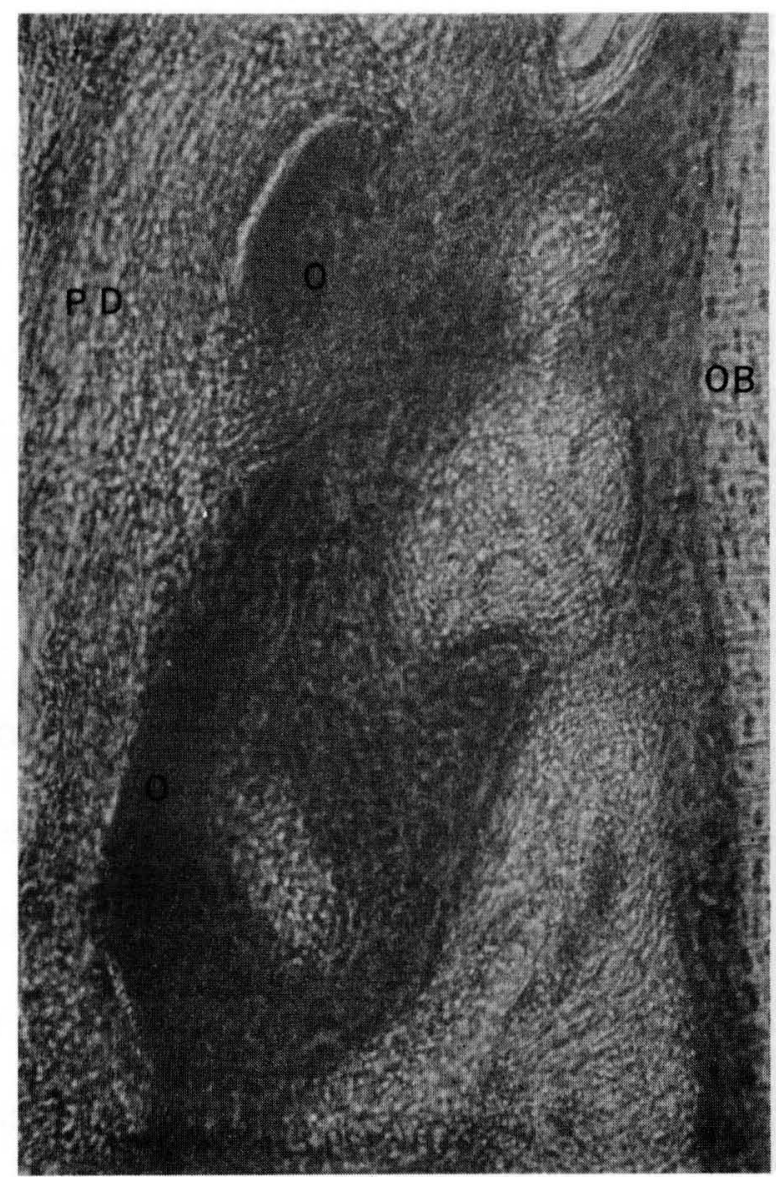

PD PERIODONTAL LIGAMENT

O OSTEOPHYTIC BONE

OB OLD BONE

FIGURE 25

OSTEOPHYTIC BONE ON

LINGUAL CREST OF ALVEOLAR BONE PROPER

$(210 \mathrm{X})$ 


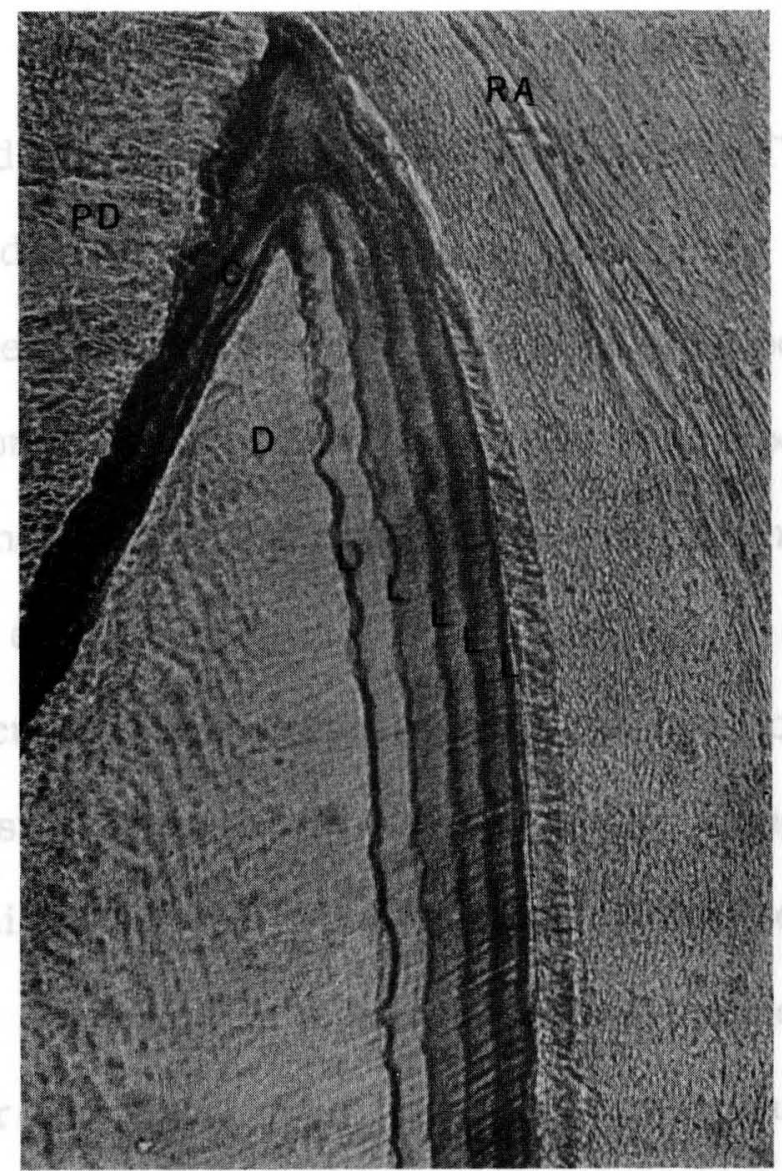

$\begin{aligned} \text { PD } & \text { PERIODONTAL LIGAMENT } \\ \text { C } & \text { CEMENTUM } \\ \text { D } & \text { DENTIN } \\ \text { L } & \text { LEAD LINES } \\ \text { RA } & \text { OPEN ROOT APEX }\end{aligned}$

FIGURE 26

LEAD LINES IN DENTIN NEAR APEX

(210 X) 
at the crest showed no evidence of bone resorption. There was bone resorption in the adjacent marrow spaces. Howship's lacunae were seen above and below the alveolar crest as the bone was being removed by undermining resorption Figure 27. There was also root resorption limited only to cementum in the area of the root immediately above the labial alveolar crest.

Howship's lacuane were present along the old bone below the labial alveolar crest. There was bone deposition along the alveolar bone proper from the middle of the labial surface of the root to the apex. The bone had been deposited in a wedge-shaped manner with the widest portion near the apex. The bone deposition was osteophytic but the lead lines were more regular than those in animal I.

There was some bone deposition at the fundus but it appeared to be much less than in animal I indicating this tooth had not been extruded as the tooth in animal $\mathrm{I}$. There was resorption of the bone adjoining the lingual aspect of the apex. There was slight root resorption which was limited to the cementum. The periodontal ligament along the apical two-thirds of the root on the lingual aspect was compressed. Numerous bays of resorption were found in the bone in this area. There was a 

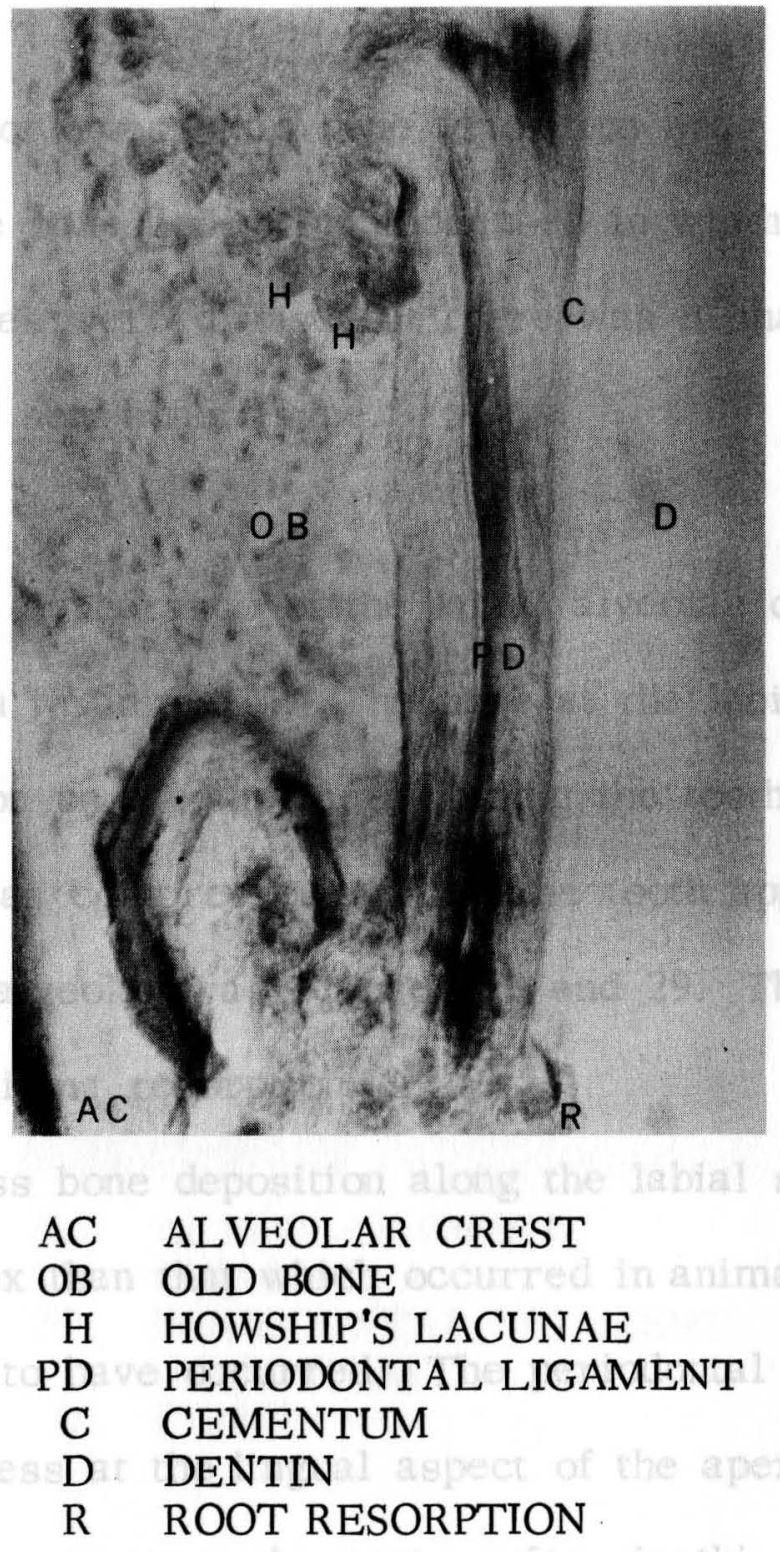

FIGURE 27

LABIAL ALVEOLAR CREST IN ANIMAL II

$(210 \mathrm{X})$ 
wedge-shaped area of osteophytic bone deposition near the lingual alveolar crest. The bone deposition increased in width near the alveolar crest. The lead lines were diffuse but there was a sharp demarcation between the old and new bone tissue.

Animal III

The histologic appearance of the labial alveolar crest was very similar to that seen in animal II. The bone at the labial alveolar crest showed no resorption on the surface adjoining the tooth. At this point the periodontal space was compressed so that the tooth appeared to be nearly in contact with the alveolar wall Figures .28 and 29 . The bone was being removed by undermining resorption.

There was less bone deposition along the labial surface of the root approaching the apex than that which occurred in animals I and II. No extrusion appeared to have occurred. The periodontal ligament was decreased in thickness at the lingual aspect of the apex. Numerous bays of resorption were present on the root surface in this area Figure 30. The alveolar bone was undergoing resorption at the lingual aspect of the alveolar bone proper. Undermining resorption was occurring in this area. There was a wedge-shaped area of darkly stained osteophytic bone 


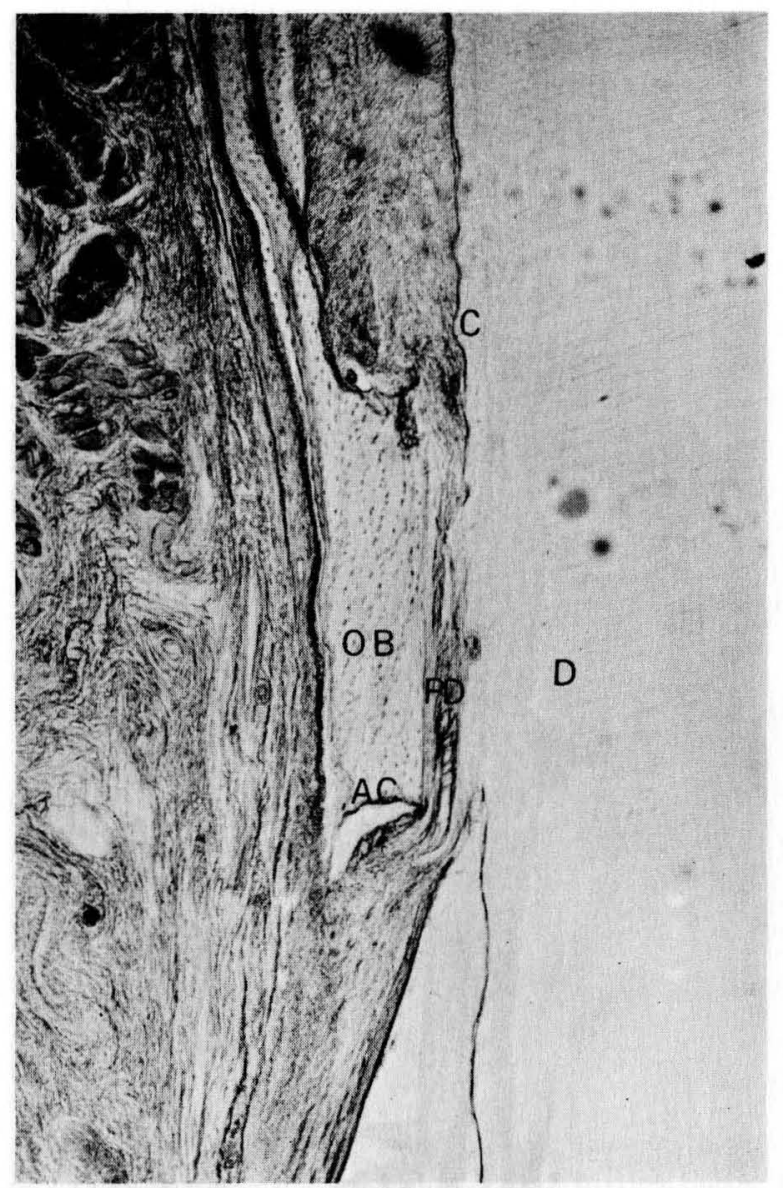

\section{AC ALVEOLAR CREST \\ OB OLD BONE \\ PD PERIODONTAL LIGAMENT \\ C CEMENTUM \\ D DENTIN}

FIGURE 28

LABIAL ALVEOLAR CREST IN ANIMAL III

(85 X) 


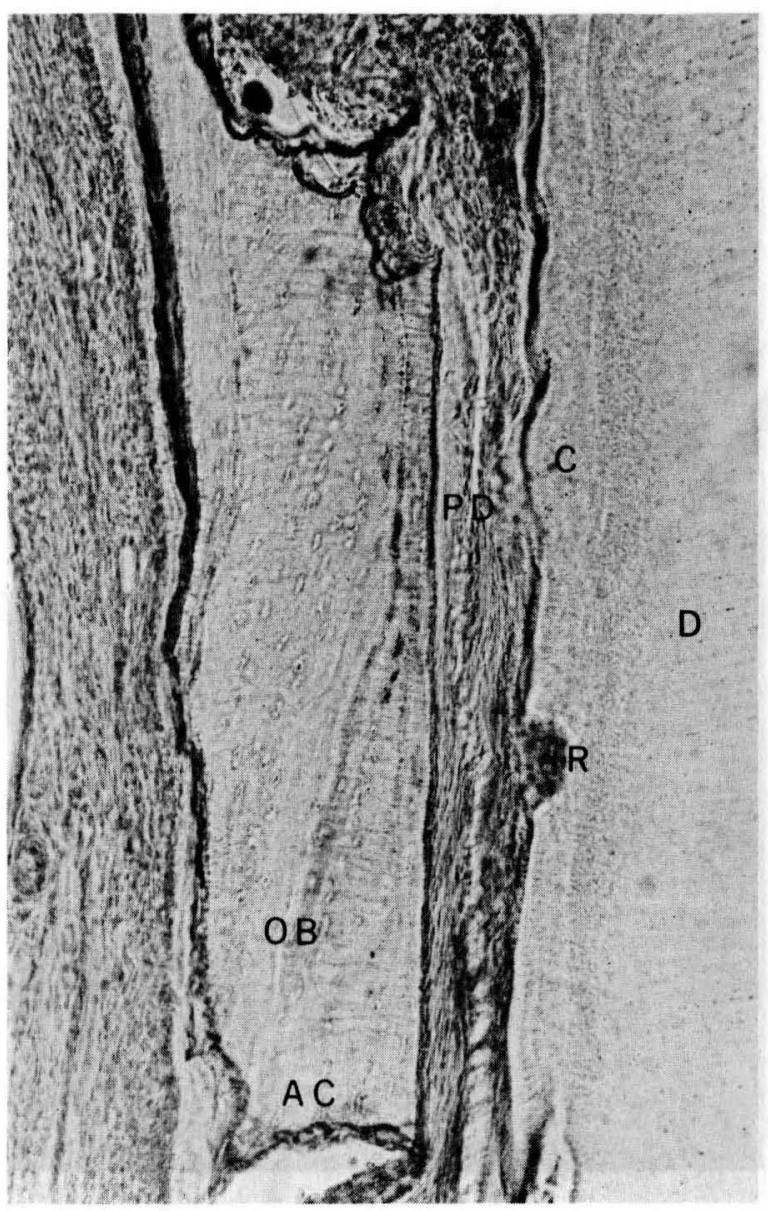

$\begin{aligned} \text { AC } & \text { ALVEOLAR CREST } \\ \text { OB } & \text { OLD BONE } \\ \text { PD } & \text { PERIODONTAL LIGAMENT } \\ \text { C } & \text { CEMENTUM } \\ \text { R } & \text { ROOT RESORPTION } \\ \text { D } & \text { DENTIN }\end{aligned}$

FIGURE 29

ENLARGED VIEW OF LABIAL ALVEOLAR CREST IN ANIMAL III (210 X) 


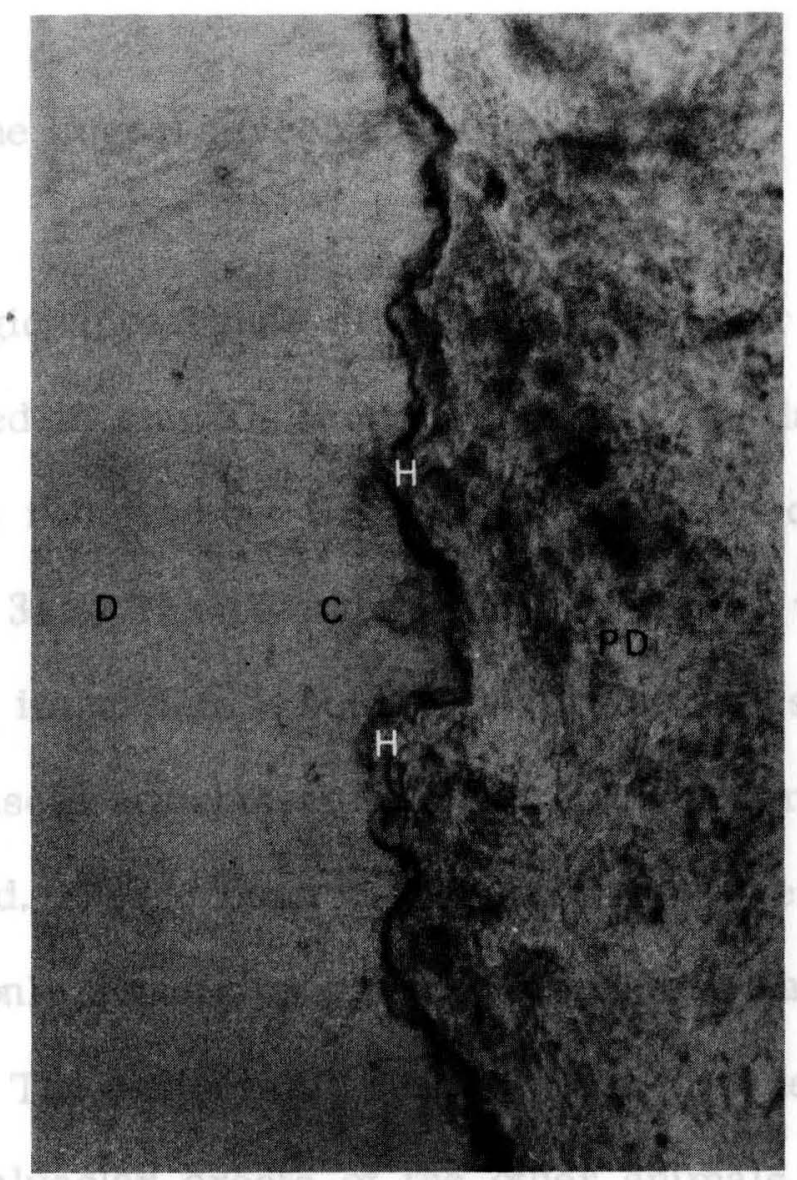

D DENTIN

C CEMENTUM

$\mathrm{H}$ HOWSHIP'S LACUNAE

PD PERIODONTAL LIGAMENT

FIGURE 30

HOWSHIP'S LACUNAE IN CEMENTUM OF ROOT

$(210 \mathrm{X})$ 
deposition near the lingual alveolar crest. Animal IV

The histologic appearance of the labial alveolar crest was different from that observed in animals II and III but was similar to that of anima I. The crest was removed but there still was evidence of undermining resorption Figure 31. The remaining bone observed was that portion of the alveolar bone immediately below the alveolar crest. The tendonous portion of the muscle attachment was lost in those areas where the bone was removed. These portions of the muscle were undergoing atrophy and the only remaining muscle attachment was in the old bone below the crest. The periodontal space appeared wider than those examined at the alveolar crests of the other animals.

The new bone deposition along the labial surface of the root was osteophytic. The osteophytes were occasionally mushroom shaped Figure 32. The lead lines were faint and irregular. No bone deposition took place at the fundus, therefore, it appeared that no extrusion occurred.

There was extensive root resorption on the lingual surface of the root just above the apex Figure 33 . The depth of the resorbed area 


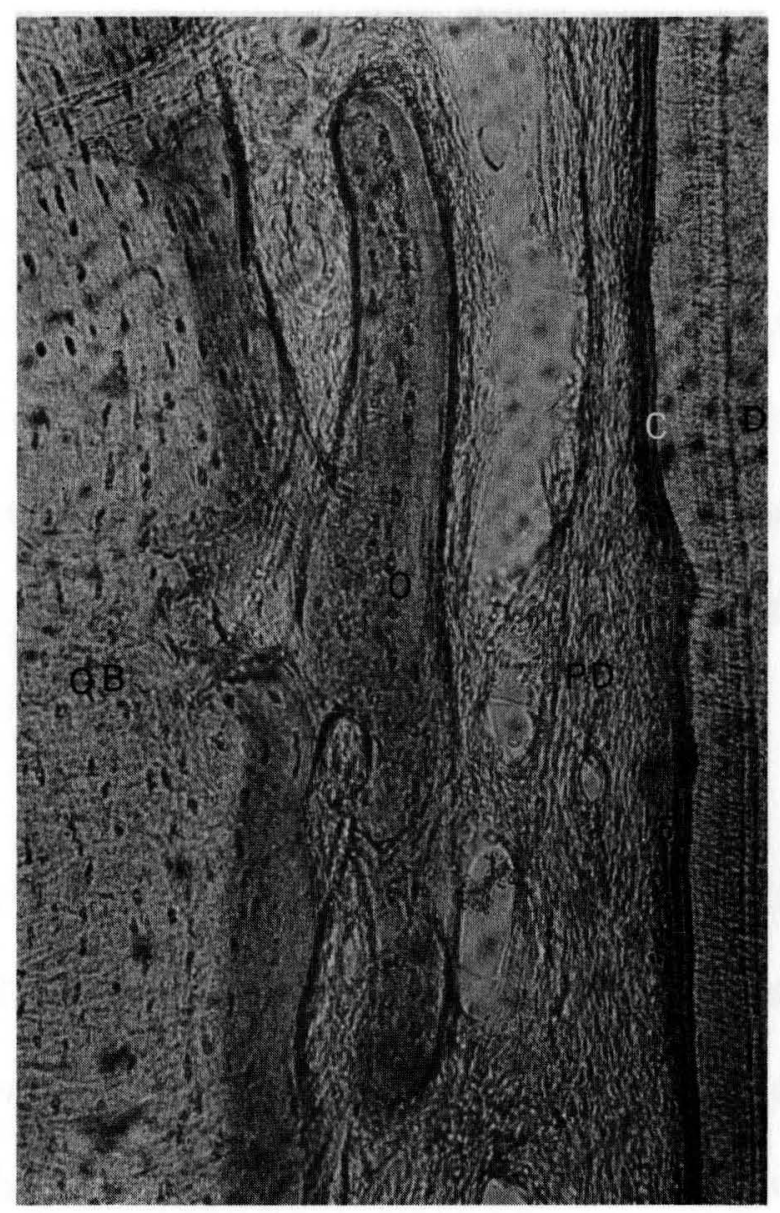

$\begin{aligned} \text { OB } & \text { OLD BONE } \\ \text { O } & \text { OSTEOPHYTE } \\ \text { PD } & \text { PERIODONTAL LIGAMENT } \\ \text { C } & \text { CEMENTUM } \\ \text { D } & \text { DENTIN }\end{aligned}$

FIGURE 32

OSTEOPHYTE ALONG LABIAL SURFACE OF ALVEOLAR BONE $(210 \mathrm{X})$ 


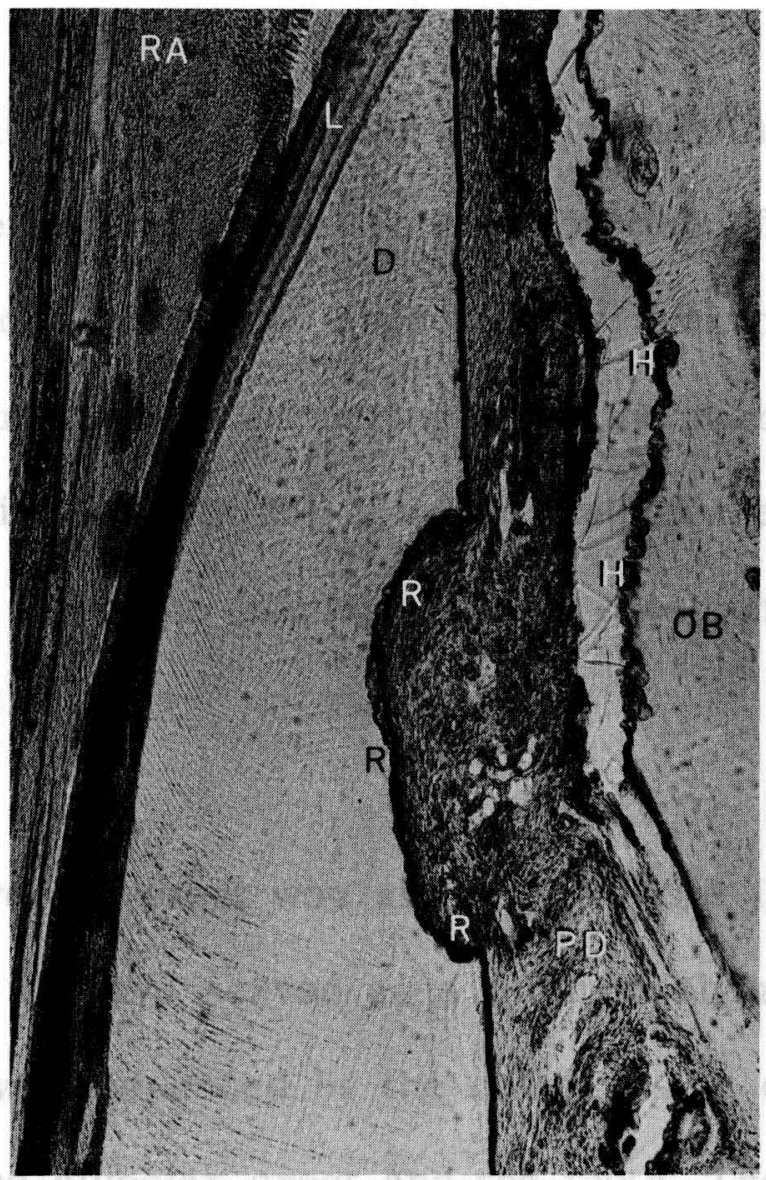

\section{RA OPEN ROOT APEX \\ L LEAD LINES \\ D DENTIN \\ R ROOT RESORPTION \\ PD PERIODONTAL LIGAMENT \\ $\mathrm{H}$ HOWSHIP'S LACUNAE \\ OB OLD BONE}

FIGURE 33

ROOT RESORPTION ON LINGUAL SURFACE OF ROOT NEAR APEX

$(85 \mathrm{X})$ 
of the root was $0.16 \mathrm{~mm}$. This is the first animal that had root resorption that entered the dentin. Bone resorption of the alveolar bone proper continued from the lingual aspect of the apex to the middle of the root. The resorption was occurring from the marrow spaces indicating undermining resorption. A wedge-shaped area of darkly stained bone was deposited along the lingual alveolar crest on the surface adjoining the root. Animal V

The labial alveolar crest was similar to those in animals II and III. The crest appeared to have served as a fulcrum about which the tooth was rotated. This was evidenced by the compression of the periodontal ligament between the alveolar crest and the tooth. The labial alveolar crest in this case was very nearly resorbed by undermining resorption Figure 34. The alveolar bone below the crest was undermined leaving what appeared to be an island of bone at the crest.

New bone was deposited in a wedge-shaped fashion on the alveolar bone proper along the labial surface of the root toward the apex. The amount of new bone deposited was less than that which occurred in the previous animals examined. No extrusion appeared to have taken place and there was no bone deposition at the fundus. The lingual surface of the root at the apex seemed to be nearly in contact with the adjoining 


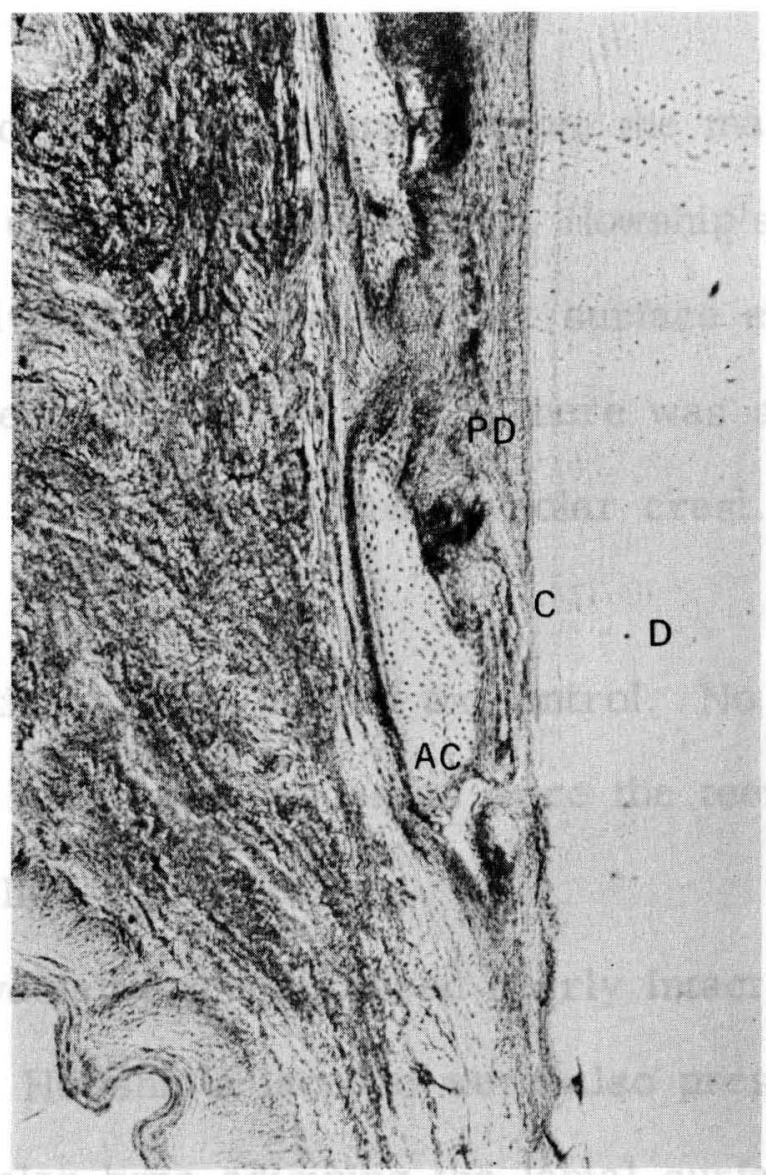

AC ALVEOLAR CREST

PD PERIODONTAL LIGAMENT

C CEMENTUM

D DENTIN

FIGURE 34

LABIAL ALVEOLAR CREST IN ANIMAL V

(85 X) 
alveolar bone. Resorption was occurring from the marrow spaces of the bone indicating undermining resorption. Howship's lacunae were present along the alveolar wall and the root surface extending approximately to the middle of the root. There was a wedge of darkly stained, osteophytic bone at the lingual alveolar crest. Animal VI

The tooth of this animal served as control. No orthodontic forces were applied to it, but it was banded as were the teeth of all the experimental animals.

The labial alveolar crest appeared nearly intact except for a few Howship's lacunae. Howship's lacunae were also present along the surface of the alveolar bone adjoining the labial surface of the root from the middle of the root to the labial alveolar crest. Compensating bone deposition occurred on the cancellous bone of the marrow spaces adjacent to the areas of resorption of the alveolar bone proper Figure 35. Bone deposition occurred along the fundus adjoining the root apex Figure 36. The bone deposition was regular and lead lines were faint but occasionally distinguishable. Lead lines were faint but visable all along the alveolar bone proper adjoining the lingual surface of the root. The lines became diffuse near the lingual alveolar crest. No evidence of root resorption was found. The tooth extruded and moved labially. 


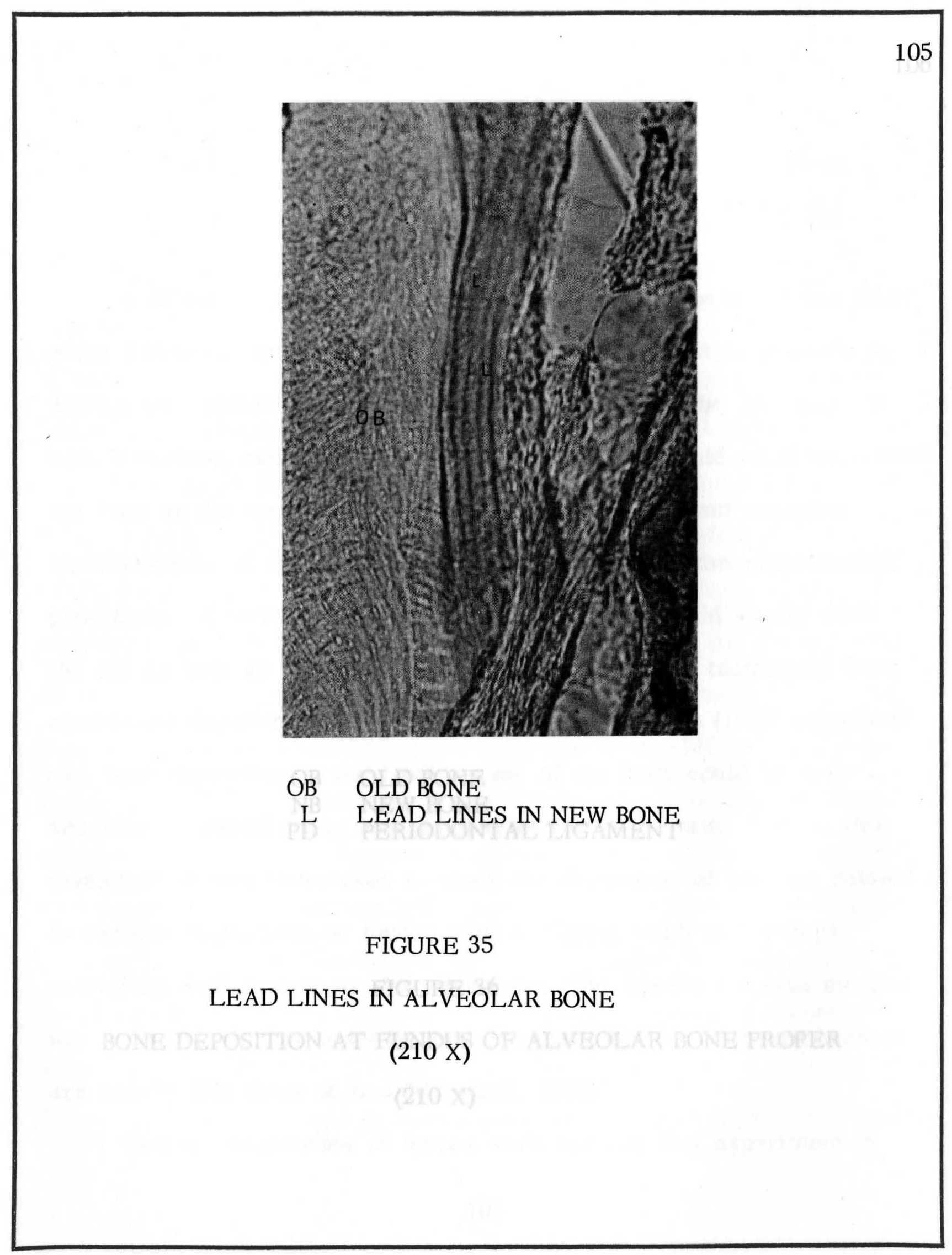




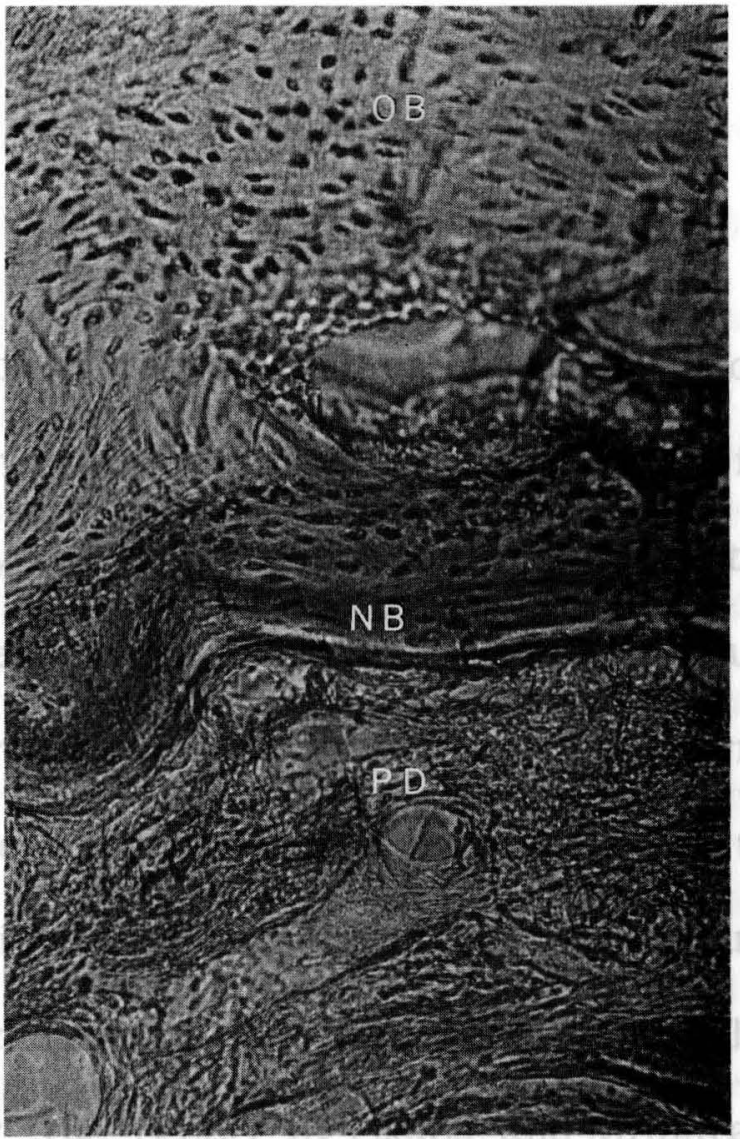

$\begin{array}{ll}\text { OB } & \text { OLD BONE } \\ \text { NB } & \text { NEW BONE }\end{array}$

PD PERIODONTAL LIGAMENT

FIGURE 36

BONE DEPOSITION AT FUNDUS OF ALVEOLAR BONE PROPER

$(210 \mathrm{X})$ 


\section{CHAPTER V \\ DISCUSSION}

A determination of the amount of bone deposition which has taken place following tooth movement can only be made if it is possible to distinguish precisely the newly deposited bone from the old bone. It was, therefore, necessary to use a method which would accurately mark the bone at the start of the experiment, and then permit accurate measurements of the newly deposited bone following the experimental procedure. A technique was thus required which would vitally stain the old as well as the newly deposited bone. Several techniques were considered, however, the report by Okada and Mimura (1938) suggested that bone deposition in the hard tissues of the body could be very accurately marked using lead acetate as the vital stain. Hence, this investigation was undertaken to study the deposition of bone as related to various magnitudes of forces used in tipping teeth in monkeys employing lead acetate as the vital stain. The Rhesus Macaque monkey was selected for this study because its teeth and alveolar environment are nearly like those of man (Marshall, 1933).

Various magnitudes of forces were used in this experiment to 
study the effect of these forces on bone deposition. Early orthodontists knew that when forces are applied to teeth some changes must occur in the supporting structures of the teeth which permit them to move, but they based their conclusions on clinical observations. They paid little or no attention to the force magnitudes used to produce these changes. Sandstedt (1904) and Oppenhiem (1911) reported on the changes occurring in the tissues as a result of orthodontic tipping, but they failed to relate their histologic findings with the force magnitudes applied. Schwarz (1932) was the first investigator to recommend a range of force magnitudes for moving teeth.: He asserted that forces not greater than 20-26 gms. $/ \mathrm{cm}^{2}$ produced the most favorable movement with the least damage to the periodontal tissues. Storey and Smith (1952) reported on forces that give the optimal rate of tooth movement without causing damage to the tissues. Their findings were based on roentgenographic and clinical determinations. Jeffry and Kostiwa (1965) found that 45-50 per cent of the force value used for tooth movement in humans may be used favorably for tooth movement in monkeys. Their determinations were made on the ratio of tooth sizes.

Various magnitudes of forces were used in this experiment because 
the optimal force magnitude that will produce tipping is not yet known. The magnitudes of forces selected for this experiment were $25,50,75$, 100 and 150 gms. An intrinsic horizontal force system was selected to produce the labial tipping. This force system used to develop the continuous tipping force was designed according to the principles outlined by Jarabak and Fizzell (1963). The force was derived from a round wire with helical loops designed for activation in the transverse plane. The high elasticity and wide range of force magnitudes which can be built into this appliance makes it ideally suited for tipping teeth. A detailed description of this appliance can be found in Chapter III, Materials and Methods.

It was noted from Table II following the experimental procedure that the weights of the animals varied from week to week. An analysis of variance revealed a significant difference in the weight changes of the animals. The significant weight changes did not occur within the experimental animal group but between the experimental animals and the control animal. It was unlikely that these weight changes were brought about by the injections of lead acetate. Okada and Mimura suggested doses of 1-2 mg. $/ \mathrm{kg}$. body weight injected up to a dozen times daily with 
no ill effects. The dosage used in this experiment was $4 \mathrm{mg}$. $/ \mathrm{kg}$. body weight administered weekly. This dosage was considerably less than the daily or weekly dose used by Okada and Mimura. In addition no symptoms suggesting lead toxicity were observed in any of the animals. The weight change may have been due to the interference of the arm casts and bite plane with the eating habits of the animals. The control animal was also the youngest and probably best able to adapt to the conditions.

The histologic examination of the sections obtained following the sacrifice of the animals revealed that the pattern of bone deposition was very irregular. It was difficult to find any uniformity between the lead lines in the newly deposited bone. The newly deposited dentin, however, showed very distinct and regular lead deposition lines. The newly deposited bone in the areas of tension was generally osteophytic. Irregular finger-like and mushroom-like projections were found in the areas of greatest tension. This suggested that the bone deposition which occurred in these areas was of a reparative nature. It seems that the rapid destruction of bone cannot be compensated for by the rather slow process of deposition of mature lamellated compact bone or even the 
formation of mature spongy bone. In this emergency, spongy bone of the immature type is produced forming osteophytes. Osteophytes are found quite commonly wherever the rate of bone destruction exceeds the maximal rate of production of mature lamellated bone (Weinmann and Sicher, 1955). It appears, therefore, that there was a great deal of bone matrix undergoing calcification when the vital staining injections were administered. As calcification took place the lead also was deposited throughout the matrix. This may explain the smear-stained appearance of the osteophytes. The histologic evidence supported the occurrence of labial tipping movements. Direct bone resorption occurred at the areas of pressure in the animal that received the force magnitude of 25 gms. Undermining resorption of bone occurred at the labial alveolar crest and at the lingual aspect of the fundus of the alveolar bone proper in all animals where the tipping force magnitudes on the maxillary central incisor exceeded 25 gms. There was direct bone resorption on the labial alveolar bone proper and bone deposition at the fundus and lingual alveolar bone proper in the control animal. This indicated that extrusion and labial movement took place in the central incisor tooth of the animal because the anterior teeth were taken out of occlusion. This may have also been caused by the 
increased tissue fluid pressure brought about by the mandibular incisors striking the acrylic resin bite plane which contacted the soft tissues of the palate. Animal I was the only experimental animal that showed bone deposition at the fundus indicating extrusion. It is likely that the extrusion was due to the appliance not being completely seated.

Root resorption was noted on all animals except the control animal. The root resorption was limited to the cementum in those animals that received force magnitudes up to $75 \mathrm{gms}$. during the four week period. Forces in excess of 75 gms. caused root resorption that extended into the dentin.

The findings in this experiment were based on the measurements taken from the histologic sections of the teeth of the six animals. The preciseness of the method used for recording and quantitating bone deposition was expressed by the experimental error. The experimental error was calculated to be $\pm 0.047 \mathrm{~mm}$. This was about four to five times the least count $(0.01 \mathrm{~mm}$.) of the measuring instrument. The preciseness of this method can be attributed mainly to two factors. One of these factors was the clarity of the lead demarcation line between the old and new bone. The other was the reliability of the measure- 
ments made with the measuring microscope. It was found that the accuracy of the measuring microscope at the $99 \%$ confidence limits is less than $\pm 1 / 100 \mathrm{~mm}$. A search of the literature revealed that few methods have evolved which are as precise, accurate, and practical in spite of the many studies documenting and measuring tooth movement in animals.

Further evidence of the preciseness of the method was found in the analysis of variance. The analysis of variance was used to determine the significance of the variation which exists between animals, sections, areas, and the interactions between these effects. There was no significant difference between the sections. There was also no significant difference in the interactions of aniamls $\mathrm{x}$ sections and areas $\mathrm{x}$ sections. The significant difference between areas, however, was important in this experiment. This indicated that the bone deposition recorded did depend upon the area from which the measurement was taken. The tipping movement was expected to show increased bone deposition in the areas away from the central axis of tipping and decreased bone deposition near the axis of rotation. Thus, the significance of the areas of measurement were substantiated. 
The significant difference between animals and the interaction between animals $\mathrm{x}$ areas was also important. The one significant factor which made each animal different from the other was the force magnitude assigned to each animal. It would be more specific then to refer to the animals in terms of force magnitudes applied. The significance of the interaction between force magnitude $\mathrm{x}$ area (animals $\mathrm{x}$ area) was evidence that the bone deposition in each area measured was influenced by the force magnitude applied.

The data was used to determined the relationship between the amount of bone deposited and the force magnitudes applied in tipping. The values for all the experimental animals were used but no significant correlation could be determined.

An attempt was made in the experimental animals to measure the distances between the lead lines in those areas where the lines were present. This was done so that the bone deposition could be evaluated for a particular period of the experiment. The statistical analysis showed there was no significant difference between the weeks.

The determination of the center of tipping and the degree of tipping was found by estimating a regression line from the data obtained from 
the measurements. The distances of the measurements from each other along the long axis of the tooth were plotted along the $\mathrm{X}$ axis. The estimated distance the tooth moved was plotted along the $\mathrm{Y}$ axis. It was necessary to use the distance the tooth moved rather than bone deposition because this was a determination of the amount the tooth tipped and the axis about which the tooth tipped. The estimation of the distance the tooth moved was found by subtracting the mean periodontal widths of the control animal from the respective total distances measured. The control animal was used because the widths of the periodontal ligament in the experimental animals were altered due to the tension or compression exerted upon the periodontal ligament in these areas. The sections were cut in the labiolingual plane and, because of this, no other teeth on these sections were available for measurements of their periodontal space. Measurements of the periodontal space at the crest, middle, and apex were therefore taken from the sections of the control animal.

It was stated in Chapter IV that only two points of reference B and $\mathrm{C}$ were used to determine the center and degrees of tipping for animals I, IV, and V. Measurement A was not used because there was bone resorption at the labial alveolar crest in these animals. Animal V 
demonstrated the least amount of direct resorption at the alveolar crest but since some resorption did occur there, the measurement at that point was considered questionable. Measurements taken at the lingual alveolar crest also were not used because the tooth tipped about an axis near the labial crest and because of the possibility of extrusion influencing the measurements there. Any extrusion which may have taken place would move the tooth out of the socket thereby decreasing the thickness of tooth material at the alveolar crest. This would result in an increase of the measurement of tooth movement at the lingual alveolar crest. Similarly, if the tooth tipped about a point at the labial alveolar crest, the corresponding point on the lingual alveolar crest will have moved incisally and labially further distorting measurements at the lingual alveolar crest. Two areas of measurements, B and C, were therefore used in animals I, IV and V.

The purpose of these calculations was to locate the axis of tipping and determine the degree the tooth tipped about that axis. The intercept of the calculated line on the $\mathrm{X}$ axis was used to locate the center of tipping. Table IX lists the distances of the centers of rotation from the respective root apices. It appeared that the distances of the axes of 
rotation from the root apex increased as the magnitude of force increased. The center of rotation in animal IV, however, decreased in distance from the root apex, in relation to the distances found for the other animals. It is likely that this was due to the early resorption of the labial alveolar crest. It is the opinion of this investigator that when force magnitudes in excess of $25 \mathrm{gms}$. were used on the maxillary central incisor teeth of monkeys in tipping, the labial alveolar crest served as a bony fulcrum around which the tooth was tipped. The histologic examination revealed that the alveolar crest on the labial aspect and the alveolar bone of the fundus on the lingual aspect came into near contact with the parts of the root opposing these areas when forces in excess of $25 \mathrm{gms}$. were applied. The maximum resistance occurred at the labial alveolar crest which then served as a fulcrum for tipping. The alveolar bone in these areas must remodel by undermining resorption, a secondary reparative process. The vital formative processes needed for direct bone resorption were temporarily violated (Jarabak and Fizzell, 1963). It appears in animal IV that undermining resorption continued until those portions of alveolar bone under compression were removed and biologic and physiologic homeostasis were 
reestablished.

A correlation coefficient was then calculated to determine the relationship between the force magnitude applied and the corresponding centers of rotation. The values for all the experimental animals were used but no significant correlation could be discovered. This finding may be explained on the basis of the preceeding discussion. It is likely that when the labial alveolar crest of animal IV was resorbed, the fulcrum effect was lost. This allowed the tooth to advance labially into the area where undermining resorption had removed the alveolar bone proper. This effect positioned the center of tipping apically. The value for the center of tipping in animal IV deviated enough to prevent a positive correlation from being made. A second attempt was made to determine whether a significant correlation existed. The same statistical procedure was followed except that the values of animal IV were omitted. The correlation coefficient was found to be significant at the 95 per cent confidence limits. A positive correlation was therefore established between the force magnitude applied and the corresponding centers of rotation. This indicates that as the force applied was increased, the centers of tipping within the roots were located more coronally. 
The slope of the regression line was then used to calculate the degrees that each of the teeth tipped. Table IX lists the degrees the teeth tipped and the corresponding force magnitudes applied. It appeared the degrees the teeth tipped decreased as the force magnitude was increased. The significance of these findings led to the determination of another correlation. A correlation coefficient was calculated to determine the relationship between the force magnitudes applied and the degrees the teeth tipped. The values for all the experimental animals were used but no significant correlation could be established. This finding may be explained by again referring to the discussion on the behavior of the tooth in animal IV.. The same occurrence which changed the axis of rotation also increased the degrees of tipping of the tooth in animal IV. Another attempt was made to establish a significant correlation by again omitting the values of animal IV. The correlation coefficient was significant at the 95 per cent confidence limits. A negative correlation was discovered between the force magnitude applied and the corresponding degrees that the tooth was tipped. This indicates that as the force applied in tipping was increased, the degrees that the tooth tipped were decreased. 
A predetermined force system was used for each experimental animal. The force system was designed to have a range of deflection which would produce a relatively constant tipping force. The enamel of the teeth was lost during the decalcification procedure, and it was difficult to give a true estimate of the crown movement. The center of tipping in four of the experimental animals was located near the cervical portion of the tooth. It was conjectured from this that the labial displacement of the crown was less than the lingual movement of the root apex. The force loss which therefore occurred (Figures $6,7,8,9$, and 10) was relatively small, and for practical purposes the applied force remained relatively constant during the experimental period.

Future studies of this nature would do well to consider reducing the force magnitudes to include forces below $25 \mathrm{gms}$. as well as above. Thus, it may be possible to establish a range of forces which tip the teeth as rapidly as possible with the least amount of root damage. 


\section{CHAPTER VI \\ SUMMARY AND CONCLUSIONS}

1. Summary:

The purpose of this investigation was to study the deposition of bone as related to various magnitudes of forces employed in tipping teeth. Six Rhesus Macaque monkeys were used in the experiment with one of the monkeys serving as control. A force system was designed to tip the maxillary left central incisor labially. Various magnitudes of the force system were used to study the effect of these tipping forces on the bone deposition. An intrinsic horizontal force system was selected to produce the labial tipping movement. The force was derived from a round wire with helical loops designed for activation in the transverse plane. The desired force magnitudes were obtained by varying the leg length, wire diameter, and wire properties of the transverse helical loop appliances. Load deflection characteristics were plotted for each tested appliance.

The maxillary second molars, canines, and remaining incisor teeth served as anchor units. An acrylic resin bite plane was constructed to remove occlusal interferences. 
A vital staining technique utilizing lead acetate was used in this experiment. It has been shown that when a microquantity of lead acetate is injected intravenously into an animal, the lead replaces calcium at the site of calcifying tissues. The dosage of lead acetate used in this experiment was $4 \mathrm{mg}$. $/ \mathrm{kg}$. body weight administered weekly. This was less than the maximum daily or weekly dose suggested by Okada and Mimura (1938). The first lead acetate injection was given one hour following appliance activation. The remaining four lead acetate injections were administered each week for four weeks. The animals were sacrificed one day following the final injection. The animals were perfused and the sample tissues were fixed in formalin. Following fixation, the tissues were decalcified in $0.1 \mathrm{~N} \mathrm{HCl}$ supersaturated with hydrogen sulphide by continuously bubbling the hydrogen sulphide gas through the decalcifying solution. The tissues were then imbedded in gelatin. A cryostat was used to section the samples parallel to the direction of motion or labiolingually. The samples were sectioned at a thickness of twenty-four microns.

A micrometer slide comparator was used to measure the width of the vitally stained bone and the width of the periodontal ligament. 
Four areas about the roots of the teeth were selected for measurement. The distance of each area of measurement from the root apex was held constant within the sections of each animal. Statistical analyses were applied to the obtained data to determine the reliability of the measuring system, precision of the measurements, and the reliability of the method.

2. Conclusions:

1. This study provided a method of assessing experimental tipping of the maxillary central incisor tooth in the Rhesus Macaque monkey. This method of assessing tooth movement was shown to be precise and reliable.

2. The lead acetate vital staining method produced precise demarcation lines between the newly deposited bone and the old bone.

3. The bone deposited as the result of tipping teeth in this investigation was a reparative process, that is osteophytic and not the bone deposition related to normal remodeling.

4. The degrees of tipping, calculated from the obtained data, decreased as the force magnitude applied in tipping was increased. 
5. The axes of tipping were located more coronally as the force magnitude applied in tipping was increased.

6. Root resorption which entered the dentin was found in those teeth in which the force magnitude applied in tipping was in excess of 75 gms. during the four week period.

7. Tipping forces in excess of $25 \mathrm{gms}$. inhibited direct bone resorption causing an undermining bone resorption in the areas of greatest pressure.

8. Bone deposition at the areas of tension was greatest when the tipping force magnitude of 25 gms. was used.

9. Higher magnitudes of forces can produce a great deal of tipping, but at the expense of root resorption and undermining bone resorption. Eventually, undermining resorption removes the bone at the areas of greatest pressures and the tooth moves very rapidly into the newly created space.

10. Teeth that are out of occlusion drift or extrude spontaneously. 


\section{BIBLIOGRAPHY}

Belchier, J. An account of the bones of animals being to red colour by ailment only. Phil. Tr. Roy. Soc. London, 39:287-288, 1736. Cited from Bhaskar, S. N., Ph. D. Thesis, The University of Illinois, 1951.

Caffey, J. Clinical and experimental lead poisoning, some roentgenographic anatomic changes in growing bones. Radiology, 17:957-983, 1931.

Farrar, J. N. A Treatise on the Irregularities of the Teeth and their Correction. Ferre Va Ferme, New York, 1888.

Flourens, J.P. Recherches sur le developpement des os et des dents. Paris, 1847. Cited from Stuteville, O. H., 1937.

Huettner, R. J. and Whitman, C. L. Tissue changes occurring in the Macaque Rhesus monkey during orthodontic movement. American Journal of Orthodontics, 44:328-345, 1958.

Jarabak, J. R. Development of a treatment plan in the light of one's concept of treatment objectives. American Journal of Orthodontics, $7: 481-514,1960$.

Jarabak, J. R. and Fizzell, J. Technique and Treatment with the Light Wire appliances. The C. V. Mosby Co., St. Louis, 1963.

Jeffry, G. J. Biophysical Assessment of a Reciprocal Vertical Force System on Posterior Teeth in Normal Functional Occlusion. Unpublished Masters Thesis. Loyola University, 1965.

Johnson, A. L., Appleton, J. L., and Rittershofer, L.S. Tissue changes involved in tooth movement. International Journal of Orthodontia, 12:889-898, 1926.

Kingsley, N. W. An experiment with artifical plates. Dental Cosmos, 19: 23, 1877. Cited from Stuteville, O. H. , 1937. 
Kostiwa, D. K. Biophysical Assessment of a Reciprocal Vertical Force System on Posterior Teeth out of Occlusion in a Rhesus Monkey. Unpublished Masters Thesis. Loyola Universi ty, 1965.

Macapanpan, L. C., Weinmann, J. P. and Brodie, A. G. Early tissue changes following tooth movement in rats. Angle Orthodontist, 24: 79-95, 1954.

Marshall, J. A. A study of bone and tooth changes incident to experimental tooth movement and its application to orthodontic practice. International Journal of Orthodontia and Dentistry for Children, 19: 1, 1933.

Okada, M. and Asoda, A. Studies on deposition mechanism of heavy metal salts in hard tissues. I. Proc. Jap. Pharm. Soc., 34:730$735,1958$.

Okada, M. and Mimura, T. Eine Vitalfarbungsmethode mit Bleisalzen und ihre Andwendung bei den Untersuchungen uber die rhythmishe Streifenbildung der harten Zahngewebe. Japanese Journal of Medical Sciences IV. Pharm. Vol. XI, No. 2, 1938.

Tagesrhytmus in der Knochenlamellenbildung, Jap. J. Med. Sci. IV. Pharm. Vol. XIII, No. 1/2, 1940.

Oppenheim, A. Tissue changes, particularly of the bone, incident to tooth movement. American Orthodontist, 3:57-67, 113-132, 1911.

Biologic orthodontic therapy and reality. International Journal of Orthodontics and Dentistry for Children, 19:1201-1213, 20:18-24, 137-144, 250-258, 331-336, 461-466, 639-644, 759-769, 964-958, $1072-1076,1178-1181,1933$ and 1934.

Human tissues response to orthodontic intervention of short and long duration. American Journal of Orthodontics and Oral Surgery, 28: $299,1942$. 
Orban, B. Biologic problems in orthodontia. The Journal of the American Dental Association, 23:1849-1870, 1936.

Park, Jackson, and Kajdi Shadows produced by lead in the $\mathrm{x}$-ray pictures of the growing skeleton. Am. J. of Dis. of Child., 41:485-499, 1931.

Reitan, K. Continous bodily tooth movement and its histological significance. Acta Odontologica Scandinavica, 6:115, 1947.

Tissue changes following experimental tooth movement as related to the time factor. Dental Record, 73:559, 1953.

Tissue reaction as related to the age factor. Dental Record, $74: 271,1954$.

Some factors determining the evaluation of forces in orthodontics. American Journal Of Orthodontics, 43:32-45, 1957.

Behavior of Malassezs' epithelial rests during orthodontic tooth movement. Acta. Odonto. Scandinav., 19:443-468, 1961.

Sandstedt, C. Einigen Beitrage zur Theorie der Zahnregulierung, Nordisk, Tand. Tidsk. no. 4, 1904, no. 1, 1905.

Schwarz, A. M. Tissue changes incidental to orthodontic tooth movement. International Journal of Orthodontia, 18:331-352, 1932.

Sicher, H. and Weinmann, J. P. Bone growth and physiologic tooth movement. American Journal of Orthodontics and Oral Surgery, 30.109-132, 1944.

Storey, E. Bone changes associated with tooth movement. A radiographic study. The Australian Journal of Dentistry, 2:57-64, 1953.

Storey, E. and Smith, R. Force in orthodontics and its relation to tooth movement. The Australian Journal of Dentistry, 56:11-18, 1952.

The importance of force in orthodontics. The Australian Journal of Dentistry, 56:291-304, 1952. 
Stuteville, O. H. Injuries to the teeth and supporting structures caused by various orthodontic appliances. American Dental Association Journal, 24: 1494-1507, 1937.

Wentz, F. M., Jarabak, J. R., Orban, B. Experimental occlusal trauma imitating cuspal interferences. Journal of Periodontology, 29:117$127,1958$.

Weinmann, J. P. and Sicher, H. Bone and Bones. The C. V. Mosby Co., St. Louis, 1955. 


\section{APPROVAL SHEET}

The thesis submitted by Dr. James V. Martuccio has been read and approved by members of the Departments of Anatomy and Oral Biology.

The final copies have been examined by the director of the thesis and the signature which appears below verifies the fact that any necessary changes have been incorporated, and that the thesis is now given final approval with reference to content, form, and mechanical accuracy.

The thesis is therefore accepted in partial fulfillment of the requirements for the Degree of Master of Science.
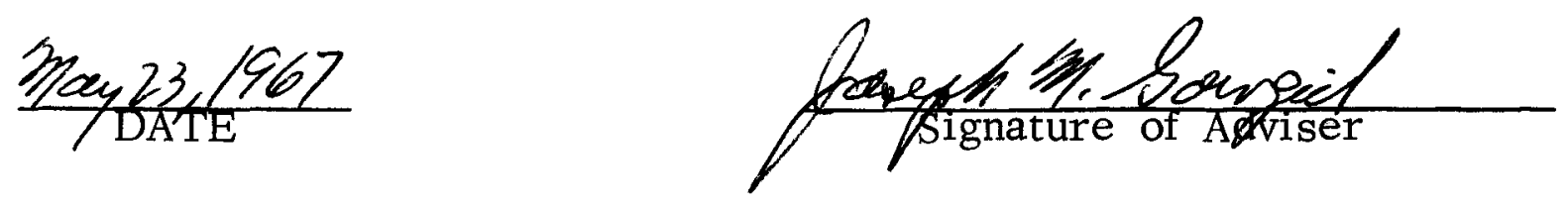